Quarterly Reviews of

Biophysics

cambridge.org/qrb

\section{Perspective}

Cite this article: Zhang $F$ (2019). Development of CRISPR-Cas systems for genome editing and beyond. Quarterly Reviews of Biophysics 52, e6, 1-31. https://doi.org/10.1017/ S0033583519000052

Received: 8 April 2019

Revised: 8 May 2019

Accepted: 13 May 2019

Key words:

Cas9; Cas12; Cas13; CRISPR; genome editing; SHERLOCK

Author for correspondence:

F. Zhang, E-mail: zhang@broadinstitute.org

\title{
Development of CRISPR-Cas systems for genome editing and beyond
}

\section{F. Zhang}

${ }^{1}$ Broad Institute of MIT and Harvard, Cambridge, MA 02142 USA; ${ }^{2}$ Department of Brain and Cognitive Sciences, Department of Biological Engineering, McGovern Institute for Brain Research, Massachusetts Institute of Technology, Cambridge, MA 02139 USA and ${ }^{3}$ Howard Hughes Medical Institute, Cambridge, MA 02139 USA

\section{Abstract}

The development of clustered regularly interspaced short-palindromic repeat (CRISPR)-Cas systems for genome editing has transformed the way life science research is conducted and holds enormous potential for the treatment of disease as well as for many aspects of biotechnology. Here, I provide a personal perspective on the development of CRISPR-Cas9 for genome editing within the broader context of the field and discuss our work to discover novel Cas effectors and develop them into additional molecular tools. The initial demonstration of Cas9-mediated genome editing launched the development of many other technologies, enabled new lines of biological inquiry, and motivated a deeper examination of natural CRISPR-Cas systems, including the discovery of new types of CRISPR-Cas systems. These new discoveries in turn spurred further technological developments. I review these exciting discoveries and technologies as well as provide an overview of the broad array of applications of these technologies in basic research and in the improvement of human health. It is clear that we are only just beginning to unravel the potential within microbial diversity, and it is quite likely that we will continue to discover other exciting phenomena, some of which it may be possible to repurpose as molecular technologies. The transformation of mysterious natural phenomena to powerful tools, however, takes a collective effort to discover, characterize, and engineer them, and it has been a privilege to join the numerous researchers who have contributed to this transformation of CRISPR-Cas systems.

\section{Introduction}

Close observers of the diversity in the natural world generally appreciate why evolution has been likened not to the work of an engineer, but to that of a tinkerer (Jacob, 1977). By repurposing a genetic material under selective pressure, nature has evolved a myriad of 'field-tested' solutions to the challenges organisms face. Evolutionary tinkering is particularly evident in the microbial world, where selective pressure is high, effective population size is large, generation time is short, and genetic information can be exchanged widely and relatively quickly. As biologists delve ever deeper into the molecular and genetic mechanisms underlying the observed phenotypic diversity, we continue to learn more about fundamental biological processes and uncover new natural systems and phenomena. In addition to providing insight into the molecular underpinnings of life, some of these novel systems have been developed into various molecular technologies. For example, heat-stable polymerases discovered in thermophilic bacteria enabled the development of polymerase chain reaction (PCR), and restriction enzymes discovered by studying host responses to phages enabled recombinant deoxyribonucleic acid (DNA) technologies.

One of the latest examples of how nature's solutions have been successfully adapted into a molecular technology is the development of clustered regularly interspaced short-palindromic repeat (CRISPR)-Cas (CRISPR-associated) systems for eukaryotic genome editing. CRISPR-Cas-mediated genome editing is a robust, easy-to-use method to precisely alter DNA sequences within the genome of living organisms. Because of the simplicity and efficiency of the system, it has been widely adopted and further developed, leading to an extraordinarily powerful molecular toolbox. Once microbiological curiosity, CRISPR has become a part of the common language of molecular biology, with its reach extending into nearly every corner of the life sciences and its impact going far beyond the confines of the laboratory. The story of CRISPR is one with two-intertwined aspects (Fig. 1): biological investigation to better understand these elegant systems and engineering of these systems into powerful molecular technologies. As the impact of these technologies spreads, it spurs further work into the biology, which continues to provide additional technological opportunities. Thus, the early part of the CRISPR revolution involved engineering Cas9 as genome editing technology, but through the recent discovery and development of additional Cas effectors, particularly the ribonucleic acid (RNA)-targeting Cas13 family, it has continued to expand into new 


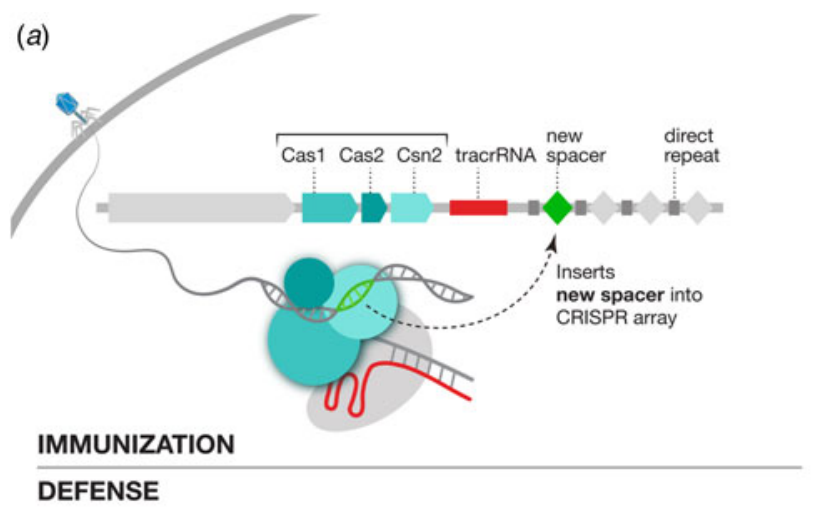

\section{DEFENSE}

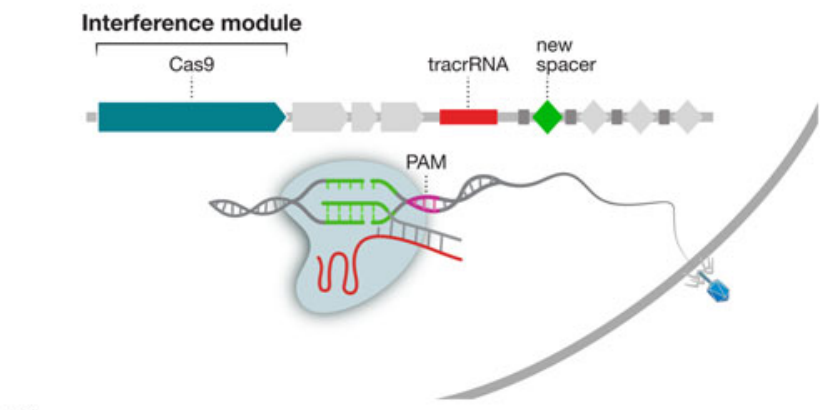

(b)

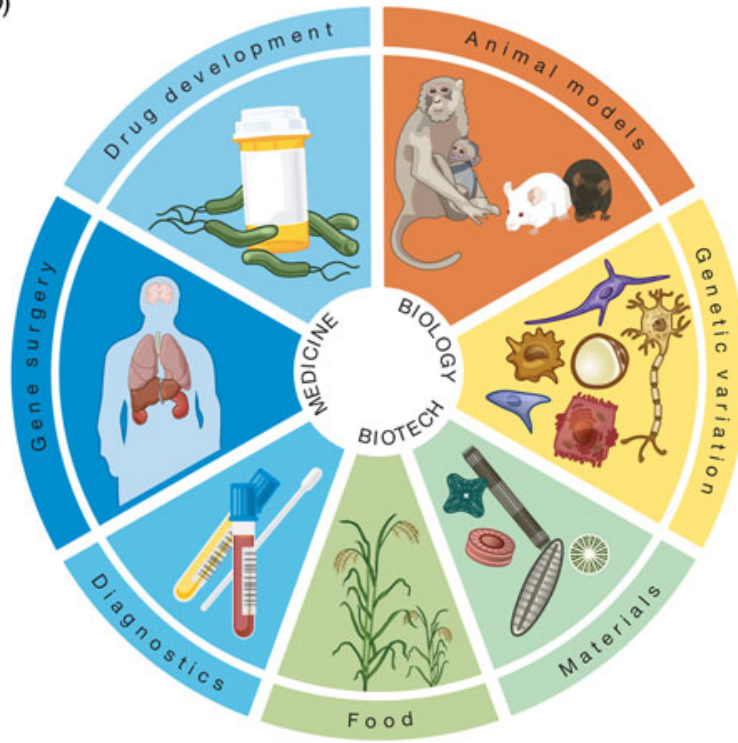

Fig. 1. Two aspects of CRISPR: biology and technology. (a) CRISPR-Cas adaptive immune systems help microbes defend against phages and other foreign genetic materials. During the immunization phase (top), an adaptation module inserts a new spacer, a stretch of DNA derived from the genome of the invader, into the CRISPR array. During the defense phase (bottom), spacers are converted into guide RNAs that direct an interference module to matching target sequences, which are then cleaved. (b) CRISPR technologies have broad applications in the life sciences, medicine, and industrial biotechnology. The CRISPR molecular toolbox allows researchers to carry out precise genome and transcriptome editing in eukaryotic cells to advance our understanding of biology through the generation of useful animal and cellular models and interrogation of genetic variation, to boost biotechnology through engineering and production of novel materials and agricultural products, and to advance human health through detection of pathogens, development of novel therapeutic approaches, and elucidation of disease mechanisms. Image adapted from (Hsu et al., 2014).

areas. CRISPR-based technologies are being employed in diverse ways to improve human health and offer the potential to fundamentally change the way we treat disease.

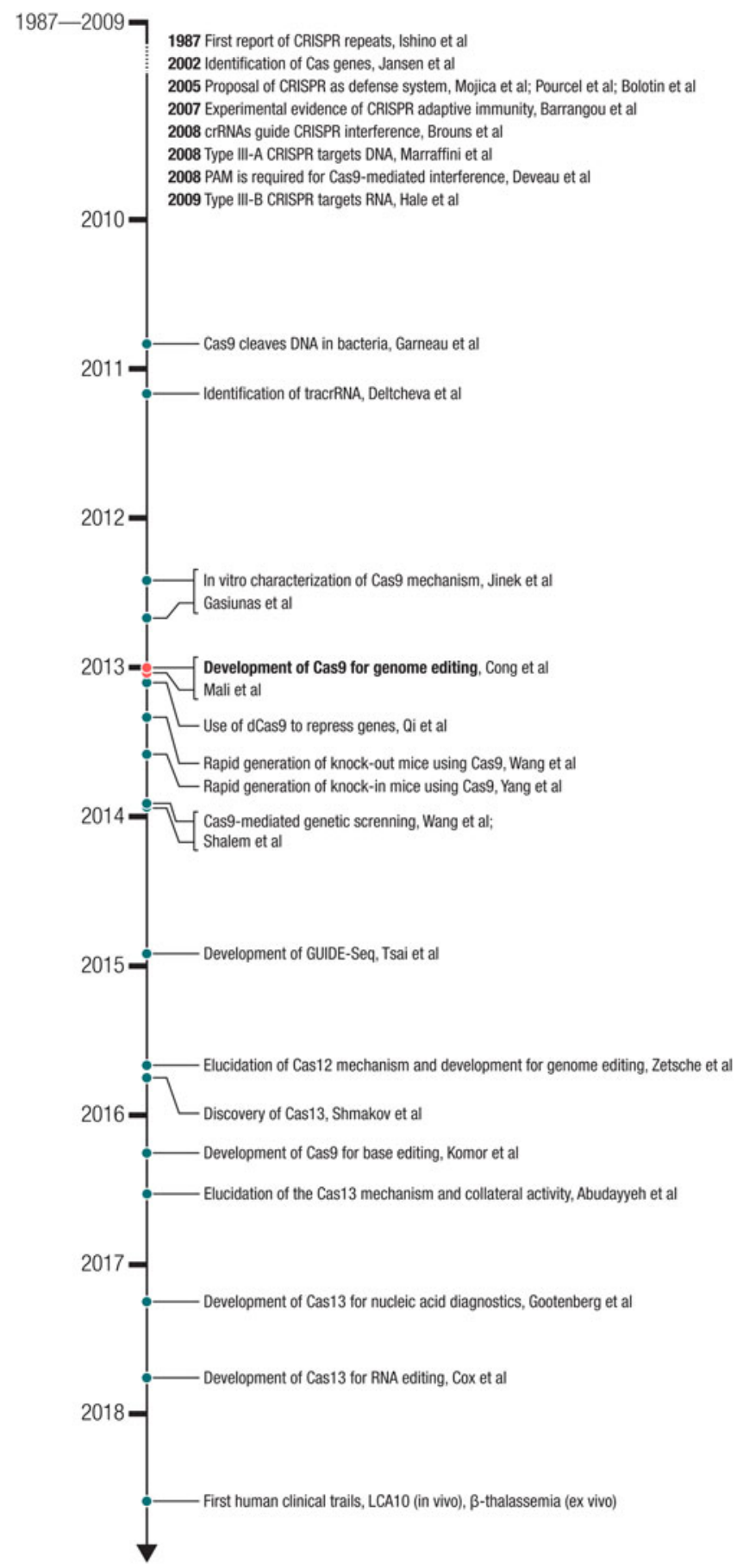

Fig. 2. Milestones in the development of CRISPR-based technologies. The development of Cas9 for genome editing ((Cong et al., 2013) - submitted on October 5 , 2012 and (Mali et al., 2013b) - submitted on October 26, 2012) built on a number of important biological studies and spurred many powerful applications as well as the discovery of new CRISPR effectors such as the DNA-targeting Cas12 and RNA-targeting Cas13.

Here, I briefly overview the natural function of CRISPR-Cas systems, followed by a personal account and perspective of the time period over which CRISPR-Cas9 was developed for genome editing in eukaryotic cells. I also discuss the continuing study and remarkable biotechnological development of CRISPR-Cas systems beyond Cas9 (Fig. 2). In particular, I highlight some of the exciting applications of this technology and identify areas for future 
improvement. Although I have striven to include many primary studies, I apologize in advance to those whose work might have unintentionally been omitted. In addition to this perspective, there are a number of general reviews covering this topic (Doudna and Charpentier, 2014; Hsu et al., 2014; van der Oost et al., 2014; Marraffini, 2015; Sontheimer and Barrangou, 2015; Mojica and Rodriguez-Valera, 2016; Barrangou and Horvath, 2017; Koonin and Makarova, 2017; Lemay et al., 2017; Ishino et al., 2018). I also refer readers to several reviews focused on various aspects related to CRISPR-Cas technologies, including the structure and mechanism of Cas effectors (Jackson and Wiedenheft, 2015; Garcia-Doval and Jinek, 2017; Jiang and Doudna, 2017), classification and evolution of CRISPR-Cas systems (Koonin and Makarova, 2017), and applications of the CRISPR technology in agriculture (Voytas and Gao, 2014; Gao, 2018), animal and cellular modeling (Hotta and Yamanaka, 2015), genetic screening (Shalem et al., 2015; Doench, 2017; Jost and Weissman, 2018), genome editing specificity (Tsai and Joung, 2016), base editing (Hess et al., 2017; Rees and Liu, 2018), drug discovery and development (Fellmann et al., 2017), and therapeutic applications (Cox et al., 2015; Porteus, 2015; Xiong et al., 2016).

I would also like to take this opportunity to acknowledge all of the members of the CRISPR research community, who have contributed to elucidating the mechanism of CRISPR-Cas systems and developing and applying this extraordinary technology. It has been tremendously inspiring to see the multitude of ways that CRISPR-Cas systems continue to be applied. In addition, I am grateful to all of the collaborators and trainees with whom I have been fortunate to work alongside to uncover novel CRISPR biology and to develop and apply these remarkable technologies.

\section{Biology of CRISPR-Cas-mediated adaptive immunity}

\section{Overview and nomenclature of CRISPR-Cas systems}

CRISPR-Cas systems are adaptive immune systems found in roughly $50 \%$ of bacterial species and nearly all archaeal species sequenced to date (Makarova et al., 2015). These systems evolved over billions of years to defend microbes from the invasion of foreign nucleic acids such as bacteriophage genomes and conjugating plasmids by targeting their DNA or RNA. The molecular machinery involved in CRISPR-Cas immunity is encoded by the CRISPR locus as two sets of genetic components that are often located next to each other in microbial genomes: (1) an operon of multiple cas genes, and (2) a set of non-coding CRISPR RNAs (crRNAs) including ones encoded by the signature repetitive CRISPR array consisting of spacers sandwiched between short-CRISPR repeats (Fig. 1a). Using these components, CRISPR-Cas systems mediate adaptive immunity (immunization and defense) through three general phases: adaptation, crRNA processing, and interference. First, during the adaptation phase, a subset of Cas proteins called the 'adaptation module' obtains and inserts fragments of an invading virus or other foreign genetic material as a 'spacer' sequence into the beginning of the CRISPR array in the host genome along with a newly duplicated CRISPR repeat. The sequence on the virus or plasmid matching the acquired spacer is called a protospacer. Second, the CRISPR array is transcribed and processed into individual crRNAs, each bearing an RNA fragment corresponding to the previously encountered virus or plasmid along with a portion of the CRISPR repeat. Third, during the interference phase, crRNAs guide the 'interference module', encoded either by complex comprising Cas effector subunits or by a single-effector protein, to destroy the invader.

There are many variations on the CRISPR theme, however, and the natural diversity of CRISPR-Cas systems is remarkably extensive, including systems that target DNA, systems that target RNA, and systems that target both DNA and RNA. CRISPR-Cas systems also operate in different ways, recognizing and cleaving their nucleic acid targets through distinct mechanisms mediated by various effector-crRNA complexes. Based on their unique effector proteins, CRISPR-Cas systems are currently classified into six types (I through VI), which are in turn grouped into two-broad classes (Makarova et al., 2015; Shmakov et al., 2017): class 1 systems (types I, III, and IV) use a multi-protein complex to achieve interference, and class 2 systems (types II, V, and VI) utilize a single-nuclease effector such as Cas9, Cas12, and Cas13 for interference.

\section{Discovery and characterization of CRISPR-Cas systems}

In 1987, a series of regularly-interspaced repeats of unknown function was observed in the genome of $E$. coli, documenting the first instance of a CRISPR array (Ishino et al., 1987). In early 2002, clues to the function of CRISPR-Cas systems came from two-bioinformatics studies, one of which reported the presence of conserved operons that appeared to encode a novel DNA repair system, which we now know are cas genes (Makarova et al., 2002), and the other of which reported the association between CRISPR arrays and cas genes (Jansen et al., 2002). Next, it was observed that spacer sequences in between CRISPR repeats matched sequences in phage genomes, leading to the suggestion that CRISPR arrays could be involved in immunity against the corresponding phages (Mojica et al., 2005; Pourcel et al., 2005). Third, work focused on Streptococcus thermophilus similarly found that more spacers matched phage sequences and identified a large CRISPR-associated protein containing the DNA-cleaving $\mathrm{HNH}$ domain, which is now known as Cas9, the hallmark protein in type II systems (Bolotin et al., 2005). Despite the linkage between CRISPR-Cas and phage infection, the specific role that CRISPR spacers played in providing immunity remained unclear.

Experimental work with the type II system of S. thermophilus showed that the spacers in the CRISPR array are acquired from phages and specify immunity against specific phages carrying matching sequences. Moreover, cas genes are required for both immunization and phage interference (Barrangou et al., 2007). These exciting results established CRISPR-Cas as a microbial adaptive immune system. Insight into the molecular mechanism of CRISPR-Cas immunity came from work using a type I CRISPR-Cas system, which revealed that the CRISPR array is transcribed and processed into short crRNAs that provide recognition of the invading phages and that the effector module can be directed to multiple targets by changing the crRNA sequences (Brouns et al., 2008). Although the prevailing hypothesis at the time was that CRISPR-Cas systems achieved interference using an RNAi-like mechanism (Makarova et al., 2006), there was evidence that the target was DNA, rather than RNA (Brouns et al., 2008). Another study reported that a type III-A CRISPR-Cas system limits horizontal gene transfer by targeting DNA (Marraffini and Sontheimer, 2008). However, other systems, such as the type III-B CRISPR-Cas system, target RNA instead (Hale et al., 2009), highlighting the substantial mechanistic differences between CRISPR-Cas systems. 
As the overall picture of CRISPR-Cas-mediated adaptive immunity began to take shape, studies also started to clarify the natural mechanism of type II CRISPR-Cas systems, which uses the nuclease effector Cas9. In one study, it was shown that a short well-conserved sequence motif at the end of CRISPR targets, called a protospacer adjacent motif (PAM) (Mojica et al., 2009), is required for Cas9-mediated interference (Deveau et al., 2008). In 2010 , it was shown that $S$. thermophilus Cas9 is guided by crRNAs to create blunt double-strand breaks (DSBs) in DNA 3 bp upstream from the PAM at targeted sites in phage genomes and in plasmids and that Cas9 is the only protein required for DNA cleavage (Garneau et al., 2010). In 2011, small-RNA sequencing of Streptococcus pyogenes revealed the presence of an additional small RNA associated with the CRISPR array. This additional RNA, termed tracrRNA, forms a duplex with direct repeat sequences on the pre-crRNA to produce mature crRNA, and it is required for Cas9-based interference (Deltcheva et al., 2011). Another study in 2011 showed that the CRISPR-Cas locus from $S$. thermophilus could be expressed in E. coli, where it could mediate interference against plasmid DNA (Sapranauskas et al., 2011). These studies collectively established that the nuclease complex of the natural Cas9 system contains three components (Cas9, crRNA, and tracrRNA) and that the DNA target site needs to be flanked by the appropriate PAM.

As the biology of CRISPR-Cas systems became better understood, it began to be adapted for use, first as an aid for bacterial strain typing (Pourcel et al., 2005; Horvath et al., 2008, 2009), and then in its native context by inoculating $S$. thermophilus with viruses to generate phage-resistant strains that can be deployed in industrial dairy applications, such as yogurt and cheese making (Quiberoni et al., 2010). Additional suggestions for its application were also raised, including microbial gene silencing (Sorek et al., 2008), combating antibiotic resistance, and targeted DNA destruction (Marraffini and Sontheimer, 2008; Garneau et al., 2010).

\section{Development of CRISPR-Cas9 for genome editing}

The ability to make precise changes to the genome holds great promise for advancing our understanding of biology and human health as well as providing new approaches to treating grievous diseases. The demonstration in 1987, the same year that CRISPR was first reported, of targeted gene insertion via homologous recombination in mice was a major breakthrough (Doetschman et al., 1987; Thomas and Capecchi, 1987), but the efficiency in mammalian cells was extremely low outside of mouse embryonic stem cells. Work in both yeast and mammalian cells demonstrated that the efficiency of gene insertion could be increased through the generation of a DSB at the target site (Rudin et al., 1989; Plessis et al., 1992; Rouet et al., 1994). These observations motivated the development of targetable nucleases such as meganucleases, zinc finger nucleases, and transcription activator-like effector (TALE) nucleases that can be customized to recognize specific DNA sequences and generate DSBs at specific loci to facilitate genome editing (reviewed in (Urnov et al., 2010; Joung and Sander, 2013; Kim and Kim, 2014)). However, the targeting capacity of each of these technologies was limited, and it was challenging to reprogram them in practice, ultimately dampening their impact.

As a Junior Fellow at Harvard in 2009, I had experienced firsthand the challenges of working with zinc finger nucleases. After reading studies describing the DNA recognition mechanism of microbial TALE proteins (Boch et al., 2009; Moscou and Bogdanove, 2009), I asked Le Cong, a rotation graduate student, to join me to develop TALEs for use in mammalian cells (Zhang et al., 2011). In 2010, I accepted a faculty position at MIT and the Broad Institute, planning to build a research program around genome and transcriptome editing. I started to set up my lab in January 2011, and Cong joined as my first graduate student. The very next month, I heard Michael Gilmore speak at the Broad Institute about his studies on Enterococcus bacteria, during which he mentioned that Enterococcus carried CRISPR-Cas systems, which contained a new class of nucleases. Given my interest in genome editing, I was intrigued by the prospect of a new class of nucleases. After studying the CRISPR-Cas literature, I immediately recognized that CRISPR-Cas would be easier to reprogram than TALEs, and I decided to refocus a significant portion of my genome editing efforts on adapting Cas9 for genome editing in eukaryotic cells.

In early 2011, it was already known that Cas9 could cleave DNA in bacterial cells when directed by a crRNA (Garneau et al., 2010). Based on the literature, it was also known that the nuclease complex of the natural Cas9 system contains three components (Cas9, crRNA, and tracrRNA). However, CRISPR-Cas systems had only been studied in bacterial and biochemical systems, and they had not been explored in the context of eukaryotic cells. Thus, the key question that needed to be answered, in my mind, was whether Cas9 could be engineered to achieve genome editing in eukaryotic cells. Bacterial enzymes evolved to function optimally in their native bacterial environment, which has substantially different biochemical properties than that of the intracellular environment of a eukaryotic cell. Indeed, I knew that previous attempts to harness bacterial systems for use in eukaryotic cells had failed, including Group II introns (Mastroianni et al., 2008) and ribozymes (Link and Breaker, 2009). From my past experiences developing microbial opsins for use in mammalian neurons for optogenetics (Boyden et al., 2005; Zhang et al., 2007) and TALEs for use in mammalian cells for genome editing (Zhang et al., 2011), I decided to directly answer the question of whether Cas9 could be used as a programmable nuclease in eukaryotic cells by using a human cell culture system. Working with human cells, I developed a three-component CRISPR-Cas9 system - Cas9, crRNA, and tracrRNA - for genome editing.

As a brand new Assistant Professor, I not only designed but also carried out experiments in the laboratory myself, while mentoring trainees, recruiting lab members, and applying for grants. In one of the grants submitted to the National Institutes of Health in January 2012, I described my strategy to use a threecomponent Cas9 system (Cas9, crRNA, and tracrRNA) for genome editing in mammalian cells, as was later published in our study (Fig. 3) (Cong et al., 2013). The strategy for this work was based on the synthesis of the available literature in the CRISPR field, which had established the requirement for these three components for function in bacteria.

During the course of our experiments, a detailed biochemical analysis of the mechanism of Cas9 in vitro was published (Jinek et al., 2012). First, it showed that the purified S. pyogenes Cas9-crRNA-tracrRNA complex cleaves DNA 3 bp upstream of the PAM of the target site, in agreement with previous in vivo results with the $S$. thermophilus system (Garneau et al., 2010). Second, it showed that tracrRNA and crRNA are both required for target cleavage by the Cas9-crRNA-tracrRNA complex. Furthermore, by truncating the tracrRNA, the study found that a short fragment of the tracrRNA (nucleotides 23 to 48 , without 
(a)

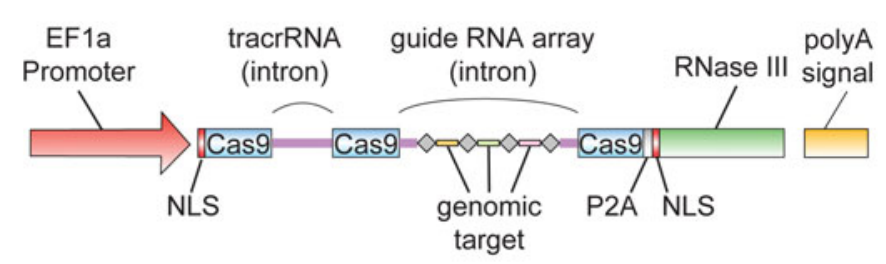

(b)
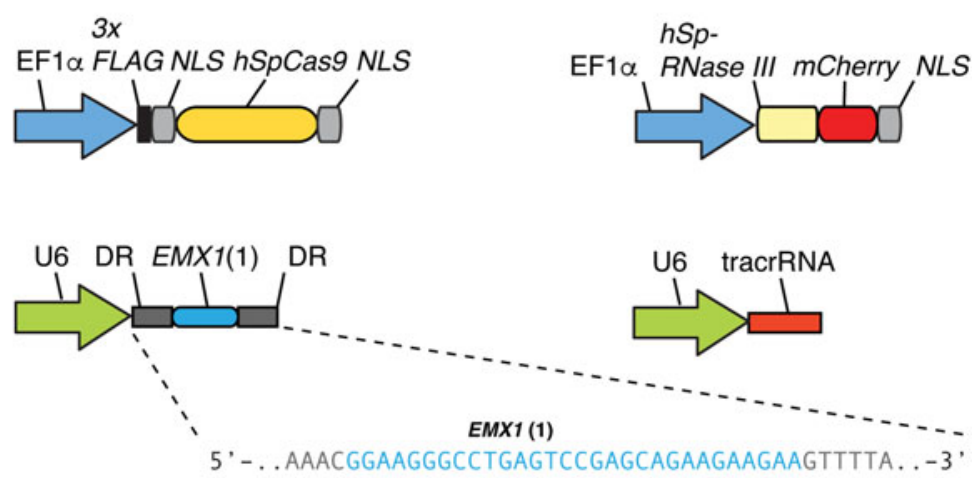

(c)

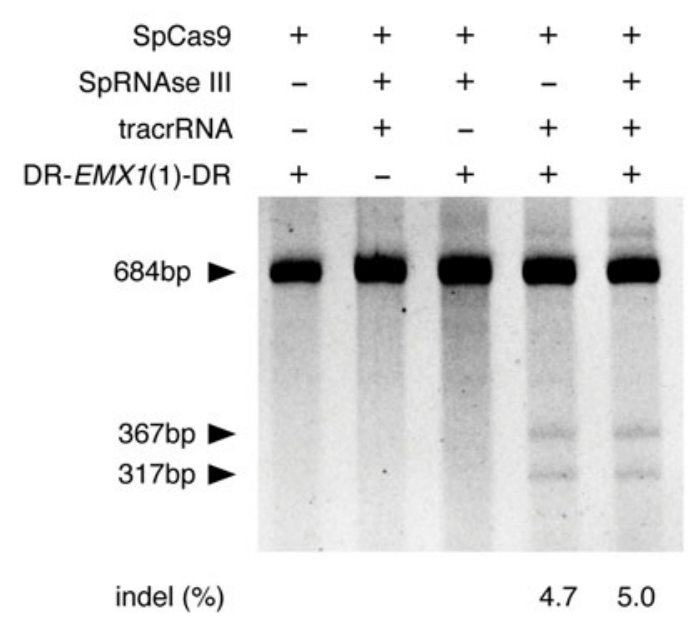

Fig. 3. Development of CRISPR-Cas9 for genome editing. (a) The design of a three-component system (Cas9, crRNA, and tracrRNA) for Cas9-mediated genome editing in eukaryotic cells, which was included in a grant submitted in January 2012 to the National Institutes of Health. In this design, the EF1a promoter drives expression of Cas9 (with a NLS) and the tracrRNA and guide RNA array with four genomic targets. In addition, RNase III is expressed to aid the processing of crRNA, although we later determined it is not necessary (see panel c). Image adapted from NIH Grant 5R01DK097768. (b) Design of the three-component system used in human cells to demonstrate editing of the human genome. S. pyogenes Cas9, CRISPR array (DR-EMX(1)-DR), and tracrRNA are individually expressed. The guide sequence in the CRISPR array targets the human EMX1 gene. Image adapted from Cong et al. (2013). (c) Polyacrylamide gel showing successful editing of the EMX1 target in the human genome. The SURVEYOR reaction is used to detect the presence of Cas9-induced indels at the EMX1 locus. Transfection of Cas9, CRISPR array, and tracrRNA alone mediated successful genome editing (RNase III is not required). Image adapted from Cong et al. (2013). the $3^{\prime}$ stem loops) was sufficient for supporting robust dual-RNAguided cleavage of DNA by the Cas9-crRNA-tracrRNA complex in vitro. Third, it showed that the $\mathrm{HNH}$ domain is responsible for cleaving the target DNA strand and the RuvC domain cleaves the non-target DNA strand. Inactivation of either domain turns the Cas9-crRNA-tracrRNA complex into a DNA nickase. Fourth, it showed that single-base mutations in the PAM and in the $3^{\prime}$ region of the guide sequence abolished DNA cleavage by the Cas9-crRNA-tracrRNA complex, whereas single-base mismatches closer to the $5^{\prime}$ region of the guide RNA did not. Fifth, it showed that the crRNA and the 23-48-nt tracrRNA can be fused into a single-guide RNA (sgRNA) and this Cas9-sgRNA two-component system can mediate cleavage of plasmid DNA under biochemical conditions.

Three months later, a biochemical analysis, using a purified complex containing the $S$. thermophilus Cas9 and crRNA, reported similar findings (Gasiunas et al., 2012). First, the study showed that the Cas9-crRNA complex cleaves target DNA 3 bp upstream of the PAM of the target site, also in agreement with previous in vivo results with the $S$. thermophilus system (Garneau et al., 2010). Second, it showed that the Cas9-crRNA complex binds to dsDNA containing both the binding site as well as PAM. Third, the study showed that the HNH domain cleaves the target DNA strand and the RuvC domain cleaves the non-target strand. Inactivation of either domain turned the Cas9-crRNA complex into a DNA nickase. However, this study purified the Cas9-crRNA complex from bacteria without analyzing the components of the complex. As a result, the paper provided an incomplete picture of the Cas9 molecular mechanism for in vitro cleavage and failed to identify the requirement for tracrRNA for Cas9 function.

While the in vitro two-component system highlighted the potential of exploiting Cas9 for genome editing, as this work was conducted entirely in vitro, it did not identify the critical components for achieving robust genome editing in cells and did not demonstrate that Cas9 could be used for genome editing. Thus, although the biochemical demonstration of RNA-guided DNA cleavage is often equated with Cas9-mediated genome editing, even within the scientific community there were concerns as to whether Cas9 could be made to function in eukaryotic cells (Carroll, 2012).

At the time, we had already established that Cas9 could function in human cells. Working alongside my first trainees, including Le Cong and Ann Ran, who are co-first authors of our 
publication (Cong et al., 2013), we focused on two orthologs of Cas9 that had been previously studied using bacterial genetics and had complementary advantages: $S$. thermophilus Cas9 (StCas9), which was small enough to be packaged into an adeno-associated viral vector (AAV) for in vivo delivery, and $S$. pyogenes Cas9 (SpCas9), which had a less restrictive PAM sequence (SpCas9, PAM 5'-NGG, can target on average every $12.7 \mathrm{bp}$ in the human genome, whereas StCas9, PAM 5 -NNAGAAW, can target on average every $106.6 \mathrm{bp}$ in the human genome), and thus broader targeting potential. First, we found that both SpCas9 and StCas9 can be engineered to mediate genome editing in human and mouse cells. However, Cas9 aggregated in the nucleolus, pointing to the obstacle of correct subcellular localization when moving a bacterial system into eukaryotic cells. After experimenting with a number of nuclear localization signals (NLSs), we found that the combination of a monopartite and a bipartite NLS allowed Cas9 to localize efficiently into the human cell nucleus without any aggregation in the nucleolus. Second, we found that although the natural bacteria expressed multiple isoforms of the tracrRNA, all of which can provide CRISPR immunity in bacteria (Deltcheva et al., 2011), only the 89-nt isoform was stably expressed in human cells and was important for achieving robust genome editing. Third, we found that across 16 target sites in human and mouse cells, the threecomponent system for SpCas9 and StCas9 can mediate robust editing of the genome. Fourth, we found that a CRISPR array encoding multiple spacers can be processed by human cells into individual guide RNAs to target multiple genes in the genome. Fifth, we showed that DSBs introduced by Cas9 can stimulate homologous recombination, leading to targeted gene insertion, and that Cas 9 nickase activity can also stimulate homologous recombination in cells, while avoiding the formation of DSB-induced indels. Sixth, we also explored a two-component design. We found that the additional $3^{\prime}$ stem loops on the tracrRNA are important for gene editing, as the three-component system achieved significantly more robust genome editing in human cells than the two-component design employed, which failed to edit at a number of genomic sites. Together, these results established a foundation for the molecular mechanism by which CRISPR-Cas9 can mediate robust genome editing and further underscores that the ability of CRISPR-Cas9 to function in eukaryotic cells cannot be predicted from in vitro studies (Cong et al., 2013).

If Cas9 could function in eukaryotic cells, however, it would unlock the potential for a range of sought after applications in research, biotechnology, and medicine. It was therefore not surprising that, in addition to our efforts to develop Cas9 for genome editing, other groups were inspired by the biochemical characterization of Cas9 (Jinek et al., 2012) to explore applications of Cas9 as well. Concurrent with our study, a second report of gene editing using Cas9 was published (Mali et al., 2013b). Shortly thereafter, additional studies also reported the use of Cas9 in human and animal cells (Cho et al., 2013; Hwang et al., 2013; Jinek et al., 2013) and the use of a catalytically inactivated variant of Cas9 to achieve targeted gene repression (Qi et al., 2013).

\section{Initial impact of Cas9-mediated genome editing}

Following the demonstration of Cas9-mediated genome editing in eukaryotic cells, many outstanding scientists contributed to the advancement and application of the technology, pushing the field ahead at a remarkable rate. We continued to develop the technology by focusing on three major areas: (1) further understanding the biology of Cas9 so as to improve and extend its utility; (2) developing applications of Cas9, including genome-wide screening, a Cas9 knock-in mouse, and conversion of Cas9 to a catalytically inactive programmable DNA-binding scaffold; and (3) exploring the natural diversity of CRISPR-Cas systems to identify other Cas effectors with unique properties that may be advantageous for technological development. Through these endeavors we had the opportunity to collaborate with a number of talented researchers from diverse backgrounds, further amplifying the impact of CRISPR-based technologies.

One way the immediate impact of Cas9 can be seen is in its rapid adoption for other organisms, which highlights the broad utility of this tool as well as the robustness and ease-of-use of the system. Catalyzed by the success of Cas9-mediated genome editing in human cells, within a year, groups from around the world reported the successful application of Cas9 in a number of eukaryotic model organisms, including yeast (DiCarlo et al., 2013), mice (Wang et al., 2013), Drosophila (Gratz et al., 2013), C. elegans (Friedland et al., 2013), Arabidopsis (Li et al., 2013), Xenopus (Nakayama et al., 2013), and non-human primates (Niu et al., 2014). Cas9 was also successfully deployed in a number of agriculturally important species in that first year, such as rice and wheat (Shan et al., 2013), sorghum (Jiang et al., 2013), and maize (Liang et al., 2014). Before the year's end, the first reports were published on the use of Cas9 to correct a cataractcausing mutation in a mouse, leading to reversal of the disease phenotype (Wu et al., 2013). In parallel, a number of improvements and extensions of the technology were reported in quick succession.

The impact of the CRISPR-based technologies is due in no small part to the open sharing culture of the CRISPR field, which has enabled applications and further development of CRISPR-based technologies to flourish. This has been facilitated through on-line resources, such as the creation of numerous webbased tools for guide design (Hsu et al., 2013; Bae et al., 2014; Schmid-Burgk et al., 2014; Labun et al., 2016; Pinello et al., 2016; Concordet and Haeussler, 2018; Listgarten et al., 2018), and through the annual CRISPR meetings. CRISPR reagents have also been shared widely and openly. To date, more than 350 laboratories from around the world have made their CRISPR-based reagents accessible through the non-profit molecular reagent sharing organization Addgene. For my own group, we have made it a priority to help researchers benefit from the CRISPR technological advances we made by disseminating reagents as well as know-how for CRISPR-based technologies. Through a combination of direct mailing as well as distribution through Addgene, we have been able to share more than 52000 CRISPR reagents to researchers at more than 2300 institutions spanning 62 countries.

\section{From Cas9 to beyond: Cas12 and Cas13}

The development of other molecular technologies, such as restriction enzymes (Loenen et al., 2014) and green fluorescent proteins (Rodriguez et al., 2017), has benefitted significantly from explorations of natural diversity. Similarly, my own experience with the development of optogenetics has taught me the power of exploring the diversity of microbial opsins. Therefore, we turned to the natural diversity of CRISPR-Cas systems to identify other Cas effectors with the potential to expand the capabilities of CRISPR-based technologies. By mining the microbial diversity 
for signatures of CRISPR-Cas systems (e.g., conserved genes and CRISPR-like repeat sequences), we discovered and elucidated the functions of two new types of CRISPR-Cas systems and developed them to significantly expand the CRISPR toolbox (Shmakov et al., 2015, 2017; Zetsche et al., 2015a; Smargon et al., 2017) (Fig. 4). These discoveries prompted other investigations of microbial diversity, revealing additional subtypes of CRISPR-Cas systems (Burstein et al., 2017; Harrington et al., 2018; Konermann et al., 2018; Shmakov et al., 2018; Yan et al., 2018b) and providing insight into the origin, evolution, and function of these elegant systems.

\section{SaCas9}

Beyond its immediate utility in the lab, there was enormous interest in using Cas9-mediated genome editing as a therapeutic that could theoretically treat thousands of genetic diseases. One limitation to the therapeutic use of SpCas9, however, was its relatively large size, which made delivering it challenging. We therefore sought to identify smaller Cas9 orthologs that worked efficiently in mammalian cells while maintaining a broad targeting range. We characterized a number of CRISPR-Cas 9 systems and profiled their mammalian genome editing activity. One Cas9 ortholog from Staphylococcus aureus (SaCas9, PAM 5'-NNGRRT) showed the highest levels of activity in human cells (Ran et al., 2015). SaCas9 is more than $1 \mathrm{~kb}$ shorter than SpCas9, which allowed us to deliver it, along with a guide RNA, on a single-AAV vector for in vivo use (Ran et al., 2015). SaCas9 is now being developed as the first in vivo genome editing medicine for humans (see below) (Allergan, 2019). SpCas9 is also being advanced for therapeutic applications. However, due to its large size, clinical trials employing SpCas9 are focused on electroporation of patient cells ex vivo (Vertex, 2018a, 2018b).

\section{Cas12}

We next went beyond Cas9 orthologs to study other CRISPR-Cas systems, beginning with a putative new type of class 2 CRISPR-Cas system, type V, characterized by the Cas 12 family of effector proteins. The first Cas12 enzyme, classified as type $\mathrm{V}-\mathrm{A}$ and referred to as Cas12a (previously known as Cpf1) was identified in the genomes of Prevotella and Francisella and contained a large protein of unknown function (Schunder et al., 2013; Vestergaard et al., 2014; Makarova et al., 2015). Cas12a is a distinct enzyme unrelated to Cas9. A number of Francisella species contain Cas12a in association with putative CRISPR arrays, including $F$. novicida. Heterologous expression of the F. novicida CRISPR-Cas12a locus in E. coli led to interference of plasmid DNA transformation, establishing CRISPR-Cas12a as a bona fide CRISPR-Cas system and revealing that Cas12a requires a T-rich PAM sequence preceding the DNA target site (Zetsche et al., 2015a). In contrast to Cas9, the Cas12a system does not contain a tracrRNA, and its DNA cleavage results in a $5^{\prime}$ overhang instead of a blunt DSB (Zetsche et al., 2015a). Also, unlike Cas9, which utilizes host RNase III to process its CRISPR array, Cas12a itself has RNase activity and processes its own pre-crRNA array into individual crRNAs (Fonfara et al., 2016).

A search for Cas12a orthologs identified two-Cas12a enzymes, from Acidaminococcus and Lachnospiraceae, with strong cleavage activity in human cells, comparable to SpCas9 (Zetsche et al., 2015a). Apart from expanding the range of genomic targets that can be edited given that it has a different PAM than Cas9,
Cas12a-mediated editing has several advantages over Cas9: it is significantly more specific (Kleinstiver et al., 2016b; Kim et al., $2017 b$ ), which is important for therapeutic applications; it offers a simplified guide design because it does not require tracrRNA; it generates over-hanging ends, rather than the blunt ends created by Cas9, which may be beneficial for the introduction of new sequences (Moreno-Mateos et al., 2017); it has smaller molecular size which is more suitable for viral packaging, and it is ideally suited for multiplex genome editing because multiple guide RNAs can be easily expressed as a single transcript and subsequently processed into individual guide RNAs by Cas12a itself (Zetsche et al., 2016).

Relative to the Cas9 family of Cas effectors, Cas12 is a much more diverse family. Indeed a number of subtypes of Cas12 systems have recently been reported (denoted type V-A - V-I). The Cas12b effectors (previously known as C2c1) target DNA, but in contrast to Cas12a, they are dual-RNA guided, requiring a tracrRNA (Shmakov et al., 2015). Although initial characterization of Cas12b revealed thermophilic nuclease activity, which prevented application in mammalian cells, subsequent exploration of the Cas12b diversity and protein engineering made possible the development of two-Cas12b systems with robust genome editing activity in human cells (Teng et al., 2018; Strecker et al., 2019). Comparison of Cas12b with SpCas9 showed that Cas12b has substantially reduced off-target activity, indicating it is inherently more specific than wild-type SpCas9 when targeting the human genome (Teng et al., 2018; Strecker et al., 2019). Additional Cas12 effectors have also been identified from bacterial genomic databases, including Cas12c (Shmakov et al., 2015), Cas12d (CasY) and Cas12e (CasX), both of which were found in metagenomic samples (Burstein et al., 2017), and three subtypes of Cas12f (Cas14) (Harrington et al., 2018). Two-Cas12e orthologs, DpbCasX and PlmCasX, have recently been shown to achieve targeted gene knockout in human cells (Liu et al., 2019). A recent effort to holistically identify CRISPR-Cas systems from more than 10 terabytes of genomic and metagenomic data led to the identification of a number of new type $\mathrm{V}$ subtype loci, including both DNA- and RNA-targeting Cas12 systems (Yan et al., 2019).

\section{Cas13}

The type VI family of CRISPR-Cas systems, signified by the RNA-guided RNA-targeting Cas13 effector, was first found by using the highly conserved adaptation protein Cas1 as the search seed to identify all genomic fragments that contain putative CRISPR-Cas systems. Focusing on conserved proteins of unknown function located within each CRISPR locus, we discovered a family of well-conserved large proteins carrying the higher eukaryoticprokaryotic nuclease (HEPN) domain, which suggested they are putative RNases (Shmakov et al., 2015). Subsequent expansion of the search to use CRISPR repeats as the search seed led to the identification of additional Cas13 subtypes, including Cas13b, Cas13c, and Cas13d (Shmakov et al., 2017; Smargon et al., 2017; Konermann et al., 2018; Yan et al., 2018b).

Using E. coli heterologously expressing type VI CRISPR-Cas systems, we showed that CRISPR-Cas13a and Cas13b systems confer resistance to RNA phages, and that they are single-effector RNases guided by crRNAs (Abudayyeh et al., 2016; Smargon et al., 2017). This finding paved the way for an entirely new set of molecular technologies operating at the level of RNA, rather than DNA, and offering a safer therapeutic approach to treating disease (see below). Similar to Cas12a, Cas13 proteins also 
Cas9

S. pyogenes

Cas12a

Acidaminococcus sp.

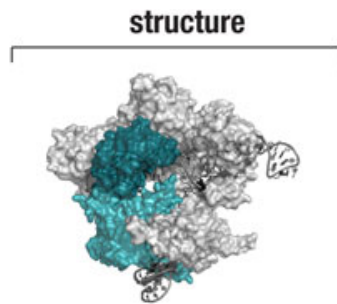

A. acidoterrestris
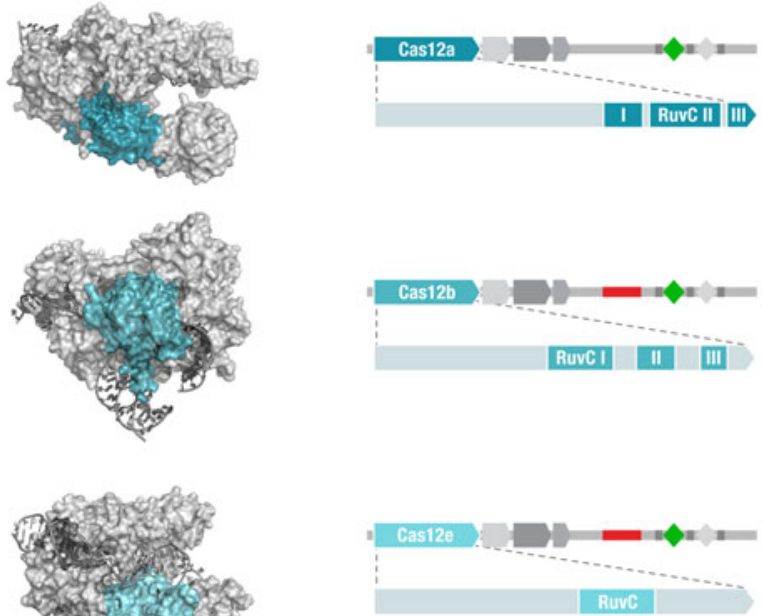

D. bacterium
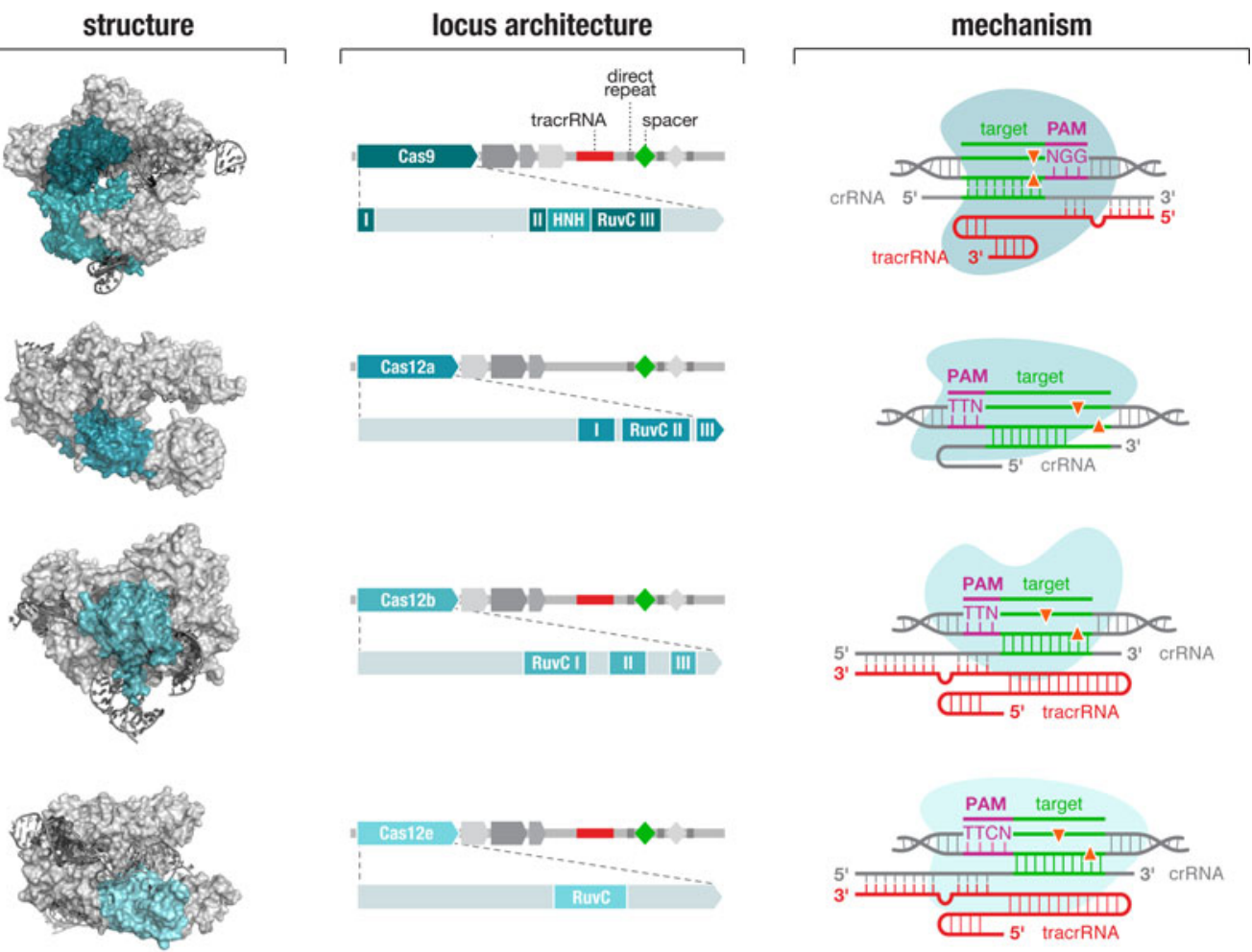

Cas13a

L. shahii
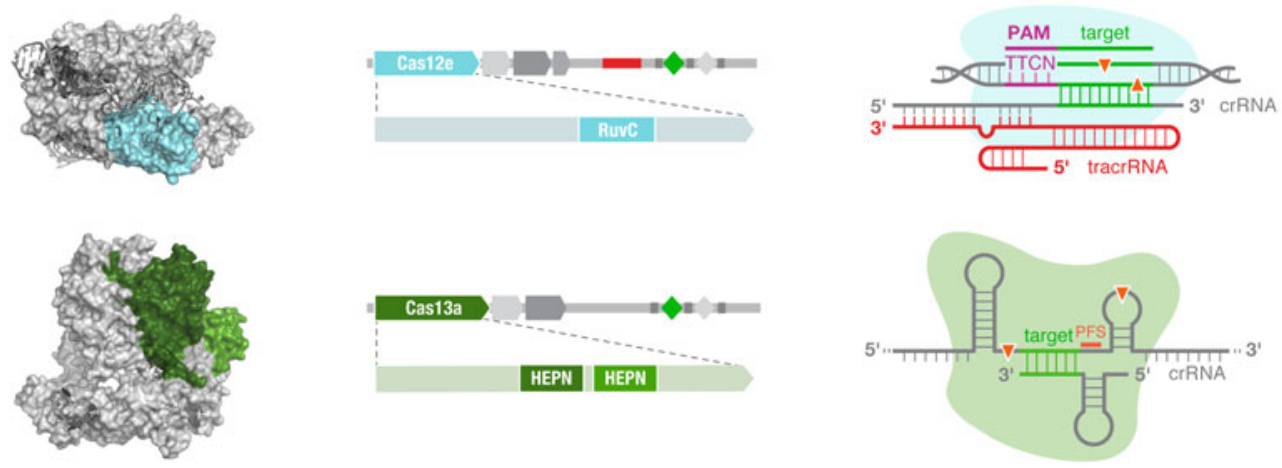

Cas13b

P. buccae
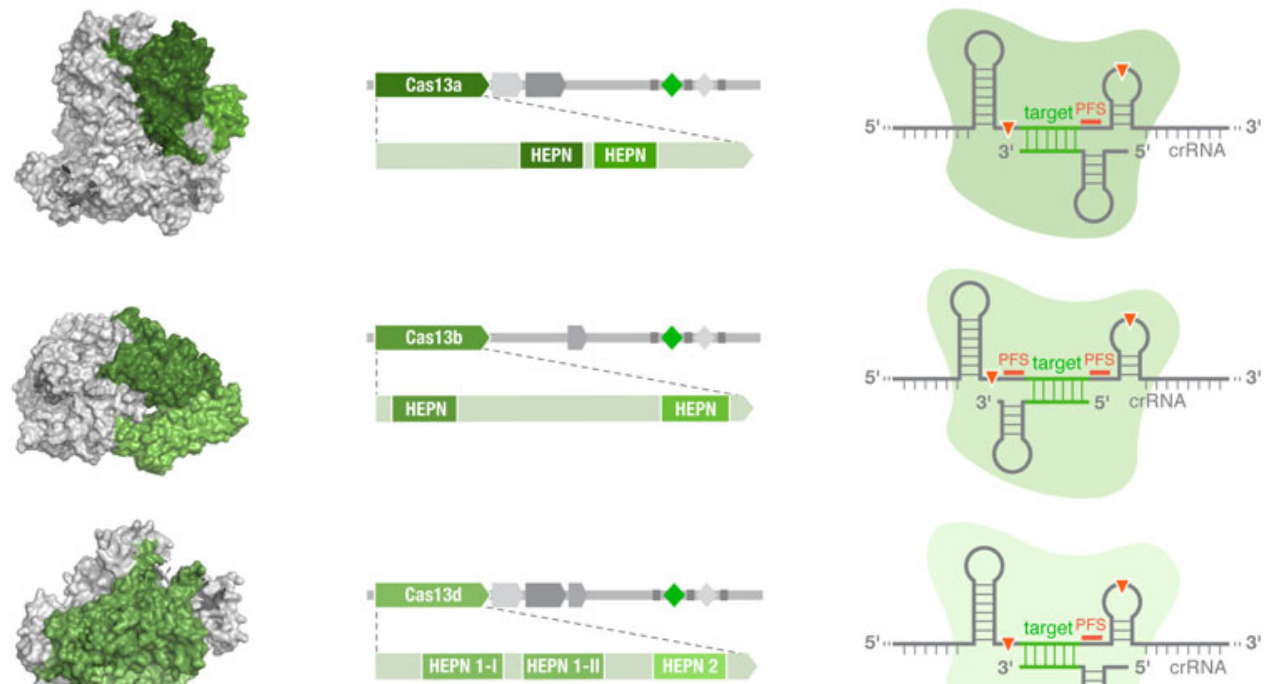

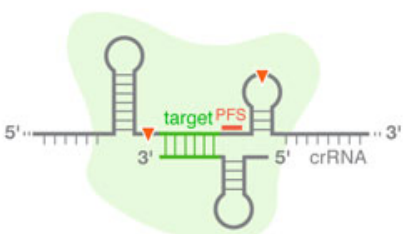

Fig. 4. Diverse class 2 CRISPR effectors have unique molecular features that contribute to an expansive toolbox for genome and transcriptome editing. To date, effectors from seven sub-types of CRISPR-Cas system have been developed for molecular technologies. These effectors differ in their locus architecture, structure, and mechanism, creating many opportunities for engineering CRISPR-based technologies. The locus architecture shows the CRISPR array, tracrRNA (if present), and catalytic domains of the effector protein. The crystal structures for each effector are shown with the catalytic domains colored as in the locus architecture. The mechanism of each effector depicts how it binds its DNA or RNA target, as well as the configuration of the crRNA and tracrRNA (if present). Crystal structures were obtained from the PDB (S. pyogenes Cas9, PDB ID: 4008; Acidaminococcus sp. Cas12a, 5B43; Alicyclobacillus acidoterrestris Cas12b, 5U30; Deltaproteobacteria bacterium Cas12e, 6NY1; Leptotrichia shahii Cas13a, 5WTK; Prevotella buccae Cas13b, 6DTD; Eubacterium siraeum Cas13d, 6E9E).

contain an RNase processing domain with the ability to cleave their corresponding CRISPR array into individual mature crRNAs (East-Seletsky et al., 2016; Smargon et al., 2017; Konermann et al., 2018). Cas13 cleaves RNA at sites outside of the target region complementary to the crRNA. Analysis of cleavage products of Leptotrichia shahii Cas13a (LshCas13a) showed that cut sites do not vary even for crRNAs targeting different positions on the same target, indicating that cut sites are likely dictated by a combination of the target RNA secondary structure and sequence features (Abudayyeh et al., 2017; Smargon et al., 2017). Further exploration of the RNase activity uncovered the 'collateral effect' of Cas13 - recognition of the target RNA by 
the Cas13-crRNA complex leads Cas13 to become a promiscuous RNase, cleaving non-target bystander RNAs at preferred cut sites (Abudayyeh et al., 2016). Collateral activity may play a role in programmed cell death in bacteria, although this remains to be fully explored. This collateral activity has been exploited to expand the applications of Cas effectors into new categories, including the development of sensitive, low-cost, and rapid diagnostics assays for viral and bacterial infections (see below).

Cas13a, b, c, and d have all been adapted for use in mammalian cells to mediate targeted RNA knockdown (Abudayyeh et al., 2017; Cox et al., 2017; Konermann et al., 2018). Interestingly, although in bacteria, each Cas13 ortholog exhibits varying levels of nucleotide preference in sequences flanking the protospacer, referred to as the protospacer flanking site (PFS), the presence of the PFS is not a strict requirement for RNA targeting in mammalian cells (Abudayyeh et al., 2017). Additionally, although collateral activity has been observed in vitro and in bacterial cells (Abudayyeh et al., 2016; Meeske and Marraffini, 2018), it has not been detected in mammalian cells (Abudayyeh et al., 2017; Konermann et al., 2018), suggesting that, similarly for Cas9 and Cas12, the differences between biochemical, bacterial, and mammalian environments can substantially affect the behavior of Cas effectors.

\section{Development of a molecular toolbox based on Cas effectors}

DNA and RNA cleavage through the nuclease activities of Cas effectors is only one way CRISPR technology can be applied. The ability to customize the binding specificity of Cas effectors using a short-guide RNA creates many additional opportunities for developing new capabilities for manipulating DNA and RNA. There are two-main categories of molecular tools based on Cas proteins (Fig. 5), with the first category utilizing the intrinsic RNA-guided nuclease activity of each effector, and the second category exploiting nuclease-inactivated Cas proteins (dCas) as RNA-guided nucleic acid binding domains to target effector modules to modulate, monitor, or modify target DNA or RNA. As tools based on Cas effectors rely on the specificity of RNA-guided target recognition, another area of focus has been to assess the specificity of Cas effectors as well as engineering solutions to enhance their specificity. Below is an overview of the broad range of molecular tools that have been developed based on Cas proteins as well as efforts to address the most critical challenges facing CRISPR-based tools.

\section{Leveraging natural and engineered properties of diverse Cas effectors}

The opportunities for developing Cas effectors as molecular technologies are further amplified by the natural diversity within each family of class 2 CRISPR-Cas systems. Based on the current publicly accessible bacterial genomic and metagenomic sequencing data, there are over 100000 Cas 9 family members, over 70000 Cas12 family members, and over 5000 Cas 13 family members. Within each family, members can exhibit a number of differences in terms of their size, guide RNA requirement, binding motif (e.g., PAM and PFS), targeting specificity, and suitability for function in eukaryotic cells. In the case of Cas13 family members, they can also exhibit different cleavage motif preferences.

A number of Cas9 orthologs have been discovered (Bolotin et al., 2005; Makarova et al., 2011, 2015; Zhang et al., 2013; Chylinski et al., 2014; Fonfara et al., 2014; Ran et al., 2015;
Shmakov et al., 2017), and an increasing number of these have been developed for use as genome editing tools beyond SpCas9 and StCas9 (Esvelt et al., 2013; Hou et al., 2013; Karvelis et al., 2015; Ran et al., 2015; Hirano et al., 2016; Lee et al., 2016; Kim et al., 2017a). The natural diversity of these enzymes has allowed expanded applications, for example some smaller Cas9 orthologs, such as $S$. aureus Cas9 (SaCas9), Neisseria meningitidis Cas9 (NmeCas9), and Campylobacter jejunii Cas9 (CjCas9) have been efficiently delivered in vivo using a single-vector strategy (Ran et al., 2015; Kim et al., 2017a; Ibraheim et al., 2018).

While exploration of natural Cas diversity provides one avenue for expanding and improving CRISPR-based tools, a complementary approach uses structure-guided engineering to modify and improve Cas effector function. Over the past several years a number of crystal structures have been solved for different members of Cas9 (Anders et al., 2014; Jinek et al., 2014; Nishimasu et al., 2014, 2015; Hirano et al., 2016; Yamada et al., 2017), Cas12 (Dong et al., 2016; Yamano et al., 2016; Yang et al., 2016; Stella et al., 2017; Swarts et al., 2017; Wu et al., 2017; Liu et al., 2019), and Cas13 (Knott et al., 2017; Liu et al., 2017a, 2017b; Zhang et al., 2018a, 2018b; Slaymaker et al., 2019) families. These structures include the apo forms with just the effector protein alone, or the effector in complex with its guide RNA alone or guide RNA in complex with target DNA or RNA, providing structural insights into target recognition and cleavage. These structural studies have been complemented by other biochemical and biophysical studies into the target search mechanism of Cas effectors (Sternberg et al., 2014; Knight et al., 2015; Ma et al., 2016a).

\section{Expanding the targeting range of DNA-targeting Cas proteins}

The DNA targeting range of Cas 9 and Cas12 is defined by the PAM sequence, a short-sequence flanking the target sequence is required for DNA targeting. A shorter PAM sequence provides a broader targeting range whereas longer PAM sequences are more restrictive. For example, wild-type SpCas9 (which has an NGG PAM) can target roughly ten times more sites in the human exome than wild-type SaCas9 (which has an NNGRRT PAM) (Scott and Zhang, 2017). In order to increase the flexibility of Cas-mediated DNA targeting, a combination of approaches has been used to expand the number of targetable PAM sequences. First, by exploring phylogenetic diversity, a number of Cas effector orthologs have been identified with distinct PAM requirements. In the case of Cas12a, a survey of more than a dozen orthologs identified one, from Moraxella bovoculi, with robust indel activity in human cells and tolerance of a shorter PAM, expanding the available targeting landscape (Zetsche et al., 2017). Ultimately, however, only a handful of Cas effectors have been successfully developed for function in eukaryotic cells (Ran et al., 2015; Zetsche et al., 2015a; Abudayyeh et al., 2017; Cox et al., 2017; Kim et al., 2017a; Chatterjee et al., 2018; Ibraheim et al., 2018; Konermann et al., 2018; Teng et al., 2018; Liu et al., 2019; Strecker et al., 2019) limiting the extent of this approach.

A second approach for expanding the DNA targeting range of Cas9 and Cas12 is to engineer new variants, either through structure-guided design or directed evolution. Based on the crystal structures of Cas effectors in complex with guide RNA and target DNA (Anders et al., 2014; Nishimasu et al., 2015; Yamano et al., 2016), targeted mutagenesis has been used to generate new protein variants with altered PAM sequences. At the same time, a 
DNA

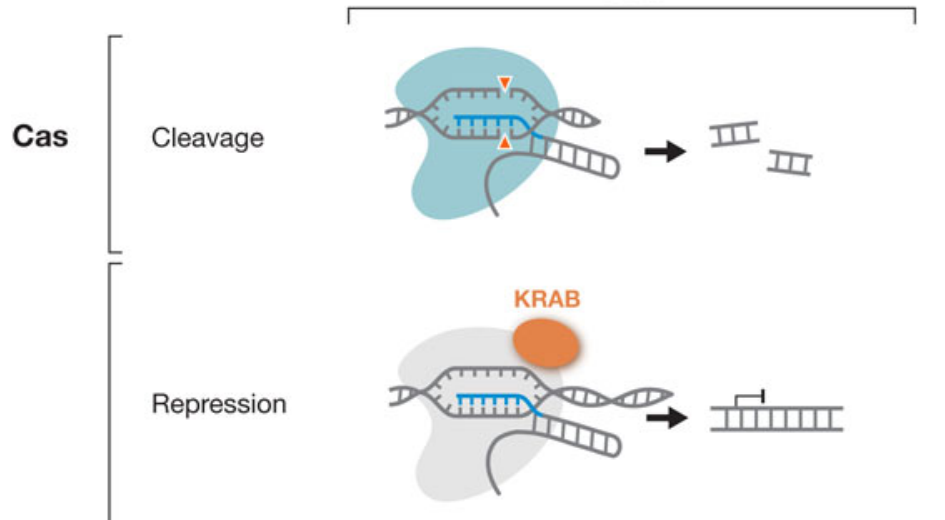

Activation

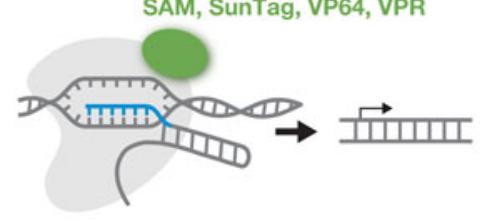

DNMT3A, TET1, p300

Epi-

modification

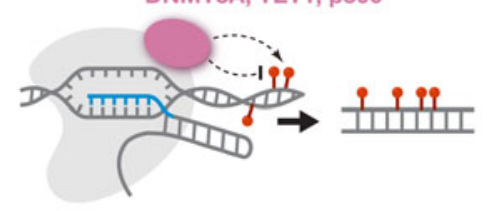

dCas

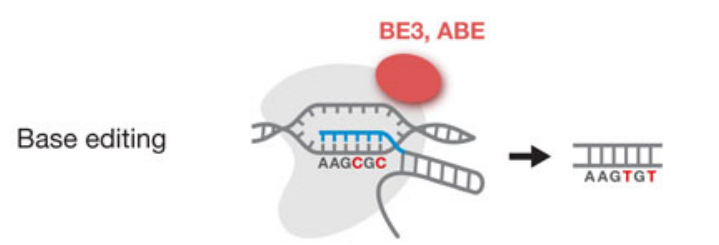

Fluorescent protein

Imaging
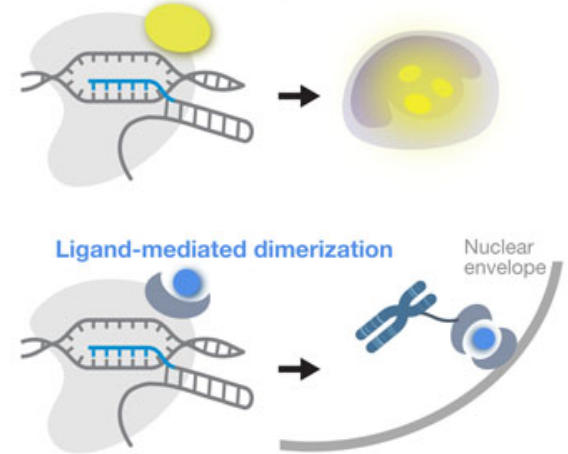

RNA
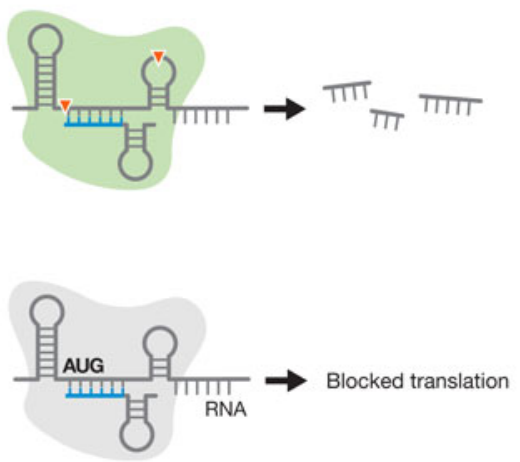

Initiation factors
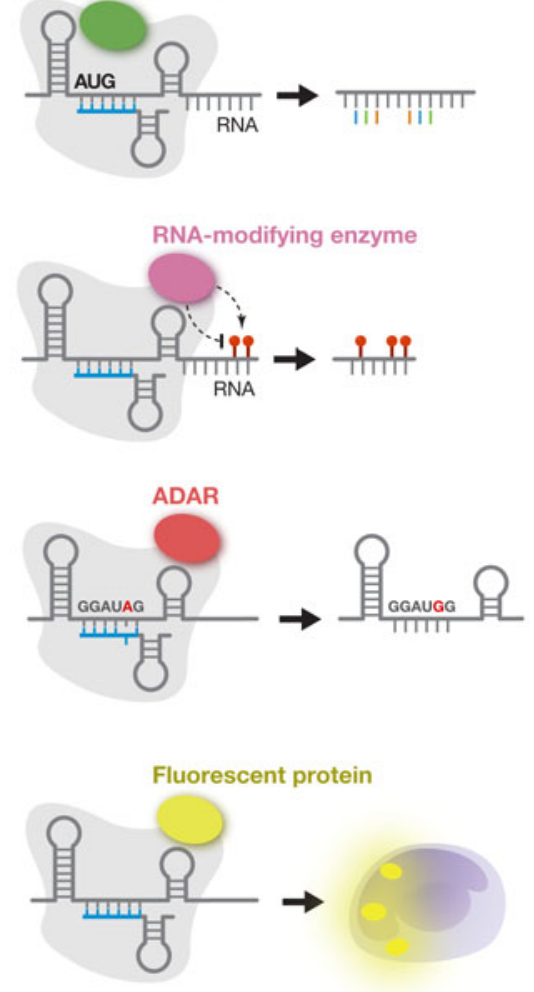

Splicing factors

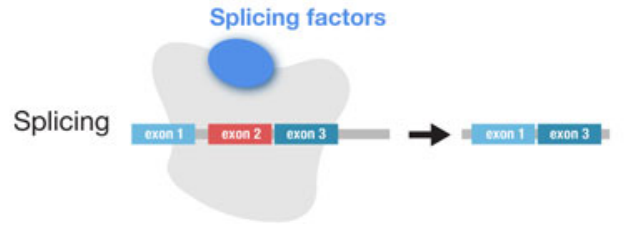

Fig. 5. The CRISPR-Cas toolbox enables a broad range of applications in eukaryotic cells. Applications of DNA-targeting Cas effectors (Cas9 and Cas12a-e) (left column) and applications of RNA-targeting Cas effectors (Cas13a-d) (right column) are shown. Active Cas effectors can be used for nucleic acid cleavage. In addition, Cas effectors can be turned into RNA-guided DNA or RNA binding domains by inactivating their catalytic residues (dCas). dCas can be fused to a variety of functional moieties to achieve targeted repression, activation, epi-modification, base editing, and imaging at either the DNA or RNA level. In addition, dCas13 can be used to modulate splicing through fusion to splicing factors. KRAB, Krüppel associated box; SAM, synergistic activation module; SunTag, SUperNova Tag; DNMT3A, DNA methyltransferase 3 alpha; TET1, ten-eleven translocation 1; p300, E1A-associated protein p300; BE3, base editor 3; ABE, adenine base editor and ADAR, adenosine deaminase acting on RNA;

number of groups have used directed evolution strategies to evolve new variants of Cas effectors with unique properties, including different PAM preferences. These efforts have led to the development of a number of Cas9 and Cas12a variants with a significantly broadened DNA targeting range (Kleinstiver et al., 2015a, 2015b; Gao et al., 2017; Hu et al., 2018; Nishimasu et al., 2018). Collectively, these variants enable targeting of virtually any genomic site. 


\section{Assessing the specificity of class 2 Cas effectors}

One of the most critical technical requirements for the application of class 2 Cas effectors is their targeting specificity. When applying Cas9 or Cas 12 as an active nuclease, minimizing off targets is particularly important because a range of undesirable genomic alterations could arise through the cell's endogenous DNA repair mechanisms, such as translocations between different cleavage sites and large-scale deletions. For nuclease as well as dCas binding applications, it is important that the effector binds selectively to the DNA or RNA targeted by the guide RNA. In the case of active nuclease applications, off-target editing activity due to pseudo-specific interactions between the Cas effector and the genome (arising when there are less than perfect matches between the target and guide RNA) can give rise to additional DSBs that lead to either small insertions and deletions (indels) or larger genomic alterations.

An initial study to characterize off-target indels used computational analyses to identify loci in the genome that share a high degree of homology to the target site, and then assayed editing events at these computationally predicted off-target loci using deep sequencing (Fu et al., 2013). The study found that SpCas9 can indeed induce off-target edits at genomic loci that carried three or fewer mismatches compared with the guide sequence. Additional studies using different approaches also showed that Cas9 can indeed introduce off-target edits (Hsu et al., 2013; Mali et al., 2013a; Pattanayak et al., 2013). As the early approaches covered only a very limited set of off-target sites, subsequent investigations focused on developing genome-wide unbiased approaches including in vitro assays like Digenome-seq (Kim et al., 2015), CIRCLE-seq (circularization for in vitro reporting of cleavage effects by sequencing) (Tsai et al., 2017), and SITE-seq (selective enrichment and identification of tagged genomic DNA ends by sequencing) (Cameron et al., 2017) and cellular assays like GUIDE-seq (genome-wide, unbiased identification of DSBs enabled by sequencing) (Tsai et al., 2015), BLESS (direct in situ breaks labeling, enrichment on streptavidin and nextgeneration sequencing) and BLISS (breaks labeling in situ and sequencing) (Crosetto et al., 2013; Yan et al., 2017), linear amplification-mediated PCR followed by high-throughput genome-wide translocation sequencing (LAM-HTGTS) (Frock et al., 2015), and VIVO (verification of in vivo off-targets) (Akcakaya et al., 2018). The use of these assays found that the editing specificity of SpCas9 varied widely depending on the guide RNA. When these unbiased techniques were used to profile the specificity of Cas9 orthologs as well as Cas 12 family members, it was found that SaCas9 as well as Cas12a and Cas12b are much more specific than SpCas9, with most guide RNAs exhibiting no detectable off-target editing (Kleinstiver et al., 2016b; Yan et al., 2017; Strohkendl et al., 2018; Tycko et al., 2018; Strecker et al., 2019). It is worth noting, however, that the functional impact of off-target edits will vary depending on their location. For example, off-target indels within coding regions, regulatory elements, and non-coding RNAs are likely to have more undesirable effects.

A number of studies have also explored the landscape of larger genomic alterations arising from Cas9 activity. For translocations, the use of LAM-HTGTS showed that the frequency of SpCas9-induced translocation varies considerably with the guide RNA, from undetectable to $\sim 3 \%$ (Frock et al., 2015), and the use of a tagmentation strategy found SpCas9-mediated translocation rates of $\sim 2.5 \%$ for two-different guides (Giannoukos et al., 2018). For large deletions, the use of PacBio and Sanger sequencing with SpCas9-edited hemizygous embryonic stem cells showed that 10 out of 48 edited alleles represented deletions larger than $250 \mathrm{bp}$ (ranging up to nearly $6 \mathrm{~kb}$ ) (Kosicki et al., 2018). The same study also identified a number of other events such as transversions, duplications, and other structural rearrangements (Kosicki et al., 2018).

Similar approaches have not been applied to the highspecificity variants of Cas 9 or to Cas $12 \mathrm{a} / \mathrm{b}$, all of which show substantially fewer indel off-targets, and it will be interesting to see if the number of large deletions and structural rearrangements is similarly reduced with these other Cas effectors. These studies, along with empirical testing of guide RNAs, will inform the best choice of the Cas effector for applications requiring particularly high levels of editing specificity. In addition, methods have been developed to quantify the on-target editing outcomes of Cas9 (Miyaoka et al., 2016, 2018).

When assessing the RNA targeting specificity of Cas13, the considerations are slightly different. Although off-target cleavage arising from pseudo-specific binding remains a concern, an additional issue with Cas13 is potential collateral cleavage of bystander transcripts. To assess the likelihood of off-target RNA knockdown, the effect of an increasing number of mismatches between the guide sequence and its RNA target was examined. From these studies it was found that Cas 13 can tolerate up to a single mismatch throughout the guide sequence and still cleave the target RNA (Abudayyeh et al., 2017). Additionally, transcriptome-wide sequencing revealed that Cas13 can achieve highly specific knockdown of the target transcript without significant off-target effects. In contrast, short-hairpin RNA (shRNA) knockdown of the same transcript led to downregulation of hundreds of off-targets (Abudayyeh et al., 2017). In addition, biochemical analysis of target RNA binding by Cas13a revealed that perfect matching in a central seed region of the guide sequence is required for binding, but a different guide region is required for the activation of RNase activity (Tambe et al., 2018). Together, these studies provided detailed insight into the potential off-target effects due to pseudo-specific binding as well as suggested that collateral activity is not significant in mammalian cells, which has been supported by additional studies (Konermann et al., 2018).

\section{Improving the targeting specificity of Cas effectors}

A number of approaches have been developed to improve the specificity of DNA editing by Cas9, and many of these approaches have also been applied or are relevant to Cas12 as well. The approaches can be divided into strategies that either seek to reduce overall exposure to the nuclease or directly improve specificity through engineering of the system.

For the first category of approaches, we observed early on that the editing specificity can be improved by more than 10 -fold by introducing less Cas9 into cells (Hsu et al., 2013). In agreement with this observation, several other groups have demonstrated that using either mRNA to deliver Cas9 or delivering Cas9-sgRNA ribonucleoprotein (RNP) complexes directly into the target cell can significantly increase the editing specificity (Cho et al., 2014; Lin et al., 2014). In addition to use of different delivery methods to limit the dosage of Cas9 in cells, it is also possible to engineer Cas9 so that its nuclease activity becomes drugor light-inducible (Davis et al., 2015; Nihongaki et al., 2015; Truong et al., 2015; Wright et al., 2015; Zetsche et al., 2015b; Liu et al., 2016a; Nguyen et al., 2016; Rose et al., 2017). This 
inducible approach has also been applied to Cas12a (Tak et al., 2017).

For the second category of approaches, various strategies have been used, beginning with engineering the system to increase the number of target DNA bases that must be specifically recognized by Cas 9 in order to activate nuclease activity. The first strategy doubles the number of DNA bases that need to be recognized to introduce a DSB by utilizing a Cas9 nickase and twojuxtaposed guide RNAs to create two off-set nicks (Mali et al., 2013a; Ran et al., 2013). This method was found to reduce offtarget edits beyond the detection limit (Ran et al., 2013). Related to this double-nicking approach, a second strategy uses dCas9-FokI fusions and a pair of juxtaposed guide RNAs to facilitate the introduction of a DSB (Guilinger et al., 2014; Tsai et al., 2014). The specificity of Cas 9 targeting can also be enhanced by modifying the guide RNA. One study showed that SpCas9 targeting can be significantly improved using truncated-guide RNAs with $17 \mathrm{nt}$ of the targeting sequence (Fu et al., 2014), which decreases the tolerance for mismatches. More recently, it was shown that the use of bridged or locked-nucleic acids can also improve Cas9 specificity by slowing the reaction rate (Cromwell et al., 2018), and that engineering the guide RNA to create a hairpin in the spacer region improves specificity of a number of Cas9 and Cas12 enzymes (Kocak et al., 2019).

In addition to these strategies, rational engineering of Cas9 and Cas 12 has been used to create high-specificity variants, offering a simpler solution to the specificity challenge. We developed the first of these variants, eSpCas9, which exhibits substantially reduced off-target activity while maintaining on-target efficiency (Slaymaker et al., 2015). A number of groups have subsequently used structural information or directed evolution to develop additional high-specificity variants of Cas9 (Kleinstiver et al., 2016a; Chen et al., 2017; Casini et al., 2018; Hu et al., 2018; Lee et al., 2018; Vakulskas et al., 2018) and Cas12a (Kleinstiver et al., 2019).

The specificity of Cas effectors will continue to be improved through rational engineering and directed evolution, which will be particularly important for the clinical use of Cas effectors. It is important to note that the development of variants of Cas effectors with increased specificity needs to be complemented with higher sensitivity assays, such as the recently developed genomewide off-target analysis by the two-cell embryo injection (GOTI) method (Zuo et al., 2019), for detecting the presence of off-target activity, particularly large deletions and chromosomal rearrangements.

\section{dCas platforms}

In addition to their utility as nucleases, class 2 Cas effectors can also be inactivated to turn the proteins into RNA-guided DNAor RNA-binding domains (Fig. 5). These inactivated variants can be used for a wide variety of powerful applications by serving as programmable nucleic acid binding scaffolds for the recruitment of a variety of effector functions. To deactivate the nuclease activity of Cas9, alanine substitutions are introduced into the catalytic residues of the $\mathrm{HNH}$ and RuvC nuclease domains (Sapranauskas et al., 2011). In early 2013, using this mutant version of Cas9, termed dead Cas9 (dCas9), it was shown that dCas9 could achieve programmable gene repression in bacteria and mammalian cells by simply binding to the genome and blocking transcription (Qi et al., 2013). Since then, many new applications have been developed by using dCas9 to recruit effectors that modulate, modify, or visualize DNA or RNA (for examples see:
(Bikard et al., 2013; Chen et al., 2013; Gilbert et al., 2013, 2014; Konermann et al., 2013, 2014; Maeder et al., 2013; Perez-Pinera et al., 2013; Tanenbaum et al., 2014; Hilton et al., 2015; Ma et al., 2015, 2016b; Thakore et al., 2015)). Similar to Cas9, the RuvC nuclease domain of Cas12 (Zetsche et al., 2015a), and the HEPN nuclease domains of Cas13 (Abudayyeh et al., 2016) can also be inactivated to generate $\mathrm{dCas} 12$ and $\mathrm{dCas} 13$, respectively.

In the case of Cas9, we showed that it is also possible to use a truncated guide sequence that does not trigger the nuclease activity of Cas9 (Dahlman et al., 2015). Using this strategy, researchers can simultaneously use Cas9 as a nuclease to cleave one set of genomic targets and as a DNA binding domain for a different set of genomic targets simply by using guide RNAs with full length (20-nt) or truncated (12-nt) guide sequences, respectively. This approach is particularly relevant when using transgenic mouse lines expressing the nuclease-active form of Cas9 (Platt et al., 2014). Using this truncated guide RNA strategy, DNA binding experiments can be conducted without creating an additional mouse line expressing dCas9 (Liao et al., 2017).

There are a several ways to recruit effectors to dCas. The simplest method is to directly fuse the effector protein to either the $\mathrm{N}$ - or C-terminus of the Cas protein (Gilbert et al., 2013; Konermann et al., 2013; Abudayyeh et al., 2017; Tak et al., 2017). However, in some applications, particularly for the recruitment of fluorescent proteins for imaging, a second strategy has been used where a SunTag is attached to dCas9 to attract effectors that are fused to a single-chain variable fragment antibody fragment with SunTag affinity (Tanenbaum et al., 2014). Yet another approach is to engineer the guide RNA such that exposed hairpins can serve as potential sites for insertion of RNA aptamers. By engineering new guide RNAs carrying the MS2 aptamer inserted into stem loops on the guide RNA, we showed that effector domains can be recruited via MS2 binding (Konermann et al., 2014). Subsequent studies have shown that other aptamers such as PP7 and com can also be inserted into the guide RNA to allow for multiplexing applications (Zalatan et al., 2015; Liu et al., 2016a).

The applications of dCas are quite broad. Initial work showed that simply by recruiting dCas9 to target loci, gene expression could be repressed in both bacterial and human cells (Bikard et al., 2013; Qi et al., 2013). Fusions of dCas9 to transcriptional repressors, such as Krüppel-associated box (KRAB), have also been used to programmably repress gene expression (Gilbert et al., 2013) in human cell lines. dCas9-KRAB fusions have been combined with inducible Cas9 systems for fine-tuned regulatory control of gene networks (Mandegar et al., 2016). dCas9 can also be used to facilitate transcriptional activation of target genes (Bikard et al., 2013; Gilbert et al., 2013; Konermann et al., 2013, 2014; Maeder et al., 2013; Perez-Pinera et al., 2013). Additionally, dCas9 has been fused with epigenetic modifiers to achieve targeted histone acetylation (Hilton et al., 2015), histone demethylation (Kearns et al., 2015), and DNA methylation and demethylation (Liu et al., 2016b; Vojta et al., 2016; Xu et al., 2016). A number of groups have used dCas9 for genomic locus and chromosome imaging as well as spatial manipulation of genomic organization (Chen et al., 2013; Morgan et al., 2017; Wang et al., 2018). Through the use of either orthogonal Cas enzymes or aptamers and multiple fluorophores, multiplex locus imaging can be achieved (Chen et al., 2016; Liu et al., 2016a). Similarly, RNA can be imaged using dCas effectors, including dCas9 (Nelles et al., 2016) and dCas13a (Abudayyeh et al., 2017). dCas13 has also been fused to hnRNP1, a negative regulator of 
splicing, to achieve targeting exon skipping (Konermann et al., 2018). Through fusion to the engineered peroxidase APEX2, dCas9 can be used to identify proteins associated with a specific genomic locus (Myers et al., 2018). Additional functional platforms have also been developed, such as the fusion of a Cas9 nickase with an error-prone polymerase to create EvolvR, a system for rapid diversification of the DNA sequence within a few hundred base-pair window (Halperin et al., 2018). Another system, CRISPR-X, uses dCas9 and modified-guide RNAs to recruit cytidine deaminase variants to generate localized windows of variation, which may have applications for directed evolution (Hess et al., 2016).

\section{Targeted base editing of DNA and RNA}

Another exciting application of dCas enzymes has been the development of programmable DNA and RNA base editors, which can achieve the precise chemical change of one base to another (reviewed comprehensively by (Rees and Liu, 2018)). Base editors are particularly promising for the development of therapeutic applications, as more than half of the known pathological variants are point mutations. Furthermore, both DNA and RNA base editing provide the possibility of making targeted changes without relying on homologous recombination, which is inefficient especially in post-mitotic cells such as neurons.

DNA base editors are generated by fusing dCas9 or Cas9 nickase (Komor et al., 2016; Nishida et al., 2016; Gaudelli et al., 2017) or dCas12 (Li et al., 2018c) to single-strand DNA deaminases (Fig. 5). The first type of base editor developed used dCas9 or Cas9 nickase to bring a single-stranded DNA cytosine deaminase such as AID or APOBEC to mediate $\mathrm{C} \bullet \mathrm{G}$ to $\mathrm{T} \cdot \mathrm{A}$ conversions on target DNA. Binding of DNA by dCas9 or Cas9 nickase forms an R-loop which exposes a short stretch of single-stranded DNA for deamination by the tethered cytosine deaminase (Komor et al., 2016; Nishida et al., 2016). Application of the cytosine base editor in a variety of animal and plant cell types can lead to high levels of targeted base conversion (Rees and Liu, 2018). To expand the types of base changes achievable, a second type of base editor capable of converting A • T to $\mathrm{G} \cdot \mathrm{C}$ was created by fusing dCas9 or Cas9 nickase to an evolved form of the bacterial tRNA-specific adenine deaminase TadA (Gaudelli et al., 2017). TadA naturally acts on single-stranded RNA, but through an impressive series of directed evolution steps, TadA was converted into a DNA deaminase. DNA base editing has already been applied in animal models of disease, highlighting its potential for therapeutic use (Villiger et al., 2018). This powerful technology is being rapidly optimized to increase specificity, efficacy, and precision (Rees and Liu, 2018).

RNA base editors have been engineered by fusing dCas 13 to the adenine deaminase ADAR to achieve a precise, targeted A-to-I conversion (inosine is read out by cells as guanosine) (Fig. 5) (Cox et al., 2017). Because ADAR acts on an RNA duplex formed between the target RNA and the guide RNA at adenosines in $\mathrm{A} \cdot \mathrm{C}$ mismatch bubbles, a specific adenine can be targeted for deamination by intentional mis-pairing with a cytosine on the guide RNA (Cox et al., 2017). The ability to direct adenine deamination with single-nucleotide precision, which is not currently possible with DNA editing, has inspired efforts to use directed evolution to convert ADAR into a duplex RNA-acting cytosine deaminase, an activity which has not been found in nature, to develop a precise $\mathrm{C}$ to U RNA editor. RNA and DNA base editing complement each other to expand the range of applications. In particular, RNA editing does not depend on the presence of DNA-repair machinery for base conversion and therefore can be applied in virtually all cell types. Furthermore, because RNA editing can be potentially temporally restricted when paired with transient delivery systems, it can serve as a reversible editing system, which further expands the therapeutic potential of CRISPR-based technologies.

The specificity of base editors has recently been comprehensively profiled. Although cytosine DNA base editors have been found to generate a large number of off-target edits throughout the genome, the adenine base editor is able to achieve specific editing of the target site (Jin et al., 2019; Kim et al., 2019; Zuo et al., 2019). A study in mice also examined potential off-target effects of adenine base editing and similarly found that $\mathrm{A} \cdot \mathrm{T}$ to G - C conversion was quite specific (Liu et al., 2018d). Additionally, a recent study looking at the specificity of base editors found substantial off-target editing in the transcriptome (Grunewald et al., 2019). Future refinements aimed at reducing non-specific interactions with DNA should significantly increase the specificity of cytosine base editors. In addition to improving the specificity of the deaminase domain, specificity may also be improved through the use of more specific Cas effectors such as dSaCas9 or dCas12a rather than dSpCas9. As DNA base editors do not rely on the introduction of DSBs, the likelihood of large deletions or translocations is significantly lower than with nuclease-based approaches. The specificity of RNA base editors has also been comprehensively profiled using high-coverage transcriptome analysis. Although the initial version of the RNA base editing platform showed broad transcriptome-wide off-target editing, structure-guided engineering of ADAR reduced nonspecific interactions and improved the targeting specificity by $\sim 1000$ fold (Cox et al., 2017). The promising results with both DNA and RNA base editing are prompting rapid improvements in technology.

\section{Additional applications of CRISPR-based technologies}

CRISPR-based technologies have also been coopted for information recording, either about cell fate, activity, or even nonbiological data. Many of these approaches rely on the ability of CRISPR-Cas systems to create traceable scars that can be read out through sequencing and then related back to specific events. One of the first such uses was lineage tracing to reconstruct cellular or organismal development (McKenna et al., 2016; Frieda et al., 2017; Kalhor et al., 2017). Trackers have also been built that can record information about the cellular state, such as the presence of small molecules, metabolites, external stimuli, or transcriptional activity (Perli et al., 2016; Schmidt et al., 2018; Tang and Liu, 2018). Cas effectors have also been used to build synthetic gene circuits to advance synthetic biology applications (Nissim et al., 2014; Zalatan et al., 2015; Nakamura et al., 2019). Finally, using the adaptation modules of CRISPR-Cas systems, the Cas1 and Cas2 enzymes (Heler et al., 2015; Nunez et al., 2015; Silas et al., 2016), an approach has been developed for storing non-biological data (Shipman et al., 2016, 2017; Schmidt et al., 2018).

\section{Advancing biological research}

CRISPR-based tools have been deployed widely in the life sciences, and due to their accessibility and ease of use, they are contributing to the advancement of biological studies on nearly every 
front. Here, I highlight a few of the ways these tools are being used in high-impact applications, including creation of new animal and cellular models as well as large-scale gene function interrogation.

\section{Accelerating the generation of cellular and animal models}

One of the most immediate impacts CRISPR-based technologies have had on the advancement of biological studies is on the generation of plant, animal, and cellular models. First, CRISPR-based technologies have dramatically reduced the time and labor needed to modify the genome of conventional eukaryotic model organisms and cell lines (with the exception of yeast, for which a powerful toolbox for genetic manipulation has existed for decades). A key example of this is the generation of knockout mice. Prior to 2013, knockout mice were created using modified-embryonic stem cells and the entire process took 1-2 years, whereas Cas9-mediated knockout can be achieved in weeks to months (Wang et al., 2013; Yang et al., 2013). Recently, it was suggested that the generation of tailored mouse models could be further accelerated through use of a Cas9-mediated gene drive approach (Grunwald et al., 2019). This approach has also made it substantially more feasible to create non-human primate models (Niu et al., 2014; Chen et al., 2015b; Wan et al., 2015). Similarly, the ease of reprogramming CRISPR-based tools has enabled their large-scale application to rapidly create libraries of cell lines. Second, CRISPR technology has rendered a variety of additional organisms genetically tractable, including parasites (Ghorbal et al., 2014; Sollelis et al., 2015; Vinayak et al., 2015; Sidik et al., 2016), microorganisms (Shapiro et al., 2018), and non-model organisms such as crustaceans (Martin et al., 2016), wasps (Li et al., 2017), butterflies (Li et al., 2015), and diatoms (Nymark et al., 2016). This robustness of CRISPR-based technologies across organisms provides opportunities for studying many biological processes in their native context. Third, CRISPR-based technologies are being used to create tailored animal and cellular models that recapitulate genetic variants found in human patients (Birling et al., 2017). These tailored models enable more accurate disease modeling that can be used to understand the molecular pathology of a range of human diseases as well as to develop novel therapeutic strategies to treat these diseases. For example, a pig model of Huntington's disease has been created through Cas9-mediated gene editing, enabling the study of this disease in a more relevant animal model (Yan et al., 2018a). Fourth, Cas9 has also been used in vivo to accelerate the modeling of diseases, such as cancer (Maddalo et al., 2014; Sanchez-Rivera et al., 2014). Finally, Cas9 has also been used to successfully edit human embryos in the laboratory for research purposes (the embryos were discarded without being implanted to establish pregnancy) (Liang et al., 2015; Fogarty et al., 2017; Ma et al., 2017). These studies have the potential to advance our understanding of human embryogenesis and reproductive challenges. For one of these studies (Ma et al., 2017), an active dialog is currently underway regarding the interpretation of the editing results (Adikusuma et al., 2018; Egli et al., 2018; Ma et al., 2018).

One particularly useful advance has been the creation of transgenic mice that constitutively or conditionally express Cas9, increasing the ease of gene knockout studies in vivo (Platt et al., 2014; Dow et al., 2015). Additionally, a dCas9-EGFP knock-in mouse has been created to enable easy, dynamic tracking of targeted genomic regions (Duan et al., 2018). Using these mouse models, researchers can much more easily target specific cell types, achieve multiplexed gene knockouts, and much more rapidly model diseases. These models have been used to look at a number of biological processes, including cancer (Platt et al., 2014), wound healing (Ge et al., 2017), synaptic transmission (Yamasaki et al., 2017), circadian rhythms (Tso et al., 2017), and $\mathrm{T}$ cell differentiation (Zhang et al., 2017), among others.

\section{Genome-wide functional screening}

A second way that CRISPR technology is accelerating research is through the development of robust high-throughput screening methods (Koike-Yusa et al., 2014; Shalem et al., 2014; Wang et al., 2014; Zhou et al., 2014) that can systematically assay the impact of genes or regulatory regions on a phenotype of interest (see (Doench, 2017; Guo et al., 2017) for a recent review of CRISPR-based genetic screening) (Fig. 6). Large-guide RNA expression libraries can be computationally designed to target every gene in the genome. Delivery of this library of guides along with Cas9 into cells generates a population of cells, each with a single gene perturbed, collectively knocking out every gene in the genome (Shalem et al., 2014). By phenotypically screening the library of cells, candidate genes involved in a process of interest can be identified through sequencing the guides in selected cells in the perturbed population. Although the approach is similar to methodologies using genome-wide libraries of shRNAs, CRISPR screens are significantly more reliable (Shalem et al., 2014). In addition, as interest in non-coding regions and cis-regulatory elements has grown in recent years (nearly $99 \%$ of the human genome is non-coding and the overwhelming majority of disease-associated variants identified in genome-wide association studies (GWAS) are in non-coding regions), CRISPRbased screening has also been extended to identify non-coding regulatory elements in the endogenous genome (Canver et al., 2015; Sanjana et al., 2016).

dCas9-based transcription screening systems have also been developed for genome-scale screening. dCas9 alone or tethered to a transcriptional repression domain has been used to mediate genome-scale loss of function screening. Because sgRNAs for dCas9-mediated knockdown are harder to design and are not as potent as Cas9-mediated knockout, transcriptional repression screening typically requires guide RNA libraries with more redundancy per gene (Gilbert et al., 2014). However, for genes that are essential and therefore cannot be permanently knocked-out, transcription repression-based screening may be used to uncover their function. In addition, repression-based approaches circumvent some of the limitations of knockout screening, such as cellular toxicity associated with targeting DSBs to high-copy chromosomal regions (Aguirre et al., 2016; Munoz et al., 2016) and the variability in the outcome of NHEJ repair, which could generate gain-of-function alleles (Donovan et al., 2017; Ipsaro et al., 2017). dCas9-based transcription activators may also be used to carry out gain-of-function genetic screens (Gilbert et al., 2014; Konermann et al., 2014).

Additional modes of CRISPR-based screening include the use of paired guides to create libraries of large deletions, which has enabled further interrogation of IncRNAs (Zhu et al., 2016), and dCas 9 fused to epigenomic modifiers to screen for functional regulatory elements (Klann et al., 2017). The basic screening approach has also been adapted to achieve multiplex perturbations to identify gene sets involved in specific drug responses (Wong et al., 2016) and to systematically map genetic interactions at an unprecedented scale (Horlbeck et al., 2018). Pooled CRISPR screens have been combined with single-cell RNA-sequencing, 


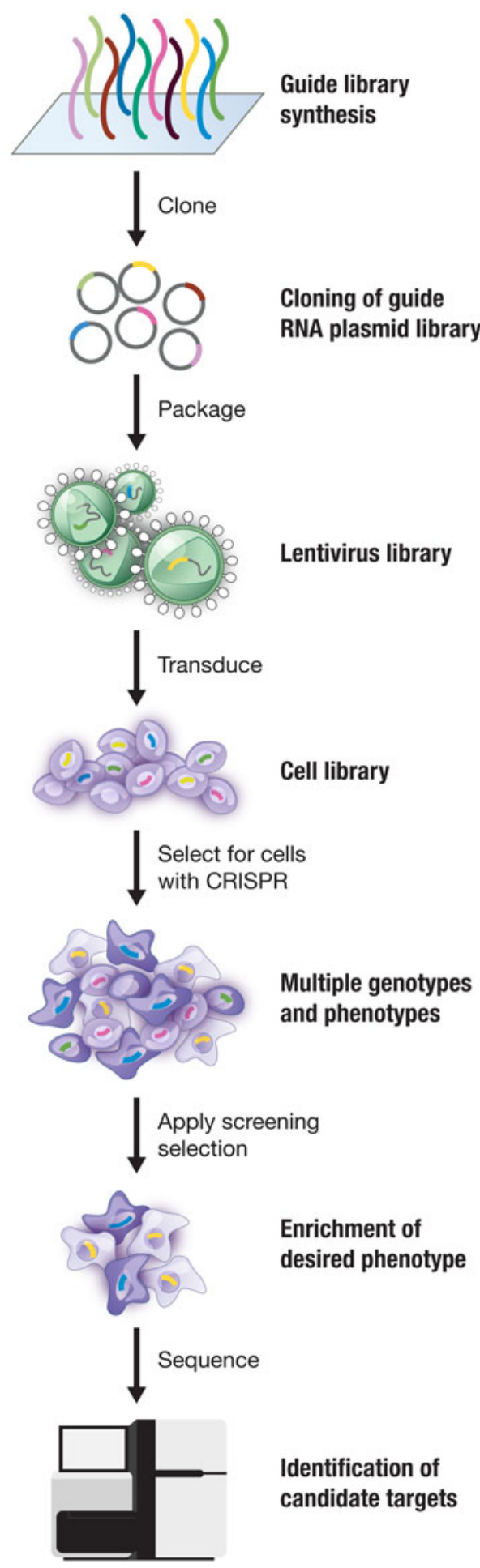

Fig. 6. CRISPR-mediated genome-wide screening allows large-scale interrogation of gene function. Cas9 can be combined with libraries of guide RNAs to facilitate gain- or loss-of-function genetic screening. First, guide RNAs designed to target coding or noncoding elements of the genome are synthesized and cloned into a Cas 9 guide RNA plasmid library. This library is then packaged into lentivirus, which is transduced into cells of interest. After selecting for cells with Cas9 and then applying a selective pressure, cells with the desired phenotype are enriched. Sequencing of the guide RNAs in this enriched cell population identifies candidate loci involved in the phenotype. Image adapted from Hsu et al. (2014). enabling dissection of complex phenotypes at the transcriptional level (Adamson et al., 2016; Dixit et al., 2016; Jaitin et al., 2016) including eQTLs (Gasperini et al., 2019). Finally, CRISPR-based screens can be adapted for in vivo large-scale gene interrogation of unique phenotypes, such as metastasis to distal organs, that cannot be captured in vitro (Chen et al., 2015a; Manguso et al., 2017).

Over the past five years, CRISPR-based screens have been applied to a large number of biological questions, including a range of aspects of cancer biology (Chen et al., 2015a; Hart et al., 2015; Shi et al., 2015; Toledo et al., 2015; Han et al., 2017, 2018; Manguso et al., 2017; Patel et al., 2017), mitochondrial disease (Jain et al., 2016), host-pathogen interactions (Marceau et al., 2016; Zhang et al., 2016; Park et al., 2017), the immune system (Parnas et al., 2015), gene essentiality (Wang et al., 2015), cell fate specification (Liu et al., 2018c), mechanisms of DNA repair (Noordermeer et al., 2018), regulatory sequences in enhancers (Canver et al., 2015; Fulco et al., 2016; Sanjana et al., 2016; Liu et al., 2018a), and the role of long non-coding RNAs (Zhu et al., 2016; Joung et al., 2017; Liu et al., 2017c), to name just a few.

To extend the utility of CRISPR-based screens and make them even more robust, a number of groups have also contributed to refining and optimizing screening approaches as well as developing a host of computational tools to aid in the design of largescale CRISPR-mediated screens, including CRISPR inhibition (CRISPRi) and activation (CRISPRa) approaches (Doench et al., 2014, 2016; Hart et al., 2015, 2017; Heigwer et al., 2016; Horlbeck et al., 2016; Meier et al., 2017; Morgens et al., 2017; Sanson et al., 2018). In addition, software has been developed for the analysis of CRISPR-mediated screens (Li et al., 2014; Hart and Moffat, 2016; Winter et al., 2016; Wang et al., 2019). To date, a number of CRISPR knockout screening libraries, some with improved efficacy and others targeting themed gene collections (e.g., kinome or transcription factors) have been developed. Together, these tools have substantially reduced the barrier to forward genetic approaches in mammalian cells, uncovering exciting new biology and revealing new potential therapeutic targets.

\section{Providing new opportunities for plant and agricultural science}

Another area of the life sciences that CRISPR technology has deeply impacted is plant biology. In particular, it has revolutionized plant breeding by dramatically reducing the time to generate new genotypes. In some plant species, homozygous knockout mutants can now be produced in a single generation (Feng et al., 2013; Mao et al., 2013; Brooks et al., 2014; Xu et al., 2014; Zhang et al., 2014). The natural ability of Cas enzymes for multiplex editing is particularly helpful for editing polyploid genomes, such as wheat, where traditional genetic manipulation strategies are difficult as well as altering complex agronomic traits. To date, CRISPR-mediated gene knockout has been applied in a number of agricultural crops, including rice, barley, soy, maize, wheat, tomato, potato, lettuce, citrus trees, mushroom, cucumber, grape, watermelon and others, and there is a substantial effort to engineer these and other plants to achieve a range of traits such as drought resistance, increased yield, pathogen resistance, and 
decreased time to ripening (Schindele et al., 2018). Cas-based approaches have also succeeded in plants that have traditionally been inaccessible to targeted gene changes, such as woody plants (Bewg et al., 2018). Methods are also being developed to achieve transgene-free gene editing in plants that rely on transforming plants with Cas9-guide RNA RNP complexes to avoid introducing foreign DNA (Woo et al., 2015; Liang et al., 2017)

Similar to the extension of Cas enzymes for many purposes in other systems, there is a growing toolbox of CRISPR-based technologies tailored to plant biology. For example, Cas12a has proven to be particularly effective in plants (Zaidi et al., 2017). Base editing approaches have also been applied successfully in a number of plant species including rice, maze, tomato, and wheat (Shimatani et al., 2017; Zong et al., 2017; Kang et al., 2018; Li et al., 2018a; Hua et al., 2019). Cas13a has been used for interference against RNA viruses in tobacco, providing a new strategy for conferring immunity (Aman et al., 2018). Together, this toolbox is advancing basic plant biology studies and holds substantial potential to contribute to global food security without relying on transgenes. To date, numerous crop strains have been generated through CRISPR-mediated genome editing, including tomatoes with higher yield (Soyk et al., 2017), reduced-gluten wheat, virus-resistant cacao, caffeine-free coffee, and mushrooms that were engineered to resist browning, which have received USDA approval (https:// www.nature.com/news/gene-edited-crispr-mushroom-escapes-usregulation-1.19754).

\section{Advancing human health}

The ability to precisely manipulate the genome, and in particular our ability to edit DNA and RNA, offers enormous potential for improving human health by offering a platform that can be tailored to any of thousands of genetic disorders (reviewed in (Cox et al., 2015)). Achieving this potential, however, will require a suite of highly specific and efficient Cas enzymes and a toolbox of delivery modalities that can be seamlessly combined to address the specific challenges of individual diseases. To date, the field has produced a spectacular diversity of editing tools, some of which are now entering clinical trials. There are still outstanding challenges in the development of CRISPR-based therapeutics, however, notably delivery and potential immunogenicity. Below I discuss some of the ways CRISPR-based technologies are advancing human health and highlight areas where additional research is needed.

\section{Applications for elimination of bacterial and viral pathogens}

CRISPR-Cas systems have been applied to improve human health in a range of ways, including the generation of new antibacterial agents. Several groups reported that CRISPR-Cas systems could be packaged in phages and used to selectively treat targeted bacteria, generating programmable, sequence-specific antimicrobial agents (Bikard et al., 2014; Citorik et al., 2014). There have also been multiple studies that leverage the natural function of CRISPR-Cas systems to treat viral infections. For example, it was shown that in a cellular model of HIV, Cas9 could be programmed to target integrated copies of the HIV virome as well as prevent HIV infection (Hu et al., 2014). With many viral infections, the persistence of latent virus in the body represents a major therapeutic challenge. Using a mouse model of Hepatitis $B$ virus (HBV) chronic infection, it was demonstrated that Cas9 targeting the genome of $\mathrm{HBV}$ can reduce viral load (Ramanan et al., 2015). Finally, CRISPR-based technologies are being used to eliminate endogenous retroviruses in pigs to generate animals that may be suitable sources of organs for transplantation into human patients (Yang et al., 2015; Niu et al., 2017).

\section{Applications for detection of bacterial and viral pathogens}

Another way that CRISPR-Cas systems are advancing human health is through the development of CRISPR-based diagnostics. Our discovery of the collateral RNase activity of Cas13 - upon binding to the target RNA, Cas13a becomes activated as a nonspecific RNase and can cleave the target RNA as well as other RNA molecules in the vicinity that do not have complementarity with the guide RNA target sequence - has made possible the development of a new approach for nucleic acid detection (Abudayyeh et al., 2016). With programmable target recognition triggering non-specific collateral cleavage of reporter molecules, these systems can be used to detect target molecules of interest at very low levels (Fig. 7). This technology has a range of applications, notably in the detection and monitoring of infectious diseases in the field, such as Zika and Ebola, and in highly sensitive genotyping, such as the detection of cancer-associated alleles in circulating DNA. Moreover, CRISPR diagnostics can be used in agricultural and industrial settings to ensure food safety and prevent the spread of contaminating agents.

A number of modalities can be integrated with collateralcleavage of reporter RNA to provide diagnostic readout. Using gel electrophoresis for visualization, diagnostic reporting can be achieved by assessing cleavage of a fluorescently tagged reporter RNA by Cas13 upon crRNA-guided recognition of target RNA (Abudayyeh et al., 2016). Using a fluorimeter for readout, detection of target nucleic acid triggers Cas 13 collateral activity and unlocks fluorescent reporters such as the commercially available RNaseAlert by unleashing the fluorophore from its quencher to yield fluorescence. Direct application of Cas13 collateral RNase activity with RNaseAlert achieved detection sensitivity in the picomolar range ( 1000000 molecules per test) (East-Seletsky et al., 2016). By integrating Cas 13 collateral activity with isothermal amplification, we developed a technique called SHERLOCK, which allowed for significantly increased detection sensitivity to the attomolar range (Gootenberg et al., 2017), enabling clinical applications. Finally, using colorimetric paper test strips, Cas13-based diagnostics can be applied in low-resource settings or in the field. To achieve this low-cost modality, we developed a lateral flow paper-based test, similar to a commonly-used pregnancy test strip, by exploiting Cas 13 collateral activity to cleave and unlock two-different affinity molecules so that the presence of the target can be read out as two-stained lines on the paper strip (Gootenberg et al., 2018). Cas13-based diagnostics tests can also be lyophilized and easily reconstituted through the addition of water, which makes it possible for SHERLOCK to be distributed and stored without requiring refrigeration (Gootenberg et al., 2017), which is especially important for application in lowresource settings in the developing world.

CRISPR-based detection technology is rapidly expanding. Recently, Cas12 was found to have natural ssDNA collateral activity that is triggered by binding DNA (Chen et al., 2018; Li et al., $2018 b$ ). Cas 12 can be similarly combined with isothermal amplification in a technique called DETECTOR or integrated into the SHERLOCK platform for multiplex detection (Chen et al., 2018; Gootenberg et al., 2018; Li et al., 2018b). Different types of Cas proteins with collateral activity can be combined to achieve 


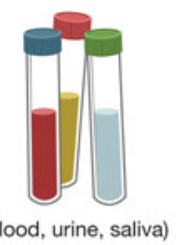

(blood, urine, saliva)

Isolate DNA or RNA
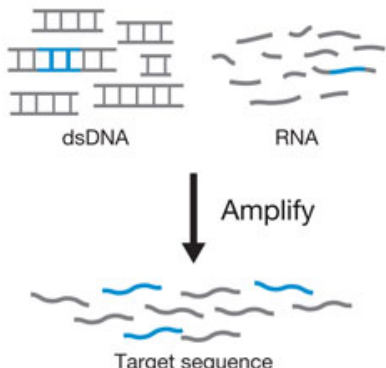

Incubate with

Cas 13 and reporter

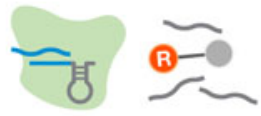

Reporter unlocking via

Cas 13 collateral activity

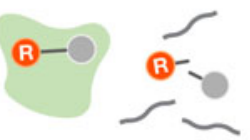

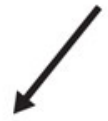

Gel

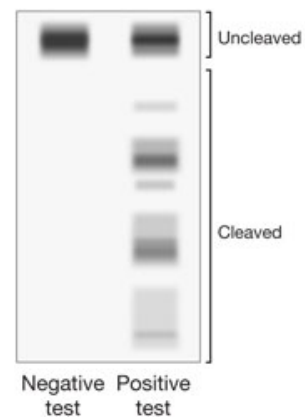

Fluorescence

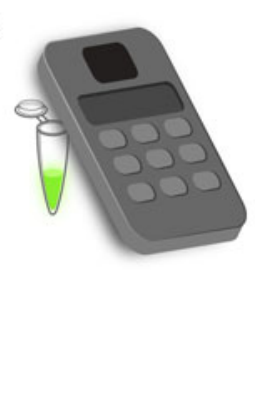

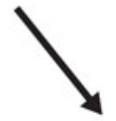

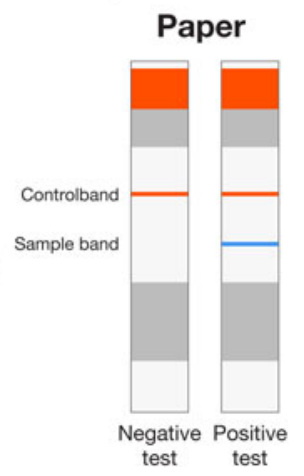

Fig. 7. Disease diagnostics using CRISPR-based detection of nucleic acids. The SHERLOCK (specific high sensitivity enzymatic reporter UnLOCKing) platform combines isothermal amplification with Cas13-mediated collateral cleavage of a reporter molecule to detect either DNA or RNA from blood, urine, or saliva. Depending on the design of the reporter molecule, SHERLOCK can be readout either through gel electrophoresis, fluorescence, or on a lateral flow strip, enabling instrument free-detection.

multiplex detection of multiple pathogens within the same test (Gootenberg et al., 2018). To further increase the multiplexing scale, it has been found that distinct Cas13 family members have unique natural cleavage sequence preferences, enabling multiplex target detection in separate fluorescent color channels
(Gootenberg et al., 2018). Already, CRISPR-based tests are being optimized rapidly for a wide range of diagnostics applications outside the lab (Chen et al., 2018; Myhrvold et al., 2018) and have the potential to deliver affordable, sensitive, and rapid detection tools to the most needed areas of the world. Aside from Cas12 and Cas13, Cas9 has also been used to enrich or deplete specific sequences ( $\mathrm{Gu}$ et al., 2016) or to construct synthetic modules for integration with existing diagnostics methodologies (Pardee et al., 2016). Recently, a CRISPR-CHIP electronic diagnostic platform was developed which uses dCas9 for rapid, sensitive detection of targeted DNA sequences (Hajian et al., 2019).

\section{CRISPR-based therapeutic treatment strategies}

CRISPR-based therapies cover a wide range of different treatment strategies, each with unique considerations. The discussion here is limited to applications in somatic cells in the body, whose DNA will not be passed on during reproduction. Applications in germline cells and embryos, whose DNA will be passed to future generations, have considerable ethical ramifications, and a community of scientists has recently called for a moratorium on germline editing for the purposes of implantation (see below) (Lander et al., 2019). DNA targeting approaches, especially those that directly change the genome of targeted cells, provide the potential for one-time treatments with curative results. RNA targeting approaches, by contrast, do not permanently change the genome, and provide the potential for transient and reversible treatments. Together, DNA and RNA targeting approaches comprise a versatile toolbox for the development of a new generation of therapeutic options for improving human health.

Strategies for applying CRISPR-based technologies to treat diseases can be classified into three categories: First, treatment of monogenic diseases, such as hemophilia, sickle cell disease, and Duchenne muscular dystrophy, by rescuing a known pathogenic mutation. Second, treatment of common diseases by introducing beneficial natural genetic variants that have been identified in the human population and are thought to provide protective effects. Examples of this category include treatment of cardiovascular disease by mimicking the effect of a natural loss-of-function mutation in the gene PCSK9, which has been linked to low levels of cholesterol (Ran et al., 2015), or mimicking the effect of a natural loss-of-function mutation in the gene CCR5, which has been found to confer protection against HIV in those individuals who are naturally CCR5-null (Mandal et al., 2014). Third, treatment of diseases by introducing novel changes to cell types that can be harnessed to achieve a therapeutic benefit, a particularly rich strategy in the immune system. Examples of this category include engineering of immune cells to increase their tumorkilling efficiency by knocking out the immune check-point inhibitor PD1 or by knocking in a chimeric antigen receptor (Eyquem et al., 2017).

For each of these three categories, CRISPR-based technologies can be deployed in several ways, at either the level of DNA or RNA. Gene inactivation, either through disruption of the openreading frame through the generation of indels or through repression at the genetic, epigenetic or transcriptomic level, is the most straightforward application and may be useful particularly in the case of pathogenic gain-of-function mutations. The strategic placement of indels can also effect exon skipping to eliminate mutated segments of a protein. For example, Duchenne's muscular dystrophy, which can be caused by a number of mutations, 
including deletions and frame-shift mutations, can be treated with NHEJ-based exon skipping strategies, leading to restoration of the reading frame and a functional gene product (Long et al., 2016; Nelson et al., 2016; Tabebordbar et al., 2016). In other situations, gene upregulation using dCas-activation platforms can achieve a therapeutic effect. This approach is appealing for X-linked dominant diseases, such as Fragile $\mathrm{X}$, where upregulating the silent wild-type copy of the gene could ameliorate the phenotype; proof-of-concept experiments have shown that a dCas9-Tet fusion can erase methylation at the inactivated FMR1 locus, leading to reactivation (Liu et al., 2018b).

One particularly promising approach to treat a range of pathologies is base editing at either the DNA or RNA level. Because base editing does not introduce DSBs, it offers a safer, less restricted route to correcting pathogenic mutations, the majority of which are single-nucleotide changes that either disrupt regulatory regions or result in truncated or abnormal protein variants. Several proof-of-concept studies have been performed in human cells and in mice demonstrating that base editing can lead to measurable expression levels of the corrected transcript (Rees and Liu, 2018). The ability to edit RNA opens additional possibilities for treatment, including transient alterations to the transcriptome. Such transient RNA editing would allow reversible alteration of protein function, such as editing $\beta$-catenin to temporarily alter cellular signaling pathways to drive cellular regeneration (Bastakoty and Young, 2016).

Although the most technically challenging, HR-mediated approaches to achieve targeted insertion of the desired-DNA sequence have the potential to correct the broadest swath of pathogenic mutations. Currently, this approach is somewhat limited, although techniques for increasing the efficiency of gene insertion either through homologous recombination or independent pathways are continuing to be developed (Maruyama et al., 2015; Paquet et al., 2016; Richardson et al., 2016, 2018; Schmid-Burgk et al., 2016; Suzuki et al., 2016; Kan et al., 2017; Canny et al., 2018). Gene insertion strategies may be most usefully deployed in disorders where a small increase in the corrected genotype is likely to have an outsized phenotypic impact, as may be the case when edited cells have a selection or fitness advantage over non-edited cells.

Any of the above CRISPR-based therapeutic strategies can be achieved either ex vivo or in vivo (Fig. 8). Ex vivo approaches offer substantial advantages in terms of safety and efficiency of editing but are limited to certain cell types that can be manipulated in the lab and subsequently engrafted, such as $\mathrm{T}$ cells (Roth et al., 2018), hematopoietic stem cells (Dever et al., 2016), and intestinal stem cell-derived organoids (Schwank et al., 2013). By contrast, in vivo approaches may be applicable to a wider range of tissues, but the potential for off-targets, particularly if editing at the DNA level, is a safety concern. Currently, in vivo delivery modes for gene therapies typically rely on AAV vectors, which have been approved by the U.S. Food and Drug Administration (FDA). Although promising, AAV vectors have relatively limited cargo capacity, making it challenging to deliver SpCas9 and guide RNA effectively. Other Cas9 orthologs (SaCas9, CjCas9, and NmeCas9) are smaller than SpCas9, making them better suited for AAV delivery (Ran et al., 2015; Kim et al., 2017a; Ibraheim et al., 2018). Recently, high levels of AAV integration into the genome have been reported, which may have long-term safety implications (Nelson et al., 2019). Another challenge with AAV or any other type of in vivo delivery modality, such as lipid nanoparticles (Finn et al., 2018), is achieving cell- type specificity to ensure that only the pathological tissues are targeted. In vivo applications must also take into account potential immunogenicity of the therapy, which may be particularly relevant for SpCas9 and SaCas9, as they are derived from pathogenic bacteria (Charlesworth et al., 2019).

\section{CRISPR in the clinic}

Clinical trials to treat patients with CRISPR-based therapies are now underway to treat a handful of diseases. Currently, there are two sets of clinical trials entering phase 1 testing. The first set of trials are $e x$ vivo, using SpCas9 to treat $\beta$-thalassemia and sickle cell disease (Vertex, 2018a, 2018b). The second trial is in vivo, using SaCas9 and delivery by AAV into the retina to treat Type 10 Leber congenital amaurosis (LCA10) (Allergan, 2019), which causes blindness. Pre-clinical studies have recently been published reporting the use of SaCas9 to correct a splice-site mutation causing LCA10, showing that in human retinal explants, humanized mice, and non-human primates, editing rates exceed the threshold of $10 \%$ thought to be clinically relevant for disease amelioration (Maeder et al., 2019). A number of additional studies are developing Cas9, Cas12, and Cas13-based strategies to treat a wide array of diseases including genetic disorders and cancer, providing new hope for patients currently lacking treatment options.

\section{Ethical considerations}

In November 2018, it emerged that a scientist had reportedly used Cas9 to edit human embryos, creating at least two-genetically modified babies. This shocking news highlighted the far-reaching ethical challenges that CRISPR-based technologies present for society. Although a number of stakeholders, including ethicists, scientists, clinicians, and policy makers, have voiced concerns over the use of CRISPR-based technologies in germline genome editing (Baltimore et al., 2015), the exact nature of whether clinical uses of germline editing should be permitted remains a contentious topic. To advance discussions around this topic, a group of specialists, myself included, from seven countries called for a 5 -year moratorium for the use of clinical germline editing, arguing that given a combination of scientific, technical, medical, and moral considerations, society as a whole needs to wait and establish consensus before proceeding with any form of clinical germline editing (Lander et al., 2019).

Indeed, this is an enormously complicated issue. Clinical germline editing applications can be divided into two types: genetic correction and genetic enhancement, as described above. With increasing knowledge about human genetic variation at the population level, it is reasonable to expect that the outcome of converting a rare disease-causing variant to a common variant that does not lead to disease will be predictable and beneficial. By contrast, genetic enhancement relies on information about rare variants in the human population, such as APOE-4 or CCR5 null, which are much less well understood. For example, although loss of CCR5 appears to prevent HIV infection, it increases susceptibility to West Nile virus, and the selective pressures on this allele are not well understood (Telenti, 2009). Introducing such changes to the genome will likely have unpredictable consequences. Even in the future, when significant advances in our understanding of biology and human genetic variation become sufficient to predict the outcome of genome editing for enhancement, whether society as a whole should adopt germline editing still needs to be vigorously debated. The moral quandaries are 
(a)

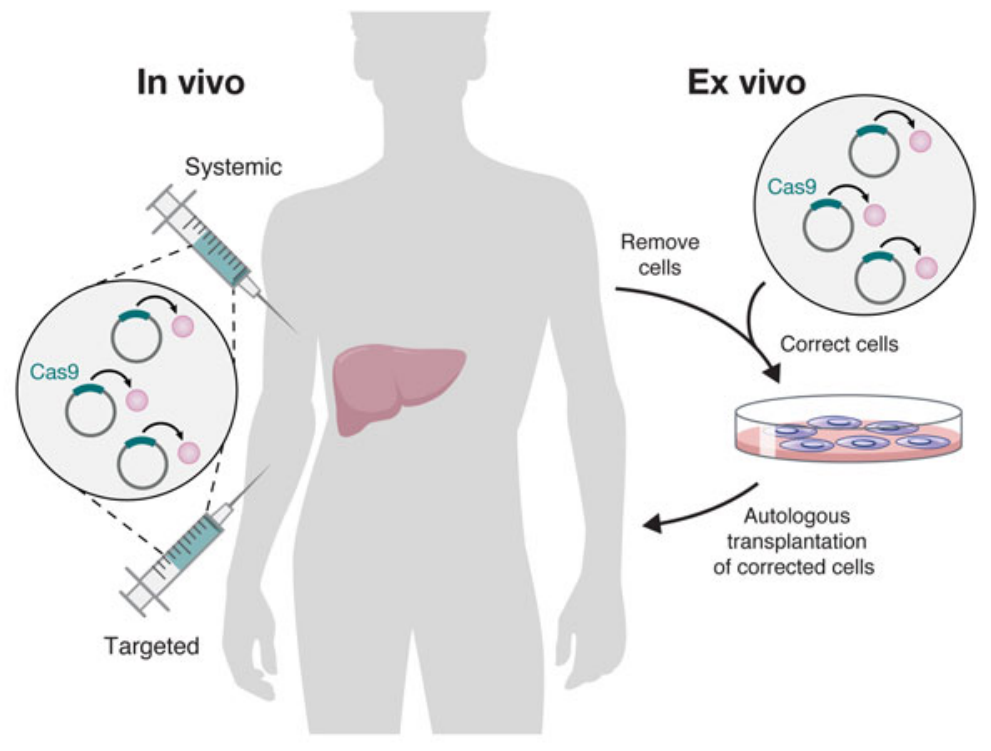

(b)
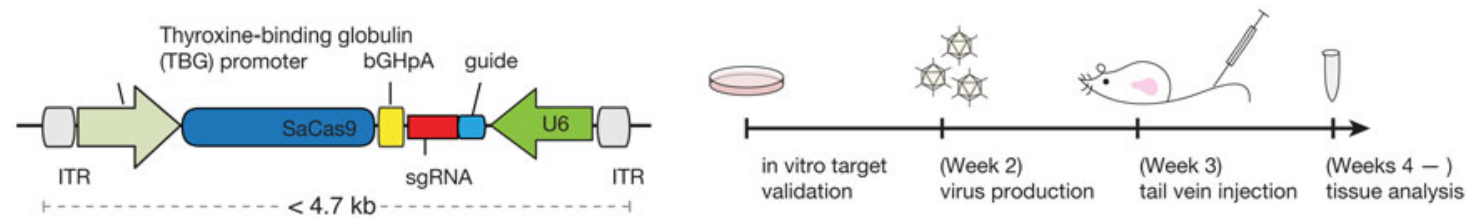

(c)
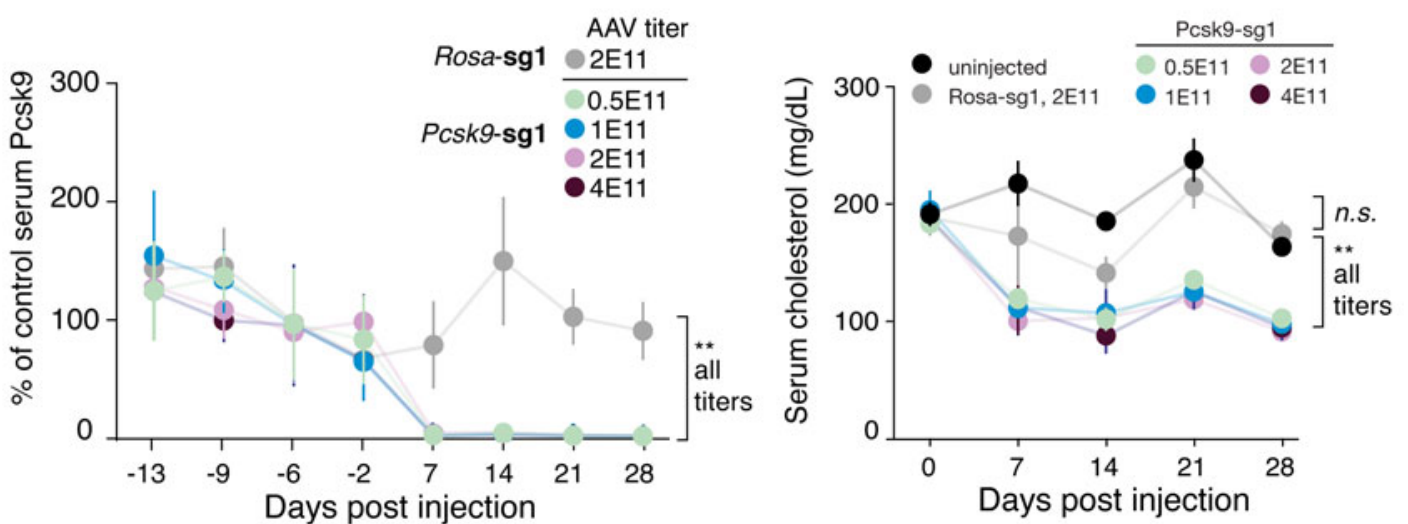

Fig. 8. CRISPR-based therapies can be used in multiple ways to treat genetic diseases. (a) CRISPR-based therapeutics can be administered either in vivo through targeted or systemic delivery or ex vivo in cells that have been removed from the body, manipulated in the lab, and then transplanted back into the patient. Image modified based on Cox et al.(2015). (b) For in vivo use of CRISPR therapeutics, a major challenge is efficient delivery. The most promising delivery vehicle for gene therapy is the AAV vector, but SpCas9 is too large to be packaged into AAV along with a guide RNA and regulatory sequences. We identified a smaller ortholog of Cas9, SaCas9, which we developed for in vivo use via AAV delivery. Shown on the left is a schematic of the AAV containing thyroxine-binding globulin promoter driving SaCas9 and the guide RNA driven by the U6 promoter, separated by the bGHpA terminator and flanked by inverted terminal repeat, which are required for packaging. Guides were used to target either Pcsk9 or the Rosa26 locus as a control. Shown on the right is the experimental timeline. Images adapted from Ran et al. (2015). (c) One week after injecting mice with AAV carrying SaCas9 and a guide targeting Pcsk9, we observed complete loss of Psck9 (left) and a concomitant reduction in serum cholesterol levels (right). SaCas9 is now being developed as the first in vivo genome editing medicine for humans. Images adapted from Ran et al. (2015).

numerous. For example, allowing genetic enhancement may further exacerbate social inequality and reduce the rich and treasured diversity of the human population.

Ethical considerations surrounding CRISPR-based technologies extend to other arenas as well. For example, Cas9-based tools have also accelerated the development of gene drives, elements in the genome that bias inheritance in their favor, resulting in non-Mendelian transmission and their rapid spread throughout a population. Gene drives could potentially be used to control the spread of certain diseases, such as malaria and Lyme disease, which are carried by insect vectors, or combat invasive species (Gantz et al., 2015; Hammond et al., 2015). Although gene drives have not yet been applied in the real world, and scientists are working on improved version of gene drives with better control and containment strategies (Akbari et al., 2015), the potentially significant and irreversible environmental and 
ecological consequences of gene drives also demand careful consideration (Lunshof, 2015; Courtier-Orgogozo et al., 2017).

\section{Looking ahead}

The accumulation of genomic sequences, which initially powered the discovery of CRISPR systems, has continued apace (Fig. 9). The availability of microbial sequences, driven in large part through developments in metagenomics, is particularly compelling. Until quite recently, our sampling of microbial genomics was severely taxonomically limited compared to the predicted diversity of organisms. Even today, roughly $50 \%$ of the $\sim 200$ 000 available bacterial genomes encompass just 20 species, leaving out a vast swath of diversity. Concerted efforts, such as the Earth Microbiome Project (earthmicrobiome.org), are underway to systematically sample genomes across microbial taxa to gain a more comprehensive understanding of prokaryotic natural diversity.

It is clear that we have only begun to scratch the surface of the full microbial diversity. For example, the discovery of singleeffector RNA targeting systems highlights the diversity within CRISPR-Cas systems, which themselves are only a sliver of the microbial defense systems that exist in nature. The continued search for CRISPR effectors as well as the large diversity of auxiliary proteins associated with CRISPR loci remain a rich source for exploration and development. Further revealing the sophistication of the arsenal used in microbial warfare, numerous anti-Cas9 and anti-Cas12 proteins (Pawluk et al., 2016; Rauch et al., 2017; Marino et al., 2018; Watters et al., 2018) as well as novel bacterial anti-phage defense systems (Doron et al., 2018) have recently been discovered. These findings prefigure yet-to-be-discovered adaptive immune systems hidden within the immense diversity of the microbial world. Hints that this may be the case lie in the diversity of immune systems in animals - while most vertebrates have an antibody-based adaptive immune system, immunity in even the jawless vertebrates is based on different distinct antibody-like proteins called variable lymphocyte receptors (VLRs) (Han et al., 2008). The existence of VLRs within a narrow branch of the animal kingdom suggests that perhaps within similarly narrow phyla of the microbial diversity there may be unique adaptive immune systems that operate through distinct mechanisms. Perhaps some bacteria have evolved protein-based adaptive immune systems that employ powerful diversification mechanisms to generate diverse proteins that provide critical survival functions for those microbes in their native environments. The technological potential of novel adaptive immune systems is also tantalizing - by virtue of being adaptive, these systems are naturally reprogrammable for the recognition of diverse substrates. Harnessing such reprogrammable systems could likely provide many new biotechnological platforms for the recognition of proteins, metabolites, or patterns of glycosylation.

Fully understanding and harnessing this natural diversity will require solving a number of open challenges, both computational and experimental. For example, further understanding of the molecular diversity of microbial species will require comprehensive genome sequencing and repeated sampling of diverse environments to capture the population dynamics in microbial communities. How do we deconvolute and assemble metagenomic data to obtain more refined genetic sequence and information about these organisms? How do we more accurately predict the function of novel protein sequences? Could protein structure help predict protein function? Perhaps advances in artificial intelligence may be applied to better infer the function of microbial proteins. Indeed, one of the key assumptions often used for the

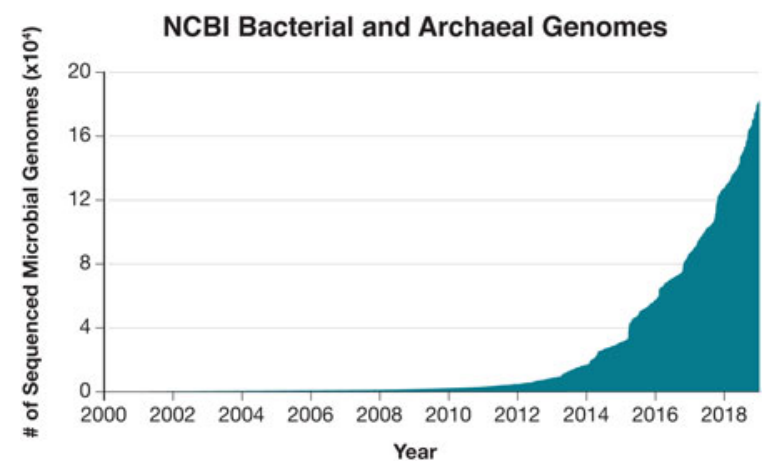

Fig. 9. The rapidly expanding database of microbial sequences holds many hidden treasures. Exploration of the natural bacterial and archaeal diversity will undoubtedly reveal new molecular systems that can provide the substrate for the development of new technologies. Data obtained from NCBI.

study of bacterial protein sequences is the idea of 'guilt by association', where genes located within the same neighborhood or operon are likely related to each other. This functional organization by neighborhood may perhaps suggest that there is a certain syntax or grammar to the organization of bacterial genomes, and approaches developed for natural language processing and deep learning may be borrowed to make advances here.

There are also experimental challenges that need to be further resolved. How can we study microbes at scale without cultivating them? How do we cultivate those microbes that we cannot currently culture so that we can study them comprehensively? How do we further accelerate some of the basic molecular biology techniques, like gene assembly, protein purification and structure determination? Solutions to some of these problems may arise through the work itself, much as CRISPR-based technologies are now being used to manipulate microbial genomes in the lab, while some may come through the intersection of molecular biology with other research fields, notably nanoscience and miniaturization and parallelization.

Indeed, it often seems that some of the biggest leaps forward in science are arrived at tangentially, and this should encourage all of us to probe the literature of unrelated fields for information that may be applicable in new situations and dare to move our own research programs not just forward, but also sideways. In February 2011, through a serendipitous encounter, I learned about CRISPR, and my imagination was captured by this fascinating and elegant mechanism of microbial adaptive immunity. This path has taken me from the development of CRISPR-Cas9 for genome editing to the exploration of the expansive world of CRISPR-Cas systems and microbial diversity. It has been particularly exciting to witness how this technology has flourished through the contributions of so many talented scientists who share the same spirit of openness and generosity.

This is a time of plenty for curious biologists - we have only glimpsed a tiny sliver of the diversity of life at the molecular level, and every few months, new genetic 'wonders' are reported: plankton with shattered chromosomes (Blanc-Mathieu et al., 2017), lamprey genome rearrangements (Smith et al., 2018), phage-encoded diversity generating retroelements (Doulatov et al., 2004; Benler et al., 2018), and marine microorganisms that use novel DNA repair systems (Deng et al., 2018). Each natural system tempts us to explore new paths, determining the mechanism and function behind these systems, and opening new opportunities to tinker, ultimately leading to a healthier and more sustainable future. 
Acknowledgements. I would like to thank my mentors, former and current lab members, collaborators, and colleagues in the CRISPR field for helpful discussions and inspiration. I would also like to thank the National Institutes of Health, National Science Foundation, Howard Hughes Medical Institute New York Stem Cell Foundation, McKnight Foundation, Gates Foundation, Keck Foundation, Klingenstein Foundation, Searles Scholars Program, Damon Runyan Cancer Research Foundation, Vallee Foundation, Mathers Foundation, Paul G. Allen Family Foundation, Simons Foundation, the Poitras Center for Affective Disorders, Merkin Foundation, Harvard Neurodiscovery Center, Jim and Patricia Poitras, Lisa Yang and Hock Tan, Bob Metcalfe, Tom Harriman, Jane Pauley, and David Cheng for their past and current research funding. I am an inventor on a number of issued patents and patent applications relating to CRISPR-based technologies. I am a co-founder and scientific advisor of Editas Medicine, Pairwise Plants, Sherlock Biosciences, Arbor Biotechnologies, and Beam Therapeutics.

\section{References}

Abudayyeh OO, Gootenberg JS, Konermann S, Joung J, Slaymaker IM, Cox DBT, Shmakov S, Makarova KS, Semenova E, Minakhin L, Severinov K, Regev A, Lander ES, Koonin EV and Zhang F (2016) $\mathrm{C} 2 \mathrm{c} 2$ is a single-component programmable RNA-guided RNA-targeting CRISPR effector. Science 353, aaf5573.

Abudayyeh OO, Gootenberg JS, Essletzbichler P, Han S, Joung J, Belanto JJ, Verdine V, Cox DBT, Kellner MJ, Regev A, Lander ES, Voytas DF, Ting AY and Zhang F (2017) RNA targeting with CRISPRCas13. Nature 550, 280-284.

Adamson B, Norman TM, Jost M, Cho MY, Nuñez JK, Chen Y, Villalta JE, Gilbert LA, Horlbeck MA, Hein MY, Pak RA, Gray AN, Gross CA, Dixit A, Parnas O, Regev A and Weissman JS (2016) A multiplexed single-cell CRISPR screening platform enables systematic dissection of the unfolded protein response. Cell 167, 1867-1882.

Adikusuma F, Piltz S, Corbett MA, Turvey M, Mccoll SR, Helbig KJ, Beard MR, Hughes J, Pomerantz RT and Thomas PQ (2018) Large deletions induced by Cas9 cleavage. Nature 560, E8-E9.

Aguirre AJ, Meyers RM, Weir BA, Vazquez F, Zhang CZ, Ben-David U, Cook A, Ha G, Harrington WF, Doshi MB, Kost-Alimova M, Gill S, Xu H, Ali LD, Jiang G, Pantel S, Lee Y, Goodale A, Cherniack AD, Oh C, Kryukov G, Cowley GS, Garraway LA, Stegmaier K, Roberts CW, Golub TR, Meyerson M, Root DE, Tsherniak A and Hahn WC (2016) Genomic copy number dictates a gene-independent cell response to CRISPR/Cas9 targeting. Cancer Discovery 6, 914-929.

Akbari OS, Bellen HJ, Bier E, Bullock SL, Burt A, Church GM, Cook KR, Duchek P, Edwards OR, Esvelt KM, Gantz VM, Golic KG, Gratz SJ, Harrison MM, Hayes KR, James AA, Kaufman TC, Knoblich J, Malik HS, Matthews KA, O'connor-Giles KM, Parks AL, Perrimon N, Port F, Russell S, Ueda R and Wildonger J (2015) BIOSAFETY. Safeguarding gene drive experiments in the laboratory. Science 349, 927-929.

Akcakaya P, Bobbin ML, Guo JA, Malagon-Lopez J, Clement K, Garcia SP, Fellows MD, Porritt MJ, Firth MA, Carreras A, Baccega T, Seeliger F, Bjursell M, Tsai SQ, Nguyen NT, Nitsch R, Mayr LM, Pinello L, Bohlooly YM, Aryee MJ, Maresca M and Joung JK (2018) In vivo CRISPR editing with no detectable genome-wide off-target mutations. Nature 561, 416-419.

ALLERGAN (2019) Single Ascending Dose Study in Participants With LCA10. ClinicalTrial.gov Identifier: NCT03872479 (clinicaltrials.gov/ct2/ show/NCT03872479).

Aman R, Ali Z, Butt H, Mahas A, Aljedaani F, Khan MZ, Ding S and Mahfouz M (2018) RNA virus interference via CRISPR/Cas13a system in plants. Genome Biology 19, 1.

Anders C, Niewoehner O, Duerst A and Jinek M (2014) Structural basis of PAM-dependent target DNA recognition by the Cas9 endonuclease. Nature 513, 569-573.

Bae S, Park J and Kim JS (2014) Cas-OFFinder: a fast and versatile algorithm that searches for potential off-target sites of Cas9 RNA-guided endonucleases. Bioinformatics 30, 1473-1475.

Baltimore D, Berg P, Botchan M, Carroll D, Charo RA, Church G, Corn JE, Daley GQ, Doudna JA, Fenner M, Greely HT, Jinek M, Martin GS,
Penhoet E, Puck J, Sternberg SH, Weissman JS and Yamamoto KR (2015) Biotechnology. A prudent path forward for genomic engineering and germline gene modification. Science 348, 36-38.

Barrangou R and Horvath P (2017) A decade of discovery: CRISPR functions and applications. Nature Microbiology 2, 17092.

Barrangou R, Fremaux C, Deveau H, Richards M, Boyaval P, Moineau S, Romero DA and Horvath P (2007) CRISPR provides acquired resistance against viruses in prokaryotes. Science 315, 1709-1712.

Bastakoty D and Young PP (2016) Wnt/beta-catenin pathway in tissue injury: roles in pathology and therapeutic opportunities for regeneration. FASEB Journal 30, 3271-3284.

Benler S, Cobian-Guemes AG, Mcnair K, Hung SH, Levi K, Edwards R and Rohwer F (2018) A diversity-generating retroelement encoded by a globally ubiquitous Bacteroides phage. Microbiome 6, 191.

Bewg WP, Ci D and Tsai CJ (2018) Genome editing in trees: from multiple repair pathways to long-term stability. Frontiers in Plant Science 9, 1732.

Bikard D, Jiang W, Samai P, Hochschild A, Zhang F and Marraffini LA (2013) Programmable repression and activation of bacterial gene expression using an engineered CRISPR-Cas system. Nucleic Acids Research 41, 74297437.

Bikard D, Euler CW, Jiang W, Nussenzweig PM, Goldberg GW, Duportet X, Fischetti VA and Marraffini LA (2014) Exploiting CRISPR-Cas nucleases to produce sequence-specific antimicrobials. Nature Biotechnology 32, 1146-1150.

Birling MC, Herault Y and Pavlovic G (2017) Modeling human disease in rodents by CRISPR/Cas9 genome editing. Mamm Genome 28, 291-301.

Blanc-Mathieu R, Krasovec M, Hebrard M, Yau S, Desgranges E, Martin J, Schackwitz W, Kuo A, Salin G, Donnadieu C, Desdevises Y, Sanchez-Ferandin S, Moreau H, Rivals E, Grigoriev IV, Grimsley N, Eyre-Walker A and Piganeau G (2017) Population genomics of picophytoplankton unveils novel chromosome hypervariability. Science Advances 3, e1700239.

Boch J, Scholze H, Schornack S, Landgraf A, Hahn S, Kay S, Lahaye T, Nickstadt A and Bonas U (2009) Breaking the code of DNA binding specificity of TAL-type III effectors. Science 326, 1509-1512.

Bolotin A, Quinquis B, Sorokin A and Ehrlich SD (2005) Clustered regularly interspaced short palindrome repeats (CRISPRs) have spacers of extrachromosomal origin. Microbiology (Reading England) 151(Pt 8), 2551-2561.

Boyden ES, Zhang F, Bamberg E, Nagel G and Deisseroth K (2005) Millisecond-timescale, genetically targeted optical control of neural activity. Nature Neuroscience 8, 1263-1268.

Brooks C, Nekrasov V, Lippman ZB and Van Eck J (2014) Efficient gene editing in tomato in the first generation using the clustered regularly interspaced short palindromic repeats/CRISPR-associated9 system. Plant Physiology 166, 1292-1297.

Brouns SJ, Jore MM, Lundgren M, Westra ER, Slijkhuis RJ, Snijders AP, Dickman MJ, Makarova KS, Koonin EV and Van Der Oost J (2008) Small CRISPR RNAs guide antiviral defense in prokaryotes. Science 321, 960-964.

Burstein D, Harrington LB, Strutt SC, Probst AJ, Anantharaman K, Thomas BC, Doudna JA and Banfield JF (2017) New CRISPR-Cas systems from uncultivated microbes. Nature 542, 237-241.

Cameron P, Fuller CK, Donohoue PD, Jones BN, Thompson MS, Carter MM, Gradia S, Vidal B, Garner E, Slorach EM, Lau E, Banh LM, Lied AM, Edwards LS, Settle AH, Capurso D, Llaca V, Deschamps S, Cigan M, Young JK and May AP (2017) Mapping the genomic landscape of CRISPR-Cas9 cleavage. Nature Methods 14, 600-606.

Canny MD, Moatti N, Wan LCK, Fradet-Turcotte A, Krasner D, MateosGomez PA, Zimmermann M, Orthwein A, Juang YC, Zhang W, Noordermeer SM, Seclen E, Wilson MD, Vorobyov A, Munro M, Ernst A, Ng TF, Cho T, Cannon PM, Sidhu SS, Sicheri F and Durocher D (2018) Inhibition of 53BP1 favors homology-dependent DNA repair and increases CRISPR-Cas9 genome-editing efficiency. Nature Biotechnology 36, 95-102.

Canver MC, Smith EC, Sher F, Pinello L, Sanjana NE, Shalem O, Chen DD, Schupp PG, Vinjamur DS, Garcia SP, Luc S, Kurita R, Nakamura Y, Fujiwara Y, Maeda T, Yuan G-C, Zhang F, Orkin SH and Bauer DE 
(2015) BCL11A enhancer dissection by Cas9-mediated in situ saturating mutagenesis. Nature 527, 192-197.

Carroll D (2012) A CRISPR approach to gene targeting. Molecular Therapy 20, 1658-1660.

Casini A, Olivieri M, Petris G, Montagna C, Reginato G, Maule G, Lorenzin F, Prandi D, Romanel A, Demichelis F, Inga A and Cereseto A (2018) A highly specific SpCas9 variant is identified by in vivo screening in yeast. Nature Biotechnology 36, 265-271.

Charlesworth CT, Deshpande PS, Dever DP, Camarena J, Lemgart VT, Cromer MK, Vakulskas CA, Collingwood MA, Zhang L, Bode NM, Behlke MA, Dejene B, Cieniewicz B, Romano R, Lesch BJ, GomezOspina N, Mantri S, Pavel-Dinu M, Weinberg KI and Porteus MH (2019) Identification of preexisting adaptive immunity to Cas9 proteins in humans. Nature Medicine 25, 249-254.

Chatterjee P, Jakimo N and Jacobson JM (2018) Minimal PAM specificity of a highly similar SpCas9 ortholog. Science Advances 4, eaau0766.

Chen B, Gilbert LA, Cimini BA, Schnitzbauer J, Zhang W, Li GW, Park J, Blackburn EH, Weissman JS, Qi LS and Huang B (2013) Dynamic imaging of genomic loci in living human cells by an optimized CRISPR/Cas system. Cell 155, 1479-1491.

Chen S, Sanjana NE, Zheng K, Shalem O, Lee K, Shi X, Scott DA, Song J, Pan JQ, Weissleder R, Lee H, Zhang F and Sharp PA (2015a) Genome-wide CRISPR screen in a mouse model of tumor growth and metastasis. Cell 160, 1246-1260.

Chen Y, Zheng Y, Kang Y, Yang W, Niu Y, Guo X, Tu Z, Si C, Wang H, Xing R, Pu X, Yang SH, Li S, Ji W and Li XJ (2015b) Functional disruption of the dystrophin gene in rhesus monkey using CRISPR/Cas9. Human Molecular Genetics 24, 3764-3774.

Chen B, Hu J, Almeida R, Liu H, Balakrishnan S, Covill-Cooke C, Lim WA and Huang B (2016) Expanding the CRISPR imaging toolset with Staphylococcus aureus Cas9 for simultaneous imaging of multiple genomic loci. Nucleic Acids Research 44, e75-e75.

Chen JS, Dagdas YS, Kleinstiver BP, Welch MM, Sousa AA, Harrington LB, Sternberg SH, Joung JK, Yildiz A and Doudna JA (2017) Enhanced proofreading governs CRISPR-Cas9 targeting accuracy. Nature 550, 407-410.

Chen JS, Ma E, Harrington LB, Da Costa M, Tian X, Palefsky JM and Doudna JA (2018) CRISPR-Cas12a target binding unleashes indiscriminate single-stranded DNase activity. Science 360, 436-439.

Cho SW, Kim S, Kim JM and Kim JS (2013) Targeted genome engineering in human cells with the Cas9 RNA-guided endonuclease. Nature Biotechnology 31, 230-232.

Cho SW, Kim S, Kim Y, Kweon J, Kim HS, Bae S and Kim JS (2014) Analysis of off-target effects of CRISPR/Cas-derived RNA-guided endonucleases and nickases. Genome Research 24, 132-141.

Chylinski K, Makarova KS, Charpentier E and Koonin EV (2014) Classification and evolution of type II CRISPR-Cas systems. Nucleic Acids Research 42, 6091-6105.

Citorik RJ, Mimee M and Lu TK (2014) Sequence-specific antimicrobials using efficiently delivered RNA-guided nucleases. Nature Biotechnology 32, 1141-1145.

Concordet JP and Haeussler M (2018) CRISPOR: intuitive guide selection for CRISPR/Cas9 genome editing experiments and screens. Nucleic Acids Research 46, W242-W245.

Cong L, Ran FA, Cox D, Lin SL, Barretto R, Habib N, Hsu PD, Wu XB, Jiang WY, Marraffini LA and Zhang F (2013) Multiplex genome engineering using CRISPR/Cas systems. Science 339, 819-823.

Courtier-Orgogozo V, Morizot B and Boete C (2017) Agricultural pest control with CRISPR-based gene drive: time for public debate: should we use gene drive for pest control? EMBO Reports 18, 878-880.

Cox DB, Platt RJ and Zhang F (2015) Therapeutic genome editing: prospects and challenges. Nature Medicine 21, 121-131.

Cox DBT, Gootenberg JS, Abudayyeh OO, Franklin B, Kellner MJ, Joung J and Zhang $\mathbf{F}$ (2017) RNA editing with CRISPR-Cas13. Science 550, eaaq0180.

Cromwell CR, Sung K, Park J, Krysler AR, Jovel J, Kim SK and Hubbard BP (2018) Incorporation of bridged nucleic acids into CRISPR RNAs improves Cas9 endonuclease specificity. Nature Communications 9, 1448.
Crosetto N, Mitra A, Silva MJ, Bienko M, Dojer N, Wang Q, Karaca E, Chiarle R, Skrzypczak M, Ginalski K, Pasero P, Rowicka $M$ and Dikic I (2013) Nucleotide-resolution DNA double-strand break mapping by next-generation sequencing. Nature Methods 10, 361-366.

Dahlman JE, Abudayyeh OO, Joung J, Gootenberg JS, Zhang F and Konermann S (2015) Orthogonal gene knockout and activation with a catalytically active Cas9 nuclease. Nature Biotechnology 33, 1159-1161.

Davis KM, Pattanayak V, Thompson DB, Zuris JA and Liu DR (2015) Small molecule-triggered Cas 9 protein with improved genome-editing specificity. Nature Chemical Biology 11, 316-318.

Deltcheva E, Chylinski K, Sharma CM, Gonzales K, Chao Y, Pirzada ZA, Eckert MR, Vogel J and Charpentier E (2011) CRISPR RNA maturation by trans-encoded small RNA and host factor RNase III. Nature 471, 602-607.

Deng W, Henriet S and Chourrout D (2018) Prevalence of mutation-prone microhomology-mediated end joining in a chordate lacking the c-NHEJ DNA repair pathway. Current Biology 28, 3337-3341 e3334.

Deveau H, Barrangou R, Garneau JE, Labonte J, Fremaux C, Boyaval P, Romero DA, Horvath $\mathbf{P}$ and Moineau S (2008) Phage response to CRISPR-encoded resistance in Streptococcus thermophilus. Journal of Bacteriology 190, 1390-1400.

Dever DP, Bak RO, Reinisch A, Camarena J, Washington G, Nicolas CE, Pavel-Dinu M, Saxena N, Wilkens AB, Mantri S, Uchida N, Hendel A, Narla A, Majeti R, Weinberg KI and Porteus MH (2016) CRISPR/cas9 beta-globin gene targeting in human haematopoietic stem cells. Nature 539, 384-389.

Dicarlo JE, Norville JE, Mali P, Rios X, Aach J and Church GM (2013) Genome engineering in Saccharomyces cerevisiae using CRISPR-Cas systems. Nucleic Acids Research 41, gkt135-gk4343.

Dixit A, Parnas O, Li B, Chen J, Fulco CP, Jerby-Arnon L, Marjanovic ND, Dionne D, Burks T, Raychowdhury R, Adamson B, Norman TM, Lander ES, Weissman JS, Friedman N and Regev A (2016) Perturb-Seq: dissecting molecular circuits with scalable single-cell RNA profiling of pooled genetic screens. Cell 167, 1853-1866.

Doench JG (2017) Am I ready for CRISPR? A user's guide to genetic screens. Nature Publishing Group 19, 67-80.

Doench JG, Hartenian E, Graham DB, Tothova Z, Hegde M, Smith I, Sullender M, Ebert BL, Xavier RJ and Root DE (2014) Rational design of highly active sgRNAs for CRISPR-Cas9-mediated gene inactivation. Nature Biotechnology 32, 1262-1267.

Doench JG, Fusi N, Sullender M, Hegde M, Vaimberg EW, Donovan KF, Smith I, Tothova Z, Wilen C, Orchard R, Virgin HW, Listgarten J and Root DE (2016) Optimized sgRNA design to maximize activity and minimize off-target effects of CRISPR-Cas9. Nature Biotechnology $\mathbf{3 4}$ 184-191.

Doetschman T, Gregg RG, Maeda N, Hooper ML, Melton DW, Thompson S and Smithies O (1987) Targetted correction of a mutant HPRT gene in mouse embryonic stem cells. Nature 330, 576-578.

Dong D, Ren K, Qiu X, Zheng J, Guo M, Guan X, Liu H, Li N, Zhang B, Yang D, Ma C, Wang S, Wu D, Ma Y, Fan S, Wang J, Gao N and Huang Z (2016) The crystal structure of Cpf1 in complex with CRISPR RNA. Nature 532, 522-526.

Donovan KF, Hegde M, Sullender M, Vaimberg EW, Johannessen CM, Root DE and Doench JG (2017) Creation of novel protein variants with CRISPR/Cas9-mediated mutagenesis: turning a screening by-product into a discovery tool. PLoS One 12, e0170445.

Doron S, Melamed S, Ofir G, Leavitt A, Lopatina A, Keren M, Amitai G and Sorek R (2018) Systematic discovery of antiphage defense systems in the microbial pangenome. Science 359, eaar4120.

Doudna JA and Charpentier E (2014) Genome editing. The new frontier of genome engineering with CRISPR-Cas9. Science 346, 1258096.

Doulatov S, Hodes A, Dai L, Mandhana N, Liu M, Deora R, Simons RW, Zimmerly S and Miller JF (2004) Tropism switching in Bordetella bacteriophage defines a family of diversity-generating retroelements. Nature 431, 476-481.

Dow LE, Fisher J, O'rourke KP, Muley A, Kastenhuber ER, Livshits G, Tschaharganeh DF, Socci ND and Lowe SW (2015) Inducible in vivo genome editing with CRISPR-Cas9. Nature Biotechnology 33, 390-394. 
Duan J, Lu G, Hong Y, Hu Q, Mai X, Guo J, Si X, Wang F and Zhang Y (2018) Live imaging and tracking of genome regions in CRISPR/dCas9 knock-in mice. Genome Biology 19, 192.

East-Seletsky A, O'connell MR, Knight SC, Burstein D, Cate JHD, Tjian R and Doudna JA (2016) Two distinct RNase activities of CRISPR-C2c2 enable guide-RNA processing and RNA detection. Nature 538, 270-273.

Egli D, Zuccaro MV, Kosicki M, Church GM, Bradley A and Jasin M (2018) Inter-homologue repair in fertilized human eggs? Nature 560, E5-E7.

Esvelt KM, Mali P, Braff JL, Moosburner M, Yaung SJ and Church GM (2013) Orthogonal Cas9 proteins for RNA-guided gene regulation and editing. Nature 10, 1116-1121.

Eyquem J, Mansilla-Soto J, Giavridis T, Van Der Stegen SJ, Hamieh M, Cunanan KM, Odak A, Gonen M and Sadelain M (2017) Targeting a CAR to the TRAC locus with CRISPR/Cas9 enhances tumour rejection. Nature 543, 113-117.

Fellmann C, Gowen BG, Lin PC, Doudna JA and Corn JE (2017) Cornerstones of CRISPR-Cas in drug discovery and therapy. Nature Reviews Drug Discovery 16, 89-100.

Feng Z, Zhang B, Ding W, Liu X, Yang DL, Wei P, Cao F, Zhu S, Zhang F, Mao Y and Zhu JK (2013) Efficient genome editing in plants using a CRISPR/Cas system. Cell Research 23, 1229-1232.

Finn JD, Smith AR, Patel MC, Shaw L, Youniss MR, Van Heteren J, Dirstine T, Ciullo C, Lescarbeau R, Seitzer J, Shah RR, Shah A, Ling D, Growe J, Pink M, Rohde E, Wood KM, Salomon WE, Harrington WF, Dombrowski C, Strapps WR, Chang Y and Morrissey DV (2018) A single administration of CRISPR/Cas9 lipid nanoparticles achieves robust and persistentiln vivo genome editing. Cell Reports 22, 2227-2235.

Fogarty NME, Mccarthy A, Snijders KE, Powell BE, Kubikova N, Blakeley $P$, Lea $R$, Elder $K$, Wamaitha SE, Kim D, Maciulyte V, Kleinjung J, Kim JS, Wells D, Vallier L, Bertero A, Turner JMA and Niakan KK (2017) Genome editing reveals a role for OCT4 in human embryogenesis. Nature 550, 67-73.

Fonfara I, Le Rhun A, Chylinski K, Makarova KS, Lécrivain A-L, Bzdrenga J, Koonin EV and Charpentier E (2014) Phylogeny of Cas9 determines functional exchangeability of dual-RNA and Cas9 among orthologous type II CRISPR-Cas systems. Nucleic Acids Research 42, 2577-2590.

Fonfara I, Richter H, Bratovič M, Le Rhun A and Charpentier E (2016) The CRISPR-associated DNA-cleaving enzyme Cpfl also processes precursor CRISPR RNA. Nature 532, 517-521.

Frieda KL, Linton JM, Hormoz S, Choi J, Chow KK, Singer ZS, Budde MW, Elowitz MB and Cai L (2017) Synthetic recording and in situ readout of lineage information in single cells. Nature 541, 107-111.

Friedland AE, Tzur YB, Esvelt KM, Colaiácovo MP, Church GM and Calarco JA (2013) Heritable genome editing in C. elegans via a CRISPR-Cas9 system. Nature Methods 10, 741-743.

Frock RL, Hu J, Meyers RM, Ho YJ, Kii E and Alt FW (2015) Genome-wide detection of DNA double-stranded breaks induced by engineered nucleases. Nature Biotechnology 33, 179-186.

Fulco CP, Munschauer M, Anyoha R, Munson G, Grossman SR, Perez EM, Kane M, Cleary B, Lander ES and Engreitz JM (2016) Systematic mapping of functional enhancer-promoter connections with CRISPR interference. Science 354, 769-773.

Fu Y, Foden JA, Khayter C, Maeder ML, Reyon D, Joung JK and Sander JD (2013) High-frequency off-target mutagenesis induced by CRISPR-Cas nucleases in human cells. Nature Biotechnology 31, 822-826.

Fu Y, Sander JD, Reyon D, Cascio VM and Joung JK (2014) Improving CRISPR-Cas nuclease specificity using truncated guide RNAs. Nature Biotechnology 32, 279-284.

Gantz VM, Jasinskiene N, Tatarenkova O, Fazekas A, Macias VM, Bier E and James AA (2015) Highly efficient Cas9-mediated gene drive for population modification of the malaria vector mosquito Anopheles stephensi. Proceedings of the National Academy of Sciences 112, E6736-E6743.

Gao C (2018) The future of CRISPR technologies in agriculture. Nature Reviews Molecular Cell Biology 19, 275-276.

Gao L, Cox DBT, Yan WX, Manteiga JC, Schneider MW, Yamano T, Nishimasu H, Nureki O, Crosetto N and Zhang F (2017) Engineered Cpf1 variants with altered PAM specificities. Nature Biotechnology 163, 759.
Garcia-Doval C and Jinek M (2017) Molecular architectures and mechanisms of class 2 CRISPR-associated nucleases. Current Opinion in Structural Biology 47, 157-166.

Garneau JE, Dupuis ME, Villion M, Romero DA, Barrangou R, Boyaval P, Fremaux C, Horvath P, Magadan AH and Moineau S (2010) The CRISPR/Cas bacterial immune system cleaves bacteriophage and plasmid DNA. Nature 468, 67-71.

Gasiunas G, Barrangou R, Horvath P and Siksnys V (2012) Cas9-crRNA ribonucleoprotein complex mediates specific DNA cleavage for adaptive immunity in bacteria. Proceedings of the National Academy of Sciences of the United States of America 109, E2579-E2586.

Gasperini M, Hill AJ, Mcfaline-Figueroa JL, Martin B, Kim S, Zhang MD, Jackson D, Leith A, Schreiber J, Noble WS, Trapnell C, Ahituv N and Shendure J (2019) A genome-wide framework for mapping gene regulation via cellular genetic screens. Cell 176, 377-390.

Gaudelli NM, Komor AC, Rees HA, Packer MS, Badran AH, Bryson DI and Liu DR (2017) Programmable base editing of A•T to G•C in genomic DNA without DNA cleavage. Nature 551, 464-471.

Ge Y, Gomez NC, Adam RC, Nikolova M, Yang H, Verma A, Lu CP, Polak L, Yuan S, Elemento O and Fuchs E (2017) Stem cell lineage infidelity drives wound repair and cancer. Cell 169, 636-650.

Ghorbal M, Gorman M, Macpherson CR, Martins RM, Scherf A and Lopez-Rubio J-J (2014) Genome editing in the human malaria parasite plasmodium falciparum using the CRISPR-Cas9 system. Nature Biotechnology $32,819-821$

Giannoukos G, Ciulla DM, Marco E, Abdulkerim HS, Barrera LA, Bothmer A, Dhanapal V, Gloskowski SW, Jayaram H, Maeder ML, Skor MN, Wang T, Myer VE and Wilson CJ (2018) UDitas, a genome editing detection method for indels and genome rearrangements. BMC Genomics 19, 212.

Gilbert LA, Larson MH, Morsut L, Liu Z, Brar GA, Torres SE, SternGinossar N, Brandman O, Whitehead EH, Doudna JA, Lim WA, Weissman JS and Qi LS (2013) CRISPR-mediated modular RNA-guided regulation of transcription in eukaryotes. Cell 154, 442-451.

Gilbert LA, Horlbeck MA, Adamson B, Villalta JE, Chen Y, Whitehead EH, Guimaraes C, Panning B, Ploegh HL, Bassik MC, Qi LS, Kampmann M and Weissman JS (2014) Genome-Scale CRISPR-mediated control of gene repression and activation. Cell 159, 647-661.

Gootenberg JS, Abudayyeh OO, Lee JW, Essletzbichler P, Dy AJ, Joung J, Verdine V, Donghia N, Daringer NM, Freije CA, Myhrvold C, Bhattacharyya RP, Livny J, Regev A, Koonin EV, Hung DT, Sabeti PC, Collins JJ and Zhang F (2017) Nucleic acid detection with CRISPRCas13a/C2c2. Science 356, 438-442.

Gootenberg JS, Abudayyeh OO, Kellner MJ, Joung J, Collins JJ and Zhang F (2018) Multiplexed and portable nucleic acid detection platform with Cas13, Cas12a, and Csm6. Science 360, 439-444.

Gratz SJ, Cummings AM, Nguyen JN, Hamm DC, Donohue LK, Harrison MM, Wildonger J and O'connor-Giles KM (2013) Genome engineering of drosophila with the CRISPR RNA-guided Cas9 nuclease. Genetics 194, 1029-1035.

Grunewald J, Zhou R, Garcia SP, Iyer S, Lareau CA, Aryee MJ and Joung JK (2019) Transcriptome-wide off-target RNA editing induced by CRISPR-guided DNA base editors. Nature 569, 433-437.

Grunwald HA, Gantz VM, Poplawski G, Xu XS, Bier E and Cooper KL (2019) Super-Mendelian inheritance mediated by CRISPR-Cas9 in the female mouse germline. Nature 566, 105-109.

Guilinger JP, Thompson DB and Liu DR (2014) Fusion of catalytically inactive Cas9 to FokI nuclease improves the specificity of genome modification. Nature Biotechnology 32, 577-582.

Guo X, Chitale P and Sanjana NE (2017) Target discovery for precision medicine using high-throughput genome engineering. Advances in Experimental Medicine and Biology 1016, 123-145.

Gu W, Crawford ED, O'donovan BD, Wilson MR, Chow ED, Retallack $H$ and Derisi JL (2016) Depletion of abundant sequences by hybridization (DASH): using Cas 9 to remove unwanted high-abundance species in sequencing libraries and molecular counting applications. Genome Biology 17, 41.

Hajian R, Balderston S, Tran T, Deboer T, Etienne J, Sandhu M, Wauford NA, Chung J-Y, Nokes J, Athaiya M, Paredes J, Peytavi R, Goldsmith B, Murthy N, Conboy IM and Aran K (2019) Detection of 
unamplified target genes via CRISPR-Cas9 immobilized on a graphene field-effect transistor. Nature Biomedical Engineering. http://doi.org/10. 1038/s41551-019-0371-x.

Hale CR, Zhao P, Olson S, Duff MO, Graveley BR, Wells L, Terns RM and Terns MP (2009) RNA-guided RNA cleavage by a CRISPR RNA-Cas protein complex. Cell 139, 945-956.

Halperin SO, Tou CJ, Wong EB, Modavi C, Schaffer DV and Dueber JE (2018) CRISPR-guided DNA polymerases enable diversification of all nucleotides in a tunable window. Nature 560, 248-252.

Hammond A, Galizi R, Kyrou K, Simoni A, Siniscalchi C, Katsanos D, Gribble M, Baker D, Marois E, Russell S, Burt A, Windbichler N, Crisanti A and Nolan T (2015) A CRISPR-Cas9 gene drive system targeting female reproduction in the malaria mosquito vector Anopheles gambiae. Nature Biotechnology 34, 78-83.

Han BW, Herrin BR, Cooper MD and Wilson IA (2008) Antigen recognition by variable lymphocyte receptors. Science 321, 1834-1837.

Han K, Jeng EE, Hess GT, Morgens DW, Li A and Bassik MC (2017) Synergistic drug combinations for cancer identified in a CRISPR screen for pairwise genetic interactions. Nature Biotechnology 35, 463-474.

Han R, Li L, Ugalde AP, Tal A, Manber Z, Barbera EP, Chiara VD, Elkon R and Agami R (2018) Functional CRISPR screen identifies AP1-associated enhancer regulating FOXF1 to modulate oncogene-induced senescence. Genome Biology 19, 118.

Harrington LB, Burstein D, Chen JS, Paez-Espino D, Ma E, Witte IP, Cofsky JC, Kyrpides NC, Banfield JF and Doudna JA (2018) Programmed DNA destruction by miniature CRISPR-Cas14 enzymes. Science 362, 839-842.

Hart T and Moffat J (2016) BAGEL: a computational framework for identifying essential genes from pooled library screens. BMC Bioinformatics 17, 164.

Hart T, Chandrashekhar M, Aregger M, Steinhart Z, Brown KR, Macleod G, Mis M, Zimmermann M, Fradet-Turcotte A, Sun S, Mero P, Dirks P, Sidhu S, Roth FP, Rissland OS, Durocher D, Angers S and Moffat J (2015) High-resolution CRISPR screens reveal fitness genes and genotype-specific cancer liabilities. Cell 163, 1515-1526.

Hart T, Tong AHY, Chan K, Van Leeuwen J, Seetharaman A, Aregger M, Chandrashekhar M, Hustedt N, Seth S, Noonan A, Habsid A, Sizova O, Nedyalkova L, Climie R, Tworzyanski L, Lawson K, Sartori MA, Alibeh S, Tieu D, Masud S, Mero P, Weiss A, Brown KR, Usaj M, Billmann M, Rahman M, Constanzo M, Myers CL, Andrews BJ, Boone C, Durocher D and Moffat J (2017) Evaluation and design of genome-wide CRISPR/SpCas9 knockout screens. G3 (Bethesda) 7, 2719-2727.

Heigwer F, Zhan T, Breinig M, Winter J, Brugemann D, Leible S and Boutros M (2016) CRISPR library designer (CLD): software for multispecies design of single guide RNA libraries. Genome Biology 17, 55.

Heler R, Samai P, Modell JW, Weiner C, Goldberg GW, Bikard D and Marraffini LA (2015) Cas9 specifies functional viral targets during CRISPR-Cas adaptation. Nature 519, 199-202.

Hess GT, Fresard L, Han K, Lee CH, Li A, Cimprich KA, Montgomery SB and Bassik MC (2016) Directed evolution using dCas9-targeted somatic hypermutation in mammalian cells. Nature Methods 13, 1036-1042.

Hess GT, Tycko J, Yao D and Bassik MC (2017) Methods and applications of CRISPR-mediated base editing in eukaryotic genomes. Molecular Cell 68, $26-43$.

Hilton IB, D'ippolito AM, Vockley CM, Thakore PI, Crawford GE, Reddy TE and Gersbach CA (2015) Epigenome editing by a CRISPRCas9-based acetyltransferase activates genes from promoters and enhancers. Nature Biotechnology 33, 510-517.

Hirano H, Gootenberg JS, Horii T, Abudayyeh OO, Kimura M, Hsu PD, Nakane T, Ishitani R, Hatada I, Zhang F, Nishimasu $H$ and Nureki $O$ (2016) Structure and engineering of Francisella novicida Cas9. Cell 164, 950-961.

Horlbeck MA, Gilbert LA, Villalta JE, Adamson B, Pak RA, Chen Y, Fields AP, Park CY, Corn JE, Kampmann M and Weissman JS (2016) Compact and highly active next-generation libraries for CRISPR-mediated gene repression and activation. Elife 5, e19760.

Horlbeck MA, Xu A, Wang M, Bennett NK, Park CY, Bogdanoff D, Adamson B, Chow ED, Kampmann M, Peterson TR, Nakamura K,
Fischbach MA, Weissman JS and Gilbert LA (2018) Mapping the genetic landscape of human cells. Cell 174, 953-967.

Horvath P, Romero DA, Coute-Monvoisin AC, Richards M, Deveau H, Moineau S, Boyaval P, Fremaux C and Barrangou R (2008) Diversity, activity, and evolution of CRISPR loci in Streptococcus thermophilus. Journal of Bacteriology 190, 1401-1412.

Horvath P, Coute-Monvoisin AC, Romero DA, Boyaval P, Fremaux C and Barrangou R (2009) Comparative analysis of CRISPR loci in lactic acid bacteria genomes. International Journal of Food Microbiology 131, 62-70.

Hotta A and Yamanaka S (2015) From genomics to gene therapy: induced pluripotent stem cells meet genome editing. Annual Review of Genetics 49, $47-70$.

Hou Z, Zhang Y, Propson NE, Howden SE, Chu LF, Sontheimer EJ and Thomson JA (2013) Efficient genome engineering in human pluripotent stem cells using Cas9 from Neisseria meningitidis. Proceedings of the National Academy of Sciences of the United States of America 110, 15644-15649.

Hsu PD, Scott DA, Weinstein JA, Ran FA, Konermann S, Agarwala V, Li Y, Fine EJ, Wu X, Shalem O, Cradick TJ, Marraffini LA, Bao G and Zhang F (2013) DNA targeting specificity of RNA-guided Cas9 nucleases. Nature Biotechnology 31, 827-832.

Hsu PD, Lander ES and Zhang F (2014) Development and applications of CRISPR-Cas9 for genome engineering. Cell 157, 1262-1278.

Hua K, Tao X and Zhu JK (2019) Expanding the base editing scope in rice by using Cas9 variants. Plant Biotechnology Journal 17, 499-504.

Hu W, Kaminski R, Yang F, Zhang Y, Cosentino L, Li F, Luo B, AlvarezCarbonell D, Garcia-Mesa Y, Karn J, Mo X and Khalili K (2014) RNA-directed gene editing specifically eradicates latent and prevents new HIV-1 infection. Proceedings of the National Academy of Sciences of the United States of America 111, 11461-11466.

Hu JH, Miller SM, Geurts MH, Tang W, Chen L, Sun N, Zeina CM, Gao X, Rees HA, Lin Z and Liu DR (2018) Evolved Cas9 variants with broad PAM compatibility and high DNA specificity. Nature 556, 57-63.

Hwang WY, Fu Y, Reyon D, Maeder ML, Tsai SQ, Sander JD, Peterson RT, Yeh JR and Joung JK (2013) Efficient genome editing in zebrafish using a CRISPR-Cas system. Nature Biotechnology 31, 227-229.

Ibraheim R, Song CQ, Mir A, Amrani N, Xue W and Sontheimer EJ (2018) All-in-one adeno-associated virus delivery and genome editing by Neisseria meningitidis Cas9 in vivo. Genome Biology 19, 137.

Ipsaro JJ, Shen C, Arai E, Xu Y, Kinney JB, Joshua-Tor L, Vakoc CR and Shi J (2017) Rapid generation of drug-resistance alleles at endogenous loci using CRISPR-Cas9 indel mutagenesis. PLoS One 12, e0172177.

Ishino Y, Shinagawa H, Makino K, Amemura M and Nakata A (1987) Nucleotide sequence of the iap gene, responsible for alkaline phosphatase isozyme conversion in Escherichia coli, and identification of the gene product. Journal of Bacteriology 169, 5429-5433.

Ishino Y, Krupovic M and Forterre P (2018) History of CRISPR-Cas from encounter with a mysterious repeated sequence to genome editing technology. Journal of Bacteriology 200, e00580.

Jackson RN and Wiedenheft B (2015) A conserved structural chassis for mounting Versatile CRISPR RNA-guided immune responses. Molecular Cell 58, 722-728.

Jacob F (1977) Evolution and tinkering. Science 196, 1161-1166.

Jain IH, Zazzeron L, Goli R, Alexa K, Schatzman-Bone S, Dhillon H, Goldberger O, Peng J, Shalem O, Sanjana NE, Zhang F, Goessling W, Zapol WM and Mootha VK (2016) Hypoxia as a therapy for mitochondrial disease. Science 352, 54-61.

Jaitin DA, Weiner A, Yofe I, Lara-Astiaso D, Keren-Shaul H, David E, Salame TM, Tanay A, Van Oudenaarden A and Amit I (2016) Dissecting immune circuits by linking CRISPR-pooled screens with singlecell RNA-Seq. Cell 167, 1883-1896.

Jansen R, Embden JD, Gaastra W and Schouls LM (2002) Identification of genes that are associated with DNA repeats in prokaryotes. Molecular Microbiology 43, 1565-1575.

Jiang F and Doudna JA (2017) CRISPR-Cas9 Structures and mechanisms. Annual Review of Biophysics 46, 505-529.

Jiang W, Zhou H, Bi H, Fromm M, Yang B and Weeks DP (2013) Demonstration of CRISPR/Cas9/sgRNA-mediated targeted gene 
modification in Arabidopsis, tobacco, sorghum and rice. Nucleic Acids Research 41, e188-e188.

Jinek M, Chylinski K, Fonfara I, Hauer M, Doudna JA and Charpentier E (2012) A programmable dual-RNA-guided DNA endonuclease in adaptive bacterial immunity. Science 337, 816-821.

Jinek M, East A, Cheng A, Lin S, Ma E and Doudna J (2013) RNA-programmed genome editing in human cells. Elife 2, e00471.

Jinek M, Jiang F, Taylor DW, Sternberg SH, Kaya E, Ma E, Anders C, Hauer M, Zhou K, Lin S, Kaplan M, Iavarone AT, Charpentier E, Nogales E and Doudna JA (2014) Structures of Cas9 endonucleases reveal RNA-mediated conformational activation. Science 343, $1247997-$ 1247997.

Jin S, Zong Y, Gao Q, Zhu Z, Wang Y, Qin P, Liang C, Wang D, Qiu J-L, Zhang F and Gao C (2019) Cytosine, but not adenine, base editors induce genome-wide off-target mutations in rice. Science 364, 292-295.

Jost M and Weissman JS (2018) CRISPR approaches to small molecule target identification. ACS Chemical Biology 13, 366-375.

Joung JK and Sander JD (2013) TALENs: a widely applicable technology for targeted genome editing. Nature Reviews Molecular Cell Biology 14, 49-55.

Joung J, Engreitz JM, Konermann S, Abudayyeh OO, Verdine VK, Aguet F, Gootenberg JS, Sanjana NE, Wright JB, Fulco CP, Tseng Y-Y, Yoon CH, Boehm JS, Lander ES and Zhang F (2017) Genome-scale activation screen identifies a lncRNA locus regulating a gene neighbourhood. Nature 548, 343-346.

Kalhor R, Mali P and Church GM (2017) Rapidly evolving homing CRISPR barcodes. Nature Methods 14, 195-200.

Kang BC, Yun JY, Kim ST, Shin Y, Ryu J, Choi M, Woo JW and Kim JS (2018) Precision genome engineering through adenine base editing in plants. Nat Plants 4, 427-431.

Kan Y, Ruis B, Takasugi T and Hendrickson EA (2017) Mechanisms of precise genome editing using oligonucleotide donors. Genome Research 27, 1099-1111

Karvelis T, Gasiunas G, Young J, Bigelyte G, Silanskas A, Cigan M and Siksnys V (2015) Rapid characterization of CRISPR-Cas9 protospacer adjacent motif sequence elements. Genome Biology 16, 253.

Kearns NA, Pham H, Tabak B, Genga RM, Silverstein NJ, Garber M and Maehr R (2015) Functional annotation of native enhancers with a Cas9histone demethylase fusion. Nature Methods 12, 401-403.

Kim H and Kim JS (2014) A guide to genome engineering with programmable nucleases. Nature Reviews Genetics 15, 321-334.

Kim D, Bae S, Park J, Kim E, Kim S, Yu HR, Hwang J, Kim J-I and Kim J-S (2015) Digenome-seq: genome-wide profiling of CRISPR-Cas9 off-target effects in human cells. Nature Methods 12, 237-243.

Kim E, Koo T, Park SW, Kim D, Kim K, Cho HY, Song DW, Lee KJ, Jung MH, Kim S, Kim JH, Kim JH and Kim JS (2017a) In vivo genome editing with a small Cas9 orthologue derived from Campylobacter jejuni. Nature Communications 8, 14500.

Kim H, Kim S-T, Ryu J, Kang B-C, Kim J-S and Kim S-G (2017b) CRISPR/ Cpf1-mediated DNA-free plant genome editing. Nature Communications 8 , 14406.

Kim D, Kim DE, Lee G, Cho SI and Kim JS (2019) Genome-wide target specificity of CRISPR RNA-guided adenine base editors. Nature Biotechnology 37, 430-435.

Klann TS, Black JB, Chellappan M, Safi A, Song L, Hilton IB, Crawford GE, Reddy TE and Gersbach CA (2017) CRISPR-Cas9 epigenome editing enables high-throughput screening for functional regulatory elements in the human genome. Nature Biotechnology 35, 561-568.

Kleinstiver BP, Prew MS, Tsai SQ, Nguyen NT, Topkar VV, Zheng Z and Joung JK (2015a) Broadening the targeting range of Staphylococcus aureus CRISPR-Cas 9 by modifying PAM recognition. Nature Biotechnology 33 , 1293-1298.

Kleinstiver BP, Prew MS, Tsai SQ, Topkar VV, Nguyen NT, Zheng Z, Gonzales APW, Li Z, Peterson RT, Yeh J-RJ, Aryee MJ and Joung JK (2015b) Engineered CRISPR-Cas9 nucleases with altered PAM specificities. Nature 523, 481-485.

Kleinstiver BP, Pattanayak V, Prew MS, Tsai SQ, Nguyen NT, Zheng Z and Joung JK (2016a) High-fidelity CRISPR-Cas9 nucleases with no detectable genome-wide off-target effects. Nature 529, 490-495.
Kleinstiver BP, Tsai SQ, Prew MS, Nguyen NT, Welch MM, Lopez JM, Mccaw ZR, Aryee MJ and Joung JK (2016b) Genome-wide specificities of CRISPR-Cas Cpf1 nucleases in human cells. Nature Biotechnology 34, 869-874.

Kleinstiver BP, Sousa AA, Walton RT, Tak YE, Hsu JY, Clement K, Welch MM, Horng JE, Malagon-Lopez J, Scarfo I, Maus MV, Pinello L, Aryee MJ and Joung JK (2019) Engineered CRISPR-Cas12a variants with increased activities and improved targeting ranges for gene, epigenetic and base editing. Nature Biotechnology 37, 276-282.

Knight SC, Xie L, Deng W, Guglielmi B, Witkowsky LB, Bosanac L, Zhang ET, El Beheiry M, Masson JB, Dahan M, Liu Z, Doudna JA and Tjian R (2015) Dynamics of CRISPR-Cas9 genome interrogation in living cells. Science 350, 823-826.

Knott GJ, East-Seletsky A, Cofsky JC, Holton JM, Charles E, O'connell MR and Doudna JA (2017) Guide-bound structures of an RNA-targeting A-cleaving CRISPR-Cas13a enzyme. Nature Structural \&Molecular Biology 24, 825-833.

Kocak DD, Josephs EA, Bhandarkar V, Adkar SS, Kwon JB and Gersbach CA (2019) Increasing the specificity of CRISPR systems with engineered RNA secondary structures. Nature Biotechnology. http://doi. org/10.1038/s41587-019-0095-1.

Koike-Yusa H, Li Y, Tan EP, Velasco-Herrera Mdel C and Yusa K (2014) Genome-wide recessive genetic screening in mammalian cells with a lentiviral CRISPR-guide RNA library. Nature Biotechnology 32, 267-273.

Komor AC, Kim YB, Packer MS, Zuris JA and Liu DR (2016) Programmable editing of a target base in genomic DNA without double-stranded DNA cleavage. Nature 533, 420-424.

Konermann S, Brigham MD, Trevino AE, Hsu PD, Heidenreich M, Cong L, Platt RJ, Scott DA, Church GM and Zhang F (2013) Optical control of mammalian endogenous transcription and epigenetic states. Nature 500, $472-476$.

Konermann S, Brigham MD, Trevino AE, Joung J, Abudayyeh OO, Barcena C, Hsu PD, Habib N, Gootenberg JS, Nishimasu H, Nureki O and Zhang F (2014) Genome-scale transcriptional activation by an engineered CRISPR-Cas9 complex. Nature 517, 583-588.

Konermann S, Lotfy P, Brideau NJ, Oki J, Shokhirev MN and Hsu PD (2018) Transcriptome engineering with RNA-targeting type VI-D CRISPR effectors. Cell 173, 665-676.

Koonin EV and Makarova KS (2017) Mobile genetic elements and evolution of CRISPR-Cas systems: all the way there and back. Genome Biology and Evolution 9, 2812-2825.

Kosicki M, Tomberg K and Bradley A (2018) Repair of double-strand breaks induced by CRISPR-Cas9 leads to large deletions and complex rearrangements. Nature Biotechnology 36, 765-771.

Labun K, Montague TG, Gagnon JA, Thyme SB and Valen E (2016) CHOPCHOP v2: a web tool for the next generation of CRISPR genome engineering. Nucleic Acids Research 44, W272-W276.

Lander ES, Baylis F, Zhang F, Charpentier E, Berg P, Bourgain C, Friedrich B, Joung JK, Li J, Liu D, Naldini L, Nie JB, Qiu R, SchoeneSeifert B, Shao F, Terry S, Wei W and Winnacker EL (2019) Adopt a moratorium on heritable genome editing. Nature 567, 165-168.

Lee CM, Cradick TJ and Bao G (2016) The Neisseria meningitidis CRISPRCas9 system enables specific genome editing in mammalian cells. Molecular Therapy 24, 645-654.

Lee JK, Jeong E, Lee J, Jung M, Shin E, Kim Y-H, Lee K, Jung I, Kim D, Kim S and Kim J-S (2018) Directed evolution of CRISPR-Cas9 to increase its specificity. Nature Communications 9, 3048.

Lemay ML, Horvath P and Moineau S (2017) The CRISPR-Cas app goes viral. Current Opinion in Microbiology 37, 103-109.

Liang Z, Zhang K, Chen K and Gao C (2014) Targeted mutagenesis in Zea mays using TALENs and the CRISPR/Cas system. Journal of Genetics and Genomics=Yi chuan xue bao 41, 63-68.

Liang P, Xu Y, Zhang X, Ding C, Huang R, Zhang Z, Lv J, Xie X, Chen Y, Li Y, Sun Y, Bai Y, Songyang Z, Ma W, Zhou C and Huang J (2015) CRISPR/Cas9-mediated gene editing in human tripronuclear zygotes. Protein Cell 6, 363-372.

Liang Z, Chen K, Li T, Zhang Y, Wang Y, Zhao Q, Liu J, Zhang H, Liu C, Ran Y and Gao C (2017) Efficient DNA-free genome editing of bread wheat 
using CRISPR/Cas9 ribonucleoprotein complexes. Nature Communications 8, 14261 .

Liao HK, Hatanaka F, Araoka T, Reddy P, Wu MZ, Sui Y, Yamauchi T, Sakurai M, O'keefe DD, Nunez-Delicado E, Guillen P, Campistol JM, Wu CJ, Lu LF, Esteban CR and Izpisua Belmonte JC (2017) In vivo target gene activation via CRISPR/Cas9-mediated trans-epigenetic modulation. Cell 171, 1495-1507.

Link KH and Breaker RR (2009) Engineering ligand-responsive gene-control elements: lessons learned from natural riboswitches. Gene Therapy 16, 1189-1201.

Lin S, Staahl BT, Alla RK and Doudna JA (2014) Enhanced homologydirected human genome engineering by controlled timing of CRISPR/ Cas9 delivery. Elife 3, e04766.

Listgarten J, Weinstein M, Kleinstiver BP, Sousa AA, Joung JK, Crawford J, Gao K, Hoang L, Elibol M, Doench JG and Fusi N (2018) Prediction of off-target activities for the end-to-end design of CRISPR guide RNAs. Nature Biomedical Engineering 2, 38-47.

Liu KI, Ramli MNB, Woo CWA, Wang Y, Zhao T, Zhang X, Yim GRD, Chong BY, Gowher A, Chua MZH, Jung J, Lee JHJ and Tan MH (2016a) A chemical-inducible CRISPR-Cas9 system for rapid control of genome editing. Nature Chemical Biology 12, 980-987.

Liu XS, Wu H, Ji X, Stelzer Y, Wu X, Czauderna S, Shu J, Dadon D, Young RA and Jaenisch R (2016b) Editing DNA methylation in the mammalian genome. Cell 167, 233-247.

Liu L, Li X, Ma J, Li Z, You L, Wang J, Wang M, Zhang X and Wang Y (2017a) The molecular architecture for RNA-guided RNA cleavage by Cas13a. Cell 170, 714-726.

Liu L, Li X, Wang J, Wang M, Chen P, Yin M, Li J, Sheng G and Wang Y (2017b) Two distant catalytic sites are responsible for C2c2 RNase activities. Cell 168, 121-134.

Liu SJ, Horlbeck MA, Cho SW, Birk HS, Malatesta M, He D, Attenello FJ, Villalta JE, Cho MY, Chen Y, Mandegar MA, Olvera MP, Gilbert LA, Conklin BR, Chang HY, Weissman JS and Lim DA (2017c) CRISPRibased genome-scale identification of functional long noncoding RNA loci in human cells. Science 355, eaah7111.

Liu N, Lee CH, Swigut T, Grow E, Gu B, Bassik MC and Wysocka J (2018a) Selective silencing of euchromatic L1s revealed by genome-wide screens for L1 regulators. Nature 553, 228-232.

Liu XS, Wu H, Krzisch M, Wu X, Graef J, Muffat J, Hnisz D, Li CH, Yuan B, Xu C, Li Y, Vershkov D, Cacace A, Young RA and Jaenisch R (2018b) Rescue of Fragile X syndrome neurons by DNA methylation editing of the FMR1 gene. Cell 172, 979-992.

Liu Y, Yu C, Daley TP, Wang F, Cao WS, Bhate S, Lin X, Still 2nd C, Liu H, Zhao D, Wang H, Xie XS, Ding S, Wong WH, Wernig $M$ and Qi LS (2018c) CRISPR activation screens systematically identify factors that drive neuronal fate and reprogramming. Cell Stem Cell 23, 758-771.

Liu Z, Lu Z, Yang G, Huang S, Li G, Feng S, Liu Y, Li J, Yu W, Zhang Y, Chen J, Sun Q and Huang X (2018d) Efficient generation of mouse models of human diseases via ABE- and BE-mediated base editing. Nature Communications 9, 2338.

Liu J-J, Orlova N, Oakes BL, Ma E, Spinner HB, Baney KLM, Chuck J, Tan D, Knott GJ, Harrington LB, Al-Shayeb B, Wagner A, Brötzmann J, Staahl BT, Taylor KL, Desmarais J, Nogales E and Doudna JA (2019) Casx enzymes comprise a distinct family of RNAguided genome editors. Nature 566, 218-223.

Li J-F, Norville JE, Aach J, Mccormack M, Zhang D, Bush J, Church GM and Sheen J (2013) Multiplex and homologous recombination-mediated genome editing in Arabidopsis and Nicotiana benthamiana using guide RNA and Cas9. Nature Biotechnology 31, 688-691.

Li W, Xu H, Xiao T, Cong L, Love MI, Zhang F, Irizarry RA, Liu JS, Brown M and Liu XS (2014) MAGeCK enables robust identification of essential genes from genome-scale CRISPR/Cas9 knockout screens. Genome Biology 15, 554.

Li X, Fan D, Zhang W, Liu G, Zhang L, Zhao L, Fang X, Chen L, Dong Y, Chen Y, Ding Y, Zhao R, Feng M, Zhu Y, Feng Y, Jiang X, Zhu D, Xiang H, Feng X, Li S, Wang J, Zhang G, Kronforst MR and Wang W (2015) Outbred genome sequencing and CRISPR/Cas9 gene editing in butterflies. Nature Communications 6, 8212 .
Li M, Au LYC, Douglah D, Chong A, White BJ, Ferree PM and Akbari OS (2017) Generation of heritable germline mutations in the jewel wasp Nasonia vitripennis using CRISPR/Cas9. Scientific Reports 7, 901.

Li C, Zong Y, Wang Y, Jin S, Zhang D, Song Q, Zhang R and Gao C (2018a) Expanded base editing in rice and wheat using a Cas9-adenosine deaminase fusion. Genome Biology 19, 59.

Li S-Y, Cheng Q-X, Wang J-M, Li X-Y, Zhang Z-L, Gao S, Cao R-B, Zhao G-P and Wang J (2018b) CRISPR-Cas12a-assisted nucleic acid detection. Cell Discovery 4, 20.

Li X, Wang Y, Liu Y, Yang B, Wang X, Wei J, Lu Z, Zhang Y, Wu J, Huang X, Yang L and Chen J (2018c) Base editing with a Cpfl-cytidine deaminase fusion. Nature Biotechnology 36, 324-327.

Loenen WA, Dryden DT, Raleigh EA, Wilson GG and Murray NE (2014) Highlights of the DNA cutters: a short history of the restriction enzymes. Nucleic Acids Research 42, 3-19.

Long C, Amoasii L, Mireault AA, Mcanally JR, Li H, Sanchez-Ortiz E, Bhattacharyya S, Shelton JM, Bassel-Duby R and Olson EN (2016) Postnatal genome editing partially restores dystrophin expression in a mouse model of muscular dystrophy. Science 351, 400-403.

Lunshof J (2015) Regulate gene editing in wild animals. Nature 521, 127.

Maddalo D, Manchado E, Concepcion CP, Bonetti C, Vidigal JA, Han YC, Ogrodowski P, Crippa A, Rekhtman N, De Stanchina E, Lowe SW and Ventura A (2014) In vivo engineering of oncogenic chromosomal rearrangements with the CRISPR/Cas9 system. Nature 516, 423-427.

Maeder ML, Linder SJ, Cascio VM, Fu Y, Ho QH and Joung JK (2013) CRISPR RNA-guided activation of endogenous human genes. Nature Methods 10, 977-979.

Maeder ML, Stefanidakis $M$, Wilson CJ, Baral R, Barrera LA, Bounoutas GS, Bumcrot D, Chao H, Ciulla DM, Dasilva JA, Dass A, Dhanapal V, Fennell TJ, Friedland AE, Giannoukos G, Gloskowski SW, Glucksmann A, Gotta GM, Jayaram H, Haskett SJ, Hopkins B, Horng JE, Joshi S, Marco E, Mepani R, Reyon D, Ta T, Tabbaa DG, Samuelsson SJ, Shen S, Skor MN, Stetkiewicz P, Wang T, Yudkoff C, Myer VE, Albright CF and Jiang H (2019) Development of a gene-editing approach to restore vision loss in Leber congenital amaurosis type 10. Nature Medicine 25, 229-233.

Makarova KS, Aravind L, Grishin NV, Rogozin IB and Koonin EV (2002) A DNA repair system specific for thermophilic archaea and bacteria predicted by genomic context analysis. Nucleic Acids Research 30, 482-496.

Makarova KS, Grishin NV, Shabalina SA, Wolf YI and Koonin EV (2006) A putative RNA-interference-based immune system in prokaryotes: computational analysis of the predicted enzymatic machinery, functional analogies with eukaryotic RNAi, and hypothetical mechanisms of action. Biology Direct 1, 7 .

Makarova KS, Haft DH, Barrangou R, Brouns SJJ, Charpentier E, Horvath P, Moineau S, Mojica FJM, Wolf YI, Yakunin AF, Van Der Oost J and Koonin EV (2011) Evolution and classification of the CRISPR-Cas systems. Nature Reviews Microbiology 9, 467-477.

Makarova KS, Wolf YI, Alkhnbashi OS, Costa F, Shah SA, Saunders SJ, Barrangou R, Brouns SJJ, Charpentier E, Haft DH, Horvath $P$, Moineau S, Mojica FJM, Terns RM, Terns MP, White MF, Yakunin AF, Garrett RA, Van Der Oost J, Backofen R and Koonin EV (2015) An updated evolutionary classification of CRISPR-Cas systems. Nature Reviews Microbiology 13, 722-736.

Mali P, Aach J, Stranges PB, Esvelt KM, Moosburner M, Kosuri S, Yang L and Church GM (2013a) CAS9 transcriptional activators for target specificity screening and paired nickases for cooperative genome engineering. Nature Biotechnology 31, 833-838.

Mali P, Yang LH, Esvelt KM, Aach J, Guell M, Dicarlo JE, Norville JE and Church GM (2013b) RNA-guided Human genome engineering via Cas9. Science 339, 823-826.

Mandal PK, Ferreira LM, Collins R, Meissner TB, Boutwell CL, Friesen M, Vrbanac V, Garrison BS, Stortchevoi A, Bryder D, Musunuru K, Brand H, Tager AM, Allen TM, Talkowski ME, Rossi DJ and Cowan CA (2014) Efficient ablation of genes in human hematopoietic stem and effector cells using CRISPR/Cas9. Cell Stem Cell 15, 643-652.

Mandegar MA, Huebsch N, Frolov EB, Shin E, Truong A, Olvera MP, Chan AH, Miyaoka Y, Holmes K, Spencer CI, Judge LM, Gordon DE, 
Eskildsen TV, Villalta JE, Horlbeck MA, Gilbert LA, Krogan NJ, Sheikh SP, Weissman JS, Qi LS, So PL and Conklin BR (2016) CRISPR interference efficiently induces specific and reversible gene silencing in human iPSCs. Cell Stem Cell 18, 541-553.

Manguso RT, Pope HW, Zimmer MD, Brown FD, Yates KB, Miller BC, Collins NB, Bi K, Lafleur MW, Juneja VR, Weiss SA, Lo J, Fisher DE, Miao D, Van Allen E, Root DE, Sharpe AH, Doench JG and Haining WN (2017) In vivo CRISPR screening identifies Ptpn2 as a cancer immunotherapy target. Nature 547, 413-418.

Mao Y, Zhang H, Xu N, Zhang B, Gou F and Zhu JK (2013) Application of the CRISPR-Cas system for efficient genome engineering in plants. Molecular Plant 6, 2008-2011.

Marceau CD, Puschnik AS, Majzoub K, Ooi YS, Brewer SM, Fuchs G, Swaminathan K, Mata MA, Elias JE, Sarnow P and Carette JE (2016) Genetic dissection of Flaviviridae host factors through genome-scale CRISPR screens. Nature 535, 159-163.

Marino ND, Zhang JY, Borges AL, Sousa AA, Leon LM, Rauch BJ, Walton RT, Berry JD, Joung JK, Kleinstiver BP and Bondy-Denomy J (2018) Discovery of widespread type I and type V CRISPR-Cas inhibitors. Science 362, 240-242.

Marraffini LA (2015) CRISPR-Cas immunity in prokaryotes. Nature 526, $55-61$.

Marraffini LA and Sontheimer EJ (2008) CRISPR interference limits horizontal gene transfer in staphylococci by targeting DNA. Science 322, 1843-1845.

Martin A, Serano JM, Jarvis E, Bruce HS, Wang J, Ray S, Barker CA, O'connell LC and Patel NH (2016) CRISPR/cas9 mutagenesis reveals versatile roles of Hox genes in crustacean limb specification and evolution. Current Biology: CB 26, 14-26.

Maruyama T, Dougan SK, Truttmann MC, Bilate AM, Ingram JR and Ploegh HL (2015) Increasing the efficiency of precise genome editing with CRISPR-Cas9 by inhibition of nonhomologous end joining. Nature Biotechnology 33, 538-542.

Mastroianni M, Watanabe K, White TB, Zhuang F, Vernon J, Matsuura M, Wallingford J and Lambowitz AM (2008) Group II intron-based gene targeting reactions in eukaryotes. PLoS One 3, e3121.

Ma H, Naseri A, Reyes-Gutierrez P, Wolfe SA, Zhang S and Pederson T (2015) Multicolor CRISPR labeling of chromosomal loci in human cells. Proceedings of the National Academy of Sciences of the United States of America 112, 3002-3007.

Ma H, Tu LC, Naseri A, Huisman M, Zhang S, Grunwald D and Pederson T (2016a) CRISPR-Cas9 nuclear dynamics and target recognition in living cells. Journal of Cell Biology 214, 529-537.

Ma H, Tu LC, Naseri A, Huisman M, Zhang S, Grunwald D and Pederson T (2016b) Multiplexed labeling of genomic loci with dCas9 and engineered sgRNAs using CRISPRainbow. Nature Biotechnology 34, 528-530.

Ma H, Marti-Gutierrez N, Park SW, Wu J, Lee Y, Suzuki K, Koski A, Ji D, Hayama T, Ahmed R, Darby H, Van Dyken C, Li Y, Kang E, Park AR, Kim D, Kim ST, Gong J, Gu Y, Xu X, Battaglia D, Krieg SA, Lee DM, Wu DH, Wolf DP, Heitner SB, Belmonte JCI, Amato P, Kim JS, Kaul S and Mitalipov S (2017) Correction of a pathogenic gene mutation in human embryos. Nature 548, 413-419.

Ma H, Marti-Gutierrez N, Park SW, Wu J, Hayama T, Darby H, Van Dyken C, Li Y, Koski A, Liang D, Suzuki K, Gu Y, Gong J, Xu X, Ahmed R, Lee Y, Kang E, Ji D, Park AR, Kim D, Kim ST, Heitner SB, Battaglia D, Krieg SA, Lee DM, Wu DH, Wolf DP, Amato P, Kaul S, Belmonte JCI, Kim JS and Mitalipov S (2018) Ma et al. Reply. Nature 560, E10-E23.

Mckenna A, Findlay GM, Gagnon JA, Horwitz MS, Schier AF and Shendure J (2016) Whole-organism lineage tracing by combinatorial and cumulative genome editing. Science 353, aaf7907.

Meeske AJ and Marraffini LA (2018) RNA guide complementarity prevents self-targeting in type VI CRISPR systems. Molecular Cell 71, 791-801.

Meier JA, Zhang F and Sanjana NE (2017) GUIDES: sgRNA design for loss-of-function screens. Nature Methods 14, 831-832.

Miyaoka Y, Berman JR, Cooper SB, Mayerl SJ, Chan AH, Zhang B, KarlinNeumann GA and Conklin BR (2016) Systematic quantification of HDR and NHEJ reveals effects of locus, nuclease, and cell type on genomeediting. Scientific Reports 6, 23549.
Miyaoka Y, Mayerl SJ, Chan AH and Conklin BR (2018) Detection and quantification of HDR and NHEJ induced by genome editing at endogenous gene loci using droplet digital PCR. Methods in Molecular Biology 1768, 349-362.

Mojica FJ and Rodriguez-Valera F (2016) The discovery of CRISPR in archaea and bacteria. FEBS Journal 283, 3162-3169.

Mojica FJ, Diez-Villasenor C, Garcia-Martinez J and Soria E (2005) Intervening sequences of regularly spaced prokaryotic repeats derive from foreign genetic elements. Journal of Molecular Evolution 60, 174-182.

Mojica FJ, Diez-Villasenor C, Garcia-Martinez J and Almendros C (2009) Short motif sequences determine the targets of the prokaryotic CRISPR defence system. Microbiology (Reading England) 155(Pt 3), 733-740.

Moreno-Mateos MA, Fernandez JP, Rouet R, Vejnar CE, Lane MA, Mis E, Khokha MK, Doudna JA and Giraldez AJ (2017) CRISPR-Cpf1 mediates efficient homology-directed repair and temperature-controlled genome editing. Nature Communications 8, 2024.

Morgan SL, Mariano NC, Bermudez A, Arruda NL, Wu F, Luo Y, Shankar G, Jia L, Chen H, Hu JF, Hoffman AR, Huang CC, Pitteri SJ and Wang KC (2017) Manipulation of nuclear architecture through CRISPR-mediated chromosomal looping. Nature Communications 8, 15993.

Morgens DW, Wainberg M, Boyle EA, Ursu O, Araya CL, Tsui CK, Haney MS, Hess GT, Han K, Jeng EE, Li A, Snyder MP, Greenleaf WJ, Kundaje A and Bassik MC (2017) Genome-scale measurement of offtarget activity using Cas9 toxicity in high-throughput screens. Nature Communications 8, 15178.

Moscou MJ and Bogdanove AJ (2009) A simple cipher governs DNA recognition by TAL effectors. Science 326, 1501.

Munoz DM, Cassiani PJ, Li L, Billy E, Korn JM, Jones MD, Golji J, Ruddy DA, Yu K, Mcallister G, Deweck A, Abramowski D, Wan J, Shirley MD, Neshat SY, Rakiec D, De Beaumont R, Weber O, Kauffmann A, Mcdonald 3rd ER, Keen N, Hofmann F, Sellers WR, Schmelzle T, Stegmeier F and Schlabach MR (2016) CRISPR screens provide a comprehensive assessment of cancer vulnerabilities but generate false-positive hits for highly amplified genomic regions. Cancer Discovery 6, 900-913.

Myers SA, Wright J, Peckner R, Kalish BT, Zhang F and Carr SA (2018) Discovery of proteins associated with a predefined genomic locus via dCas9-APEX-mediated proximity labeling. Nature Methods 15, 437-439.

Myhrvold C, Freije CA, Gootenberg JS, Abudayyeh OO, Metsky HC, Durbin AF, Kellner MJ, Tan AL, Paul LM, Parham LA, Garcia KF, Barnes KG, Chak B, Mondini A, Nogueira ML, Isern S, Michael SF, Lorenzana I, Yozwiak NL, Macinnis BL, Bosch I, Gehrke L, Zhang F and Sabeti PC (2018) Field-deployable viral diagnostics using CRISPRCas13. Science 360, 444-448.

Nakamura M, Srinivasan P, Chavez M, Carter MA, Dominguez AA, La Russa M, Lau MB, Abbott TR, Xu X, Zhao D, Gao Y, Kipniss NH, Smolke CD, Bondy-Denomy J and Qi LS (2019) Anti-CRISPR-mediated control of gene editing and synthetic circuits in eukaryotic cells. Nature Communications 10, 194.

Nakayama T, Fish MB, Fisher M, Oomen-Hajagos J, Thomsen GH and Grainger RM (2013) Simple and efficient CRISPR/Cas9-mediated targeted mutagenesis in Xenopus tropicalis. Genesis (New York N.Y. : 2000) 51, 835-843.

Nelles DA, Fang MY, O'connell MR, Xu JL, Markmiller SJ, Doudna JA and Yeo GW (2016) Programmable RNA tracking in live cells with CRISPR/ Cas9. Cell 165, 488-496.

Nelson CE, Hakim CH, Ousterout DG, Thakore PI, Moreb EA, Rivera RMC, Madhavan S, Pan X, Ran FA, Yan WX, Asokan A, Zhang F, Duan D and Gersbach CA (2016) In vivo genome editing improves muscle function in a mouse model of Duchenne muscular dystrophy. Science 351, 403-407.

Nelson CE, Wu Y, Gemberling MP, Oliver ML, Waller MA, Bohning JD, Robinson-Hamm JN, Bulaklak K, Castellanos Rivera RM, Collier JH, Asokan A and Gersbach CA (2019) Long-term evaluation of AAVCRISPR genome editing for Duchenne muscular dystrophy. Nature Medicine 25, 427-432.

Nguyen DP, Miyaoka Y, Gilbert LA, Mayerl SJ, Lee BH, Weissman JS, Conklin BR and Wells JA (2016) Ligand-binding domains of nuclear 
receptors facilitate tight control of split CRISPR activity. Nature Communications 7, 12009.

Nihongaki Y, Kawano F, Nakajima T and Sato M (2015) Photoactivatable CRISPR-Cas9 for optogenetic genome editing. Nature Biotechnology 33, 755-760.

Nishida K, Arazoe T, Yachie N, Banno S, Kakimoto M, Tabata M, Mochizuki M, Miyabe A, Araki M, Hara KY, Shimatani $Z$ and Kondo A (2016) Targeted nucleotide editing using hybrid prokaryotic and vertebrate adaptive immune systems. Science 353, aaf8729-aaf8729.

Nishimasu H, Ran FA, Hsu PD, Konermann S, Shehata SI, Dohmae N, Ishitani R, Zhang F and Nureki $\mathbf{O}$ (2014) Crystal structure of Cas9 in complex with guide RNA and target DNA. Cell 156, 935-949.

Nishimasu H, Cong L, Yan WX, Ran FA, Zetsche B, Li Y, Kurabayashi A, Ishitani R, Zhang $\mathbf{F}$ and Nureki $\mathbf{O}$ (2015) Crystal structure of Staphylococcus aureus Cas9. Cell 162, 1113-1126.

Nishimasu H, Shi X, Ishiguro S, Gao L, Hirano S, Okazaki S, Noda T, Abudayyeh OO, Gootenberg JS, Mori H, Oura S, Holmes B, Tanaka M, Seki M, Hirano H, Aburatani H, Ishitani R, Ikawa M, Yachie N, Zhang F and Nureki O (2018) Engineered CRISPR-Cas9 nuclease with expanded targeting space. Science 361, 1259-1262.

Nissim L, Perli SD, Fridkin A, Perez-Pinera P and Lu TK (2014) Multiplexed and programmable regulation of gene networks with an integrated RNA and CRISPR/Cas toolkit in human cells. Molecular Cell 54, 698-710.

Niu Y, Shen B, Cui Y, Chen Y, Wang J, Wang L, Kang Y, Zhao X, Si W, Li W, Xiang AP, Zhou J, Guo X, Bi Y, Si C, Hu B, Dong G, Wang H, Zhou Z, Li T, Tan T, Pu X, Wang F, Ji S, Zhou Q, Huang X, Ji W and Sha J (2014) Generation of gene-modified Cynomolgus monkey via Cas9/ RNA-mediated gene targeting in one-cell embryos. Cell 156, 836-843.

Niu D, Wei HJ, Lin L, George H, Wang T, Lee IH, Zhao HY, Wang Y, Kan Y, Shrock E, Lesha E, Wang G, Luo Y, Qing Y, Jiao D, Zhao H, Zhou X, Wang S, Wei H, Guell M, Church GM and Yang L (2017) Inactivation of porcine endogenous retrovirus in pigs using CRISPR-Cas9. Science 357, 1303-1307.

Noordermeer SM, Adam S, Setiaputra D, Barazas M, Pettitt SJ, Ling AK, Olivieri M, Álvarez-Quilón A, Moatti $\mathrm{N}$, Zimmermann $\mathrm{M}$, Annunziato S, Krastev DB, Song F, Brandsma I, Frankum J, Brough R, Sherker A, Landry S, Szilard RK, Munro MM, Mcewan A, De Rugy TG, Lin Z-Y, Hart T, Moffat J, Gingras A-C, Martin A, Van Attikum H, Jonkers J, Lord CJ, Rottenberg S and Durocher D (2018) The shieldin complex mediates 53BP1-dependent DNA repair. Nature 560, 117-121.

Nunez JK, Harrington LB, Kranzusch PJ, Engelman AN and Doudna JA (2015) Foreign DNA capture during CRISPR-Cas adaptive immunity. Nature 527, 535-538.

Nymark M, Sharma AK, Sparstad T, Bones AM and Winge P (2016) A CRISPR/Cas9 system adapted for gene editing in marine algae. Scientific Reports 6, 24951.

Paquet D, Kwart D, Chen A, Sproul A, Jacob S, Teo S, Olsen KM, Gregg A, Noggle $S$ and Tessier-Lavigne $M$ (2016) Efficient introduction of specific homozygous and heterozygous mutations using CRISPR/Cas9. Nature 533, 125-129.

Pardee K, Green AA, Takahashi MK, Braff D, Lambert G, Lee JW, Ferrante T, Ma D, Donghia N, Fan M, Daringer NM, Bosch I, Dudley DM, O'connor DH, Gehrke L and Collins JJ (2016) Rapid, lowcost detection of Zika virus using programmable biomolecular components. Cell 165, 1255-1266.

Park RJ, Wang T, Koundakjian D, Hultquist JF, Lamothe-Molina P, Monel B, Schumann K, Yu H, Krupzcak KM, Garcia-Beltran W, Piechocka-Trocha A, Krogan NJ, Marson A, Sabatini DM, Lander ES, Hacohen N and Walker BD (2017) A genome-wide CRISPR screen identifies a restricted set of HIV host dependency factors. Nature Genetics 49, 193-203

Parnas O, Jovanovic M, Eisenhaure TM, Herbst RH, Dixit A, Ye CJ, Przybylski D, Platt RJ, Tirosh I, Sanjana NE, Shalem O, Satija R, Raychowdhury R, Mertins P, Carr SA, Zhang F, Hacohen $N$ and Regev A (2015) A genome-wide CRISPR screen in primary immune cells to dissect regulatory networks. Cell 162, 675-686.
Patel SJ, Sanjana NE, Kishton RJ, Eidizadeh A, Vodnala SK, Cam M, Gartner JJ, Jia L, Steinberg SM, Yamamoto TN, Merchant AS, Mehta GU, Chichura A, Shalem O, Tran E, Eil R, Sukumar M, Guijarro EP, Day CP, Robbins P, Feldman S, Merlino G, Zhang F and Restifo NP (2017) Identification of essential genes for cancer immunotherapy. Nature 548, 537-542.

Pattanayak V, Lin S, Guilinger JP, Ma E, Doudna JA and Liu DR (2013) High-throughput profiling of off-target DNA cleavage reveals RNAprogrammed Cas9 nuclease specificity. Nature Biotechnology 31, 839-843.

Pawluk A, Amrani N, Zhang Y, Garcia B, Hidalgo-Reyes Y, Lee J, Edraki A, Shah M, Sontheimer EJ, Maxwell KL and Davidson AR (2016) Naturally occurring off-switches for CRISPR-Cas9. Cell 167, 1829-1838.

Perez-Pinera P, Kocak DD, Vockley CM, Adler AF, Kabadi AM, Polstein LR, Thakore PI, Glass KA, Ousterout DG, Leong KW, Guilak F, Crawford GE, Reddy TE and Gersbach CA (2013) RNA-guided gene activation by CRISPR-Cas9-based transcription factors. Nature Methods 10, 973-976.

Perli SD, Cui CH and Lu TK (2016) Continuous genetic recording with selftargeting CRISPR-Cas in human cells. Science 353, aag0511.

Pinello L, Canver MC, Hoban MD, Orkin SH, Kohn DB, Bauer DE and Yuan GC (2016) Analyzing CRISPR genome-editing experiments with CRISPResso. Nature Biotechnology 34, 695-697.

Platt RJ, Chen S, Zhou Y, Yim MJ, Swiech L, Kempton HR, Dahlman JE, Parnas $\mathrm{O}$, Eisenhaure TM, Jovanovic M, Graham DB, Jhunjhunwala $S$, Heidenreich M, Xavier RJ, Langer R, Anderson DG, Hacohen N, Regev A, Feng G, Sharp PA and Zhang F (2014) CRISPR-Cas9 knockin mice for genome editing and cancer modeling. Cell 159, 440-455.

Plessis A, Perrin A, Haber JE and Dujon B (1992) Site-specific recombination determined by I-SceI, a mitochondrial group I intron-encoded endonuclease expressed in the yeast nucleus. Genetics 130, 451-460.

Porteus MH (2015) Towards a new era in medicine: therapeutic genome editing. Genome Biology 16, 286.

Pourcel C, Salvignol G and Vergnaud G (2005) CRISPR elements in Yersinia pestis acquire new repeats by preferential uptake of bacteriophage DNA, and provide additional tools for evolutionary studies. Microbiology (Reading England) 151(Pt 3), 653-663.

Qi LS, Larson MH, Gilbert LA, Doudna JA, Weissman JS, Arkin AP and Lim WA (2013) Repurposing CRISPR as an RNA-guided platform for sequence-specific control of gene expression. Cell 152, 1173-1183.

Quiberoni A, Moineau S, Rousseau GM, Reinheimer J and Ackermann HW (2010) Streptococcus thermophilus bacteriophages. International Dairy Journal 20, 657-664.

Ramanan V, Shlomai A, Cox DBT, Schwartz RE, Michailidis E, Bhatta A, Scott DA, Zhang F, Rice CM and Bhatia SN (2015) CRISPR/cas9 cleavage of viral DNA efficiently suppresses hepatitis B virus. Scientific Reports 5, 10833.

Ran FA, Hsu PD, Lin C-Y, Gootenberg JS, Konermann S, Trevino AE, Scott DA, Inoue A, Matoba S, Zhang Y and Zhang F (2013) Double nicking by RNA-guided CRISPR Cas9 for enhanced genome editing specificity. Cell 154, 1380-1389.

Ran FA, Cong L, Yan WX, Scott DA, Gootenberg JS, Kriz AJ, Zetsche B, Shalem O, Wu X, Makarova KS, Koonin EV, Sharp PA and Zhang F (2015) In vivo genome editing using Staphylococcus aureus Cas9. Nature 520, 186-191.

Rauch BJ, Silvis MR, Hultquist JF, Waters CS, Mcgregor MJ, Krogan NJ and Bondy-Denomy J (2017) Inhibition of CRISPR-Cas9 with bacteriophage proteins. Cell 168, 150-158.

Rees HA and Liu DR (2018) Base editing: precision chemistry on the genome and transcriptome of living cells. Nature Publishing Group 19 770-788.

Richardson CD, Ray GJ, Dewitt MA, Curie GL and Corn JE (2016) Enhancing homology-directed genome editing by catalytically active and inactive CRISPR-Cas9 using asymmetric donor DNA. Nature Biotechnology 34, 339-344.

Richardson CD, Kazane KR, Feng SJ, Zelin E, Bray NL, Schafer AJ, Floor SN and Corn JE (2018) CRISPR-Cas9 genome editing in human cells occurs via the Fanconi anemia pathway. Nature Genetics 50, 1132-1139.

Rodriguez EA, Campbell RE, Lin JY, Lin MZ, Miyawaki A, Palmer AE, Shu X, Zhang J and Tsien RY (2017) The growing and glowing toolbox 
of fluorescent and photoactive proteins. Trends in Biochemical Sciences $\mathbf{4 2}$, 111-129.

Rose JC, Stephany JJ, Valente WJ, Trevillian BM, Dang HV, Bielas JH, Maly DJ and Fowler DM (2017) Rapidly inducible Cas9 and DSBddPCR to probe editing kinetics. Nature Methods 14, 891-896.

Roth TL, Puig-Saus C, Yu R, Shifrut E, Carnevale J, Li PJ, Hiatt J, Saco J, Krystofinski P, Li H, Tobin V, Nguyen DN, Lee MR, Putnam AL, Ferris AL, Chen JW, Schickel JN, Pellerin L, Carmody D, AlkortaAranburu G, Del Gaudio D, Matsumoto H, Morell M, Mao Y, Cho M, Quadros RM, Gurumurthy CB, Smith B, Haugwitz M, Hughes SH, Weissman JS, Schumann K, Esensten JH, May AP, Ashworth A, Kupfer GM, Greeley SAW, Bacchetta R, Meffre E, Roncarolo MG, Romberg N, Herold KC, Ribas A, Leonetti MD and Marson A (2018) Reprogramming human $\mathrm{T}$ cell function and specificity with non-viral genome targeting. Nature 559, 405-409.

Rouet P, Smih F and Jasin M (1994) Introduction of double-strand breaks into the genome of mouse cells by expression of a rare-cutting endonuclease. Molecular and Cellular Biology 14, 8096-8106.

Rudin N, Sugarman E and Haber JE (1989) Genetic and physical analysis of double-strand break repair and recombination in Saccharomyces cerevisiae. Genetics 122, 519-534.

Sanchez-Rivera FJ, Papagiannakopoulos T, Romero R, Tammela $T$, Bauer MR, Bhutkar A, Joshi NS, Subbaraj L, Bronson RT, Xue W and Jacks T (2014) Rapid modelling of cooperating genetic events in cancer through somatic genome editing. Nature 516, 428-431.

Sanjana NE, Wright J, Zheng K, Shalem O, Fontanillas P, Joung J, Cheng C, Regev A and Zhang F (2016) High-resolution interrogation of functional elements in the noncoding genome. Science 353, 1545-1549.

Sanson KR, Hanna RE, Hegde M, Donovan KF, Strand C, Sullender ME, Vaimberg EW, Goodale A, Root DE, Piccioni F and Doench JG (2018) Optimized libraries for CRISPR-Cas9 genetic screens with multiple modalities. Nature Communications 9, 5416

Sapranauskas R, Gasiunas G, Fremaux C, Barrangou R, Horvath P and Siksnys V (2011) The Streptococcus thermophilus CRISPR/Cas system provides immunity in Escherichia coli. Nucleic Acids Research 39, gkr606gk9282.

Schindele P, Wolter F and Puchta H (2018) Transforming plant biology and breeding with CRISPR/Cas9, Cas12 and Cas13. FEBS letters 592, 1954-1967.

Schmid-Burgk JL, Schmidt T, Gaidt MM, Pelka K, Latz E, Ebert TS and Hornung V (2014) Outknocker: a web tool for rapid and simple genotyping of designer nuclease edited cell lines. Genome Research 24, 1719-1723.

Schmid-Burgk JL, Honing K, Ebert TS and Hornung V (2016) CRISPaint allows modular base-specific gene tagging using a ligase-4-dependent mechanism. Nature Communications 7, 12338.

Schmidt F, Cherepkova MY and Platt RJ (2018) Transcriptional recording by CRISPR spacer acquisition from RNA. Nature 562, 380-385.

Schunder E, Rydzewski K, Grunow R and Heuner K (2013) First indication for a functional CRISPR/Cas system in Francisella tularensis. International Journal of Medical Microbiology 303, 51-60.

Schwank G, Koo BK, Sasselli V, Dekkers JF, Heo I, Demircan T, Sasaki N, Boymans S, Cuppen E, Van Der Ent CK, Nieuwenhuis EE, Beekman JM and Clevers H (2013) Functional repair of CFTR by CRISPR/Cas9 in intestinal stem cell organoids of cystic fibrosis patients. Cell Stem Cell 13, 653-658.

Scott DA and Zhang F (2017) Implications of human genetic variation in CRISPR-based therapeutic genome editing. Nature Medicine 23, 1095-1101.

Shalem O, Sanjana NE, Hartenian E, Shi X, Scott DA, Mikkelsen TS, Heckl D, Ebert BL, Root DE, Doench JG and Zhang F (2014) Genome-scale CRISPR-Cas9 knockout screening in human cells. Science 343, 84-87.

Shalem O, Sanjana NE and Zhang F (2015) High-throughput functional genomics using CRISPR-Cas9. Nature Reviews Genetics 16, 299-311.

Shan Q, Wang Y, Li J, Zhang Y, Chen K, Liang Z, Zhang K, Liu J, Xi JJ, Qiu J-L and Gao C (2013) Targeted genome modification of crop plants using a CRISPR-Cas system. Nature Biotechnology 31, 686-688.

Shapiro RS, Chavez A and Collins JJ (2018) CRISPR-based genomic tools for the manipulation of genetically intractable microorganisms. Nature Reviews Microbiology 16, 333-339.
Shimatani Z, Kashojiya S, Takayama M, Terada R, Arazoe T, Ishii H, Teramura H, Yamamoto T, Komatsu H, Miura K, Ezura H, Nishida K, Ariizumi T and Kondo A (2017) Targeted base editing in rice and tomato using a CRISPR-Cas9 cytidine deaminase fusion. Nature Biotechnology 35, 441-443.

Shipman SL, Nivala J, Macklis JD and Church GM (2016) Molecular recordings by directed CRISPR spacer acquisition. Science 353, aaf1175.

Shipman SL, Nivala J, Macklis JD and Church GM (2017) CRISPR-Cas encoding of a digital movie into the genomes of a population of living bacteria. Nature 547, 345-349.

Shi J, Wang E, Milazzo JP, Wang Z, Kinney JB and Vakoc CR (2015) Discovery of cancer drug targets by CRISPR-Cas9 screening of protein domains. Nature Biotechnology 33, 661-667.

Shmakov S, Abudayyeh OO, Makarova KS, Wolf YI, Gootenberg JS, Semenova E, Minakhin L, Joung J, Konermann S, Severinov K, Zhang F and Koonin EV (2015) Discovery and functional characterization of diverse class 2 CRISPR-Cas systems. Molecular Cell 60, 385-397.

Shmakov S, Smargon A, Scott D, Cox D, Pyzocha N, Yan W, Abudayyeh OO, Gootenberg JS, Makarova KS, Wolf YI, Severinov K, Zhang F and Koonin EV (2017) Diversity and evolution of class 2 CRISPR-Cas systems. Nature Reviews Microbiology 15, 169-182.

Shmakov SA, Makarova KS, Wolf YI, Severinov KV and Koonin EV (2018) Systematic prediction of genes functionally linked to CRISPR-Cas systems by gene neighborhood analysis. Proceedings of the National Academy of Sciences of the United States of America 115, E5307-E5316.

Sidik SM, Huet D, Ganesan SM, Huynh M-H, Wang T, Nasamu AS, Thiru P, Saeij JPJ, Carruthers VB, Niles JC and Lourido S (2016) A genome-wide CRISPR screen in toxoplasma identifies essential Apicomplexan genes. Cell 166, 1423-1435.

Silas S, Mohr G, Sidote DJ, Markham LM, Sanchez-Amat A, Bhaya D, Lambowitz AM and Fire AZ (2016) Direct CRISPR spacer acquisition from RNA by a natural reverse transcriptase-Cas1 fusion protein. Science 351, aad4234.

Slaymaker IM, Gao L, Zetsche B, Scott DA, Yan WX and Zhang F (2015) Rationally engineered Cas 9 nucleases with improved specificity. Science 351, 84-88.

Slaymaker IM, Mesa P, Kellner MJ, Kannan S, Brignole E, Koob J, Feliciano PR, Stella S, Abudayyeh OO, Gootenberg JS, Strecker J, Montoya G and Zhang F (2019) High-resolution structure of Cas13b and biochemical characterization of RNA targeting and cleavage. Cell Reports 26, 1-11.

Smargon AA, Cox DBT, Pyzocha NK, Zheng K, Slaymaker IM, Gootenberg JS, Abudayyeh OA, Essletzbichler P, Shmakov S, Makarova KS, Koonin EV and Zhang F (2017) Cas13b Is a type VI-B CRISPR-associated RNA-guided RNase differentially regulated by accessory proteins Csx27 and Csx28. Molecular Cell 65, 618-630.

Smith JJ, Timoshevskaya N, Ye C, Holt C, Keinath MC, Parker HJ, Cook ME, Hess JE, Narum SR, Lamanna F, Kaessmann H, Timoshevskiy VA, Waterbury CKM, Saraceno C, Wiedemann LM, Robb SMC, Baker C, Eichler EE, Hockman D, Sauka-Spengler T, Yandell M, Krumlauf R, Elgar G and Amemiya CT (2018) The sea lamprey germline genome provides insights into programmed genome rearrangement and vertebrate evolution. Nature Genetics 50, 270-277.

Sollelis L, Ghorbal M, Macpherson CR, Martins RM, Kuk N, Crobu L, Bastien P, Scherf A, Lopez-Rubio J-J and Sterkers Y (2015) First efficient CRISPR-Cas9-mediated genome editing in Leishmania parasites. Cellular Microbiology 17, 1405-1412.

Sontheimer EJ and Barrangou R (2015) The bacterial origins of the CRISPR genome-editing revolution. Human Gene Therapy 26, 413-424.

Sorek R, Kunin V and Hugenholtz P (2008) CRISPR--a widespread system that provides acquired resistance against phages in bacteria and archaea. Nature Reviews Microbiology 6, 181-186.

Soyk S, Lemmon ZH, Oved M, Fisher J, Liberatore KL, Park SJ, Goren A, Jiang K, Ramos A, Van Der Knaap E, Van Eck J, Zamir D, Eshed Y and Lippman ZB (2017) Bypassing negative epistasis on yield in tomato imposed by a domestication gene. Cell 169, 1142-1155 e1112.

Stella S, Alcón P and Montoya G (2017) Structure of the Cpf1 endonuclease R-loop complex after target DNA cleavage. Nature 546, 559-563. 
Sternberg SH, Redding S, Jinek M, Greene EC and Doudna JA (2014) DNA interrogation by the CRISPR RNA-guided endonuclease Cas9. Nature 507, $62-67$.

Strecker J, Jones S, Koopal B, Schmid-Burgk J, Zetsche B, Gao L, Makarova KS, Koonin EV and Zhang F (2019) Engineering of CRISPR-Cas12b for human genome editing. Nature Communications 10, 866.

Strohkendl I, Saifuddin FA, Rybarski JR, Finkelstein IJ and Russell R (2018) Kinetic basis for DNA target specificity of CRISPR-Cas12a. Molecular Cell 71, 816-824.

Suzuki K, Tsunekawa Y, Hernandez-Benitez R, Wu J, Zhu J, Kim EJ, Hatanaka F, Yamamoto M, Araoka T, Li Z, Kurita M, Hishida T, Li M, Aizawa E, Guo S, Chen S, Goebl A, Soligalla RD, Qu J, Jiang T, Fu X, Jafari M, Esteban CR, Berggren WT, Lajara J, NunezDelicado E, Guillen P, Campistol JM, Matsuzaki F, Liu GH, Magistretti P, Zhang $\mathrm{K}$, Callaway EM, Zhang $\mathrm{K}$ and Belmonte JC (2016) In vivo genome editing via CRISPR/Cas9 mediated homology-independent targeted integration. Nature 540, 144-149.

Swarts DC, Van Der Oost J and Jinek M (2017) Structural basis for guide RNA processing and seed-dependent DNA targeting by CRISPR-Cas12a. Molecular Cell 66, 221-233.

Tabebordbar M, Zhu K, Cheng JKW, Chew WL, Widrick JJ, Yan WX, Maesner C, Wu EY, Xiao R, Ran FA, Cong L, Zhang F, Vandenberghe LH, Church GM and Wagers AJ (2016) In vivo gene editing in dystrophic mouse muscle and muscle stem cells. Science 351, 407-411.

Tak YE, Kleinstiver BP, Nuñez JK, Hsu JY, Horng JE, Gong J, Weissman JS and Joung JK (2017) Inducible and multiplex gene regulation using CRISPR-Cpf1-based transcription factors. Nature Methods 14, 11631166.

Tambe A, East-Seletsky A, Knott GJ, Doudna JA and O'connell MR (2018) RNA binding and HEPN-nuclease activation Are decoupled in CRISPRCas13a. Cell Reports 24, 1025-1036.

Tanenbaum ME, Gilbert LA, Qi LS, Weissman JS and Vale RD (2014) A protein-tagging system for signal amplification in gene expression and fluorescence imaging. Cell 159, 635-646.

Tang W and Liu DR (2018) Rewritable multi-event analog recording in bacterial and mammalian cells. Science 360, eaap8992.

Telenti A (2009) Safety concerns about CCR5 as an antiviral target. Curr Opin HIV AIDS 4, 131-135.

Teng F, Cui T, Feng G, Guo L, Xu K, Gao Q, Li T, Li J, Zhou Q and Li W (2018) Repurposing CRISPR-Cas12b for mammalian genome engineering. Cell Discovery 4, 63.

Thakore PI, D'ippolito AM, Song L, Safi A, Shivakumar NK, Kabadi AM, Reddy TE, Crawford GE and Gersbach CA (2015) Highly specific epigenome editing by CRISPR-Cas9 repressors for silencing of distal regulatory elements. Nature Methods 12, 1143-1149.

Thomas KR and Capecchi MR (1987) Site-directed mutagenesis by gene targeting in mouse embryo-derived stem cells. Cell 51, 503-512.

Toledo CM, Ding Y, Hoellerbauer P, Davis RJ, Basom R, Girard EJ, Lee E, Corrin P, Hart T, Bolouri H, Davison J, Zhang Q, Hardcastle J, Aronow BJ, Plaisier CL, Baliga NS, Moffat J, Lin Q, Li XN, Nam DH, Lee J, Pollard SM, Zhu J, Delrow JJ, Clurman BE, Olson JM and Paddison PJ (2015) Genome-wide CRISPR-Cas9 screens reveal loss of redundancy between PKMYT1 and WEE1 in Glioblastoma stem-like cells. Cell Reports 13, 2425-2439.

Truong D-JJ, Kühner K, Kühn R, Werfel S, Engelhardt S, Wurst W and Ortiz O (2015) Development of an intein-mediated split-Cas9 system for gene therapy. Nucleic Acids Research 43, 6450-6458.

Tsai SQ and Joung JK (2016) Defining and improving the genome-wide specificities of CRISPR-Cas9 nucleases. Nature Reviews Genetics 17, 300-312.

Tsai SQ, Wyvekens N, Khayter C, Foden JA, Thapar V, Reyon D, Goodwin MJ, Aryee MJ and Joung JK (2014) Dimeric CRISPR RNAguided FokI nucleases for highly specific genome editing. Nature Biotechnology 32, 569-576.

Tsai SQ, Zheng Z, Nguyen NT, Liebers M, Topkar VV, Thapar V, Wyvekens N, Khayter C, Iafrate AJ, Le LP, Aryee MJ and Joung JK (2015) GUIDE-seq enables genome-wide profiling of off-target cleavage by CRISPR-Cas nucleases. Nature Biotechnology 33, 187-197.
Tsai SQ, Nguyen NT, Malagon-Lopez J, Topkar VV, Aryee MJ and Joung JK (2017) CIRCLE-seq: a highly sensitive in vitro screen for genomewide CRISPR-Cas9 nuclease off-targets. Nature Methods 14, 607-614.

Tso CF, Simon T, Greenlaw AC, Puri T, Mieda M and Herzog ED (2017) Astrocytes regulate daily rhythms in the Suprachiasmatic nucleus and behavior. Current Biology 27, 1055-1061.

Tycko J, Barrera LA, Huston NC, Friedland AE, Wu X, Gootenberg JS, Abudayyeh OO, Myer VE, Wilson CJ and Hsu PD (2018) Pairwise library screen systematically interrogates Staphylococcus aureus Cas9 specificity in human cells. Nature Communications 9, 2962.

Urnov FD, Rebar EJ, Holmes MC, Zhang HS and Gregory PD (2010) Genome editing with engineered zinc finger nucleases. Nature Reviews Genetics 11, 636-646.

Vakulskas CA, Dever DP, Rettig GR, Turk R, Jacobi AM, Collingwood MA, Bode NM, Mcneill MS, Yan S, Camarena J, Lee CM, Park SH, Wiebking V, Bak RO, Gomez-Ospina N, Pavel-Dinu M, Sun W, Bao G, Porteus MH and Behlke MA (2018) A high-fidelity Cas9 mutant delivered as a ribonucleoprotein complex enables efficient gene editing in human hematopoietic stem and progenitor cells. Nature Medicine 24, $1216-1224$

Van Der Oost J, Westra ER, Jackson RN and Wiedenheft B (2014) Unravelling the structural and mechanistic basis of CRISPR-Cas systems. Nature Reviews Microbiology 12, 479-492.

VERTEX (2018a) A Safety and Efficacy Study Evaluating CTX001 in Subjects With Severe Sickle Cell Disease. ClinicalTrial.gov Identifier: NCT03745287, (clinicaltrials.gov/ct2/show/NCT03745287).

VERTEX (2018b) A Safety and Efficacy Study Evaluating CTX001 in Subjects With Transfusion-Dependent $\beta$-Thalassemia. ClinicalTrial.gov Identifier: NCT03655678 (clinicaltrials.gov/ct2/show/NCT03655678).

Vestergaard G, Garrett RA and Shah SA (2014) CRISPR adaptive immune systems of Archaea. RNA Biology 11, 156-167.

Villiger L, Grisch-Chan HM, Lindsay H, Ringnalda F, Pogliano CB, Allegri G, Fingerhut R, Haberle J, Matos J, Robinson MD, Thony B and Schwank G (2018) Treatment of a metabolic liver disease by in vivo genome base editing in adult mice. Nature Medicine 24, 1519-1525.

Vinayak S, Pawlowic MC, Sateriale A and Brooks CF (2015) Genetic modification of the diarrhoeal pathogen cryptosporidium parvum. Nature 523, 477-480.

Vojta A, Dobrinić P, Tadić V, Bočkor L, Korać P, Julg B, Klasić M and Zoldoš V (2016) Repurposing the CRISPR-Cas9 system for targeted DNA methylation. Nucleic Acids Research 44, 5615-5628.

Voytas DF and Gao C (2014) Precision genome engineering and agriculture: opportunities and regulatory challenges. PLoS Biology 12, e1001877.

Wang H, Yang H, Shivalila CS, Dawlaty MM, Cheng AW, Zhang F and Jaenisch R (2013) One-Step generation of mice carrying mutations in multiple genes by CRISPR/Cas-mediated genome engineering. Cell 153, 910-918.

Wang T, Wei JJ, Sabatini DM and Lander ES (2014) Genetic screens in human cells using the CRISPR-Cas9 system. Science 343, 80-84.

Wang T, Birsoy K, Hughes NW, Krupczak KM, Post Y, Wei JJ, Lander ES and Sabatini DM (2015) Identification and characterization of essential genes in the human genome. Science 350, 1096-1101.

Wang H, Xu X, Nguyen CM, Liu Y, Gao Y, Lin X, Daley T, Kipniss NH, La Russa M and Qi LS (2018) CRISPR-mediated programmable 3D genome positioning and nuclear organization. Cell 175, 1405-1417.

Wang B, Wang M, Zhang W, Xiao T, Chen $\mathrm{CH}$, Wu A, Wu F, Traugh N, Wang X, Li Z, Mei S, Cui Y, Shi S, Lipp JJ, Hinterndorfer M, Zuber J, Brown M, Li W and Liu XS (2019) Integrative analysis of pooled CRISPR genetic screens using MAGeCKFlute. Nat Protoc 14, 756-780.

Wan H, Feng C, Teng F, Yang S, Hu B, Niu Y, Xiang AP, Fang W, Ji W, Li W, Zhao X and Zhou Q (2015) One-step generation of p53 gene biallelic mutant Cynomolgus monkey via the CRISPR/Cas system. Cell Research 25, 258-261.

Watters KE, Fellmann C, Bai HB, Ren SM and Doudna JA (2018) Systematic discovery of natural CRISPR-Cas12a inhibitors. Science 362, 236-239.

Winter J, Breinig M, Heigwer F, Brugemann D, Leible S, Pelz O, Zhan T and Boutros M (2016) Carpools: an R package for exploratory data analysis and documentation of pooled CRISPR/Cas9 screens. Bioinformatics 32, 632-634. 
Wong AS, Choi GC, Cui CH, Pregernig G, Milani P, Adam M, Perli SD, Kazer SW, Gaillard A, Hermann M, Shalek AK, Fraenkel E and Lu TK (2016) Multiplexed barcoded CRISPR-Cas9 screening enabled by CombiGEM. Proceedings of the National Academy of Sciences of the United States of America 113, 2544-2549.

Woo JW, Kim J, Kwon SI, Corvalan C, Cho SW, Kim H, Kim SG, Kim ST, Choe $S$ and Kim JS (2015) DNA-free genome editing in plants with preassembled CRISPR-Cas9 ribonucleoproteins. Nature Biotechnology 33, 1162-1164.

Wright AV, Sternberg SH, Taylor DW, Staahl BT, Bardales JA, Kornfeld JE and Doudna JA (2015) Rational design of a split-Cas9 enzyme complex. Proceedings of the National Academy of Sciences of the United States of America 112, 2984-2989.

Wu Y, Liang D, Wang Y, Bai M, Tang W, Bao S, Yan Z, Li D and Li J (2013) Correction of a genetic disease in mouse via use of CRISPR-Cas9. Cell Stem Cell 13, 659-662.

Wu D, Guan X, Zhu Y, Ren K and Huang Z (2017) Structural basis of stringent PAM recognition by CRISPR-C2c1 in complex with sgRNA. Cell Research 27, 705-708.

Xiong X, Chen M, Lim WA, Zhao D and Qi LS (2016) CRISPR/cas9 for human genome engineering and disease research. Annual Review of Genomics and Human Genetics 17, 131-154.

Xu R, Li H, Qin R, Wang L, Li L, Wei P and Yang J (2014) Gene targeting using the Agrobacterium tumefaciens-mediated CRISPR-Cas system in rice. Rice (N Y) 7, 5.

Xu X, Tao Y, Gao X, Zhang L, Li X, Zou W, Ruan K, Wang F, Xu G-L and Hu R (2016) A CRISPR-based approach for targeted DNA demethylation. Cell Discovery 2, 16009.

Yamada M, Watanabe Y, Gootenberg JS, Hirano H, Ran FA, Nakane T, Ishitani R, Zhang F, Nishimasu H and Nureki O (2017) Crystal structure of the minimal Cas9 from Campylobacter jejuni reveals the molecular diversity in the CRISPR-Cas9 systems. Molecular Cell 65, 1109-1121.

Yamano T, Nishimasu H, Zetsche B, Hirano H, Slaymaker IM, Li Y, Fedorova I, Nakane T, Makarova KS, Koonin EV, Ishitani R, Zhang F and Nureki $\mathbf{O}$ (2016) Crystal structure of Cpf1 in complex with guide RNA and target DNA. Cell 165, 949-962.

Yamasaki T, Hoyos-Ramirez E, Martenson JS, Morimoto-Tomita $M$ and Tomita S (2017) GARLH family proteins stabilize GABAA receptors at synapses. Neuron $\mathbf{9 3}, 1138-1152$.

Yang H, Wang H, Shivalila CS, Cheng AW, Shi L and Jaenisch R (2013) One-Step generation of mice carrying reporter and conditional alleles by CRISPR/Cas-mediated genome engineering. Cell 154, 1370-1379.

Yang L, Guell M, Niu D, George H, Lesha E, Grishin D, Aach J, Shrock E, Xu W, Poci J, Cortazio R, Wilkinson RA, Fishman JA and Church G (2015) Genome-wide inactivation of porcine endogenous retroviruses (PERVs). Science 350, 1101-1104.

Yang H, Gao P, Rajashankar KR and Patel DJ (2016) PAM-dependent target DNA recognition and cleavage by C2c1 CRISPR-Cas endonuclease. Cell 167, 1814-1828.

Yan WX, Mirzazadeh R, Garnerone S, Scott D, Schneider MW, Kallas T, Custodio J, Wernersson E, Li Y, Gao L, Federova Y, Zetsche B, Zhang F, Bienko $\mathbf{M}$ and Crosetto $\mathbf{N}$ (2017) BLISS is a versatile and quantitative method for genome-wide profiling of DNA double-strand breaks. Nature Communications 8, 15058.

Yan S, Tu Z, Liu Z, Fan N, Yang H, Yang S, Yang W, Zhao Y, Ouyang Z, Lai C, Yang H, Li L, Liu Q, Shi H, Xu G, Zhao H, Wei H, Pei Z, Li S, Lai L and Li XJ (2018a) A Huntingtin Knockin Pig model recapitulates features of selective neurodegeneration in Huntington's disease. Cell 173, 989-1002.

Yan WX, Chong S, Zhang H, Makarova KS, Koonin EV, Cheng DR and Scott DA (2018b) Cas13d Is a compact RNA-targeting type VI CRISPR effector positively modulated by a WYL-domain-containing accessory protein. Molecular Cell 70, 327-339.

Yan WX, Hunnewell P, Alfonse LE, Carte JM, Keston-Smith E, Sothiselvam S, Garrity AJ, Chong S, Makarova KS, Koonin EV, Cheng DR and Scott DA (2019) Functionally diverse type V CRISPRCas systems. Science 363, 88-91.
Zaidi SS-E-A, Mahfouz MM and Mansoor S (2017) CRISPR-Cpf1: a new tool for plant genome editing. Trends in Plant Science 22, 550-553.

Zalatan JG, Lee ME, Almeida R, Gilbert LA, Whitehead EH, La Russa M, Tsai JC, Weissman JS, Dueber JE, Qi LS and Lim WA (2015) Engineering complex synthetic transcriptional programs with CRISPR RNA scaffolds. Cell 160, 339-350.

Zetsche B, Gootenberg JS, Abudayyeh OO, Slaymaker IM, Makarova KS, Essletzbichler P, Volz SE, Joung J, Van Der Oost J, Regev A, Koonin EV and Zhang F (2015a) Cpf1 Is a single RNA-guided endonuclease of a class 2 CRISPR-Cas system. Cell 163, 759-771.

Zetsche B, Volz SE and Zhang F (2015b) A split-Cas9 architecture for inducible genome editing and transcription modulation. Nature Biotechnology 33, 139-142.

Zetsche B, Heidenreich M, Mohanraju P, Fedorova I, Kneppers J, Degennaro EM, Winblad N, Choudhury SR, Abudayyeh OO, Gootenberg JS, Wu WY, Scott DA, Severinov K, Van Der Oost J and Zhang F (2016) Multiplex gene editing by CRISPR-Cpf1 using a single crRNA array. Nature Biotechnology 35, 31-34.

Zetsche B, Strecker J, Abudayyeh OO, Gootenberg JS, Scott DA and Zhang F (2017) A survey of genome editing activity for 16 Cpf1 orthologs. bioRxiv. https://doi.org/10.1101/134015.

Zhang F, Wang LP, Brauner M, Liewald JF, Kay K, Watzke N, Wood PG, Bamberg E, Nagel G, Gottschalk A and Deisseroth K (2007) Multimodal fast optical interrogation of neural circuitry. Nature 446, 633-639.

Zhang F, Cong L, Lodato S, Kosuri S, Church GM and Arlotta P (2011) Efficient construction of sequence-specific TAL effectors for modulating mammalian transcription. Nature Biotechnology 29, 149-153.

Zhang Y, Heidrich N, Ampattu BJ, Gunderson CW, Seifert HS, Schoen C, Vogel J and Sontheimer EJ (2013) Processing-independent CRISPR RNAs limit natural transformation in Neisseria meningitidis. Molecular Cell 50, 488-503.

Zhang H, Zhang J, Wei P, Zhang B, Gou F, Feng Z, Mao Y, Yang L, Zhang H, Xu N and Zhu JK (2014) The CRISPR/Cas9 system produces specific and homozygous targeted gene editing in rice in one generation. Plant Biotechnology Journal 12, 797-807.

Zhang R, Miner JJ, Gorman MJ, Rausch K, Ramage H, White JP, Zuiani A, Zhang P, Fernandez E, Zhang Q, Dowd KA, Pierson TC, Cherry S and Diamond MS (2016) A CRISPR screen defines a signal peptide processing pathway required by flaviviruses. Nature 535, 164-172.

Zhang S, Takaku M, Zou L, Gu AD, Chou WC, Zhang G, Wu B, Kong Q, Thomas SY, Serody JS, Chen X, Xu X, Wade PA, Cook DN, Ting JPY and Wan YY (2017) Reversing SKI-SMAD4-mediated suppression is essential for TH17 cell differentiation. Nature 551, 105-109.

Zhang B, Ye W, Ye Y, Zhou H, Saeed AFUH, Chen J, Lin J, Perčulija V, Chen Q, Chen C-J, Chang M-X, Choudhary MI and Ouyang S (2018a) Structural insights into Cas13b-guided CRISPR RNA maturation and recognition. Cell Research 28, 1198-1201.

Zhang C, Konermann S, Brideau NJ, Lotfy P, Wu X, Novick SJ, Strutzenberg T, Griffin PR, Hsu PD and Lyumkis D (2018b) Structural basis for the RNA-guided ribonuclease activity of CRISPR-Cas13d. Cell $175,212-223$.

Zhou Y, Zhu S, Cai C, Yuan P, Li C, Huang Y and Wei W (2014) Highthroughput screening of a CRISPR/Cas9 library for functional genomics in human cells. Nature 509, 487-491.

Zhu S, Li W, Liu J, Chen C-H, Liao Q, Xu P, Xu H, Xiao T, Cao Z, Peng J, Yuan P, Brown M, Liu XS and Wei W (2016) Genome-scale deletion screening of human long non-coding RNAs using a paired-guide RNA CRISPR-Cas9 library. Nature Biotechnology 34, 1279-1286.

Zong Y, Wang Y, Li C, Zhang R, Chen K, Ran Y, Qiu JL, Wang D and Gao C (2017) Precise base editing in rice, wheat and maize with a Cas9cytidine deaminase fusion. Nature Biotechnology 35, 438-440.

Zuo E, Sun Y, Wei W, Yuan T, Ying W, Sun H, Yuan L, Steinmetz LM, Li Y and Yang H (2019) Cytosine base editor generates substantial off-target single-nucleotide variants in mouse embryos. Science 364, 289-292. 